\title{
ANÁLISE DE PILARES ESBELTOS DE CONCRETO ARMADO SOLICITADOS A FLEXO-COMPRESSÃO OBLÍQUA
}

\author{
Ana Cláudia Leão Borges
}

Dissertação apresentada à Escola de Engenharia de São Carlos da Universidade de São Paulo, como parte dos requisitos para obtenção do título de Mestre em Engenharia de Estruturas.

ORIENTADORA: Prof ${ }^{\mathrm{a}}$. Dr ${ }^{\mathrm{a}}$. Ana Lúcia H. de C. El Debs 


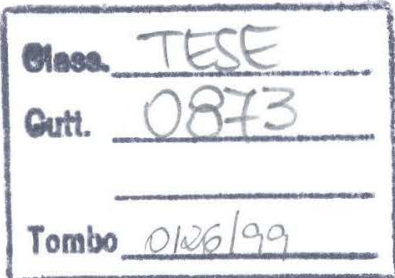

$51 / 51034466$

Ficha catalográfica preparada pela Seção de Tratamento da Informação do Serviço de Biblioteca - EESC/USP

\begin{tabular}{|c|c|}
\hline \multirow[t]{9}{*}{ B732a } & \\
\hline & \\
\hline & \\
\hline & \\
\hline & \\
\hline & \\
\hline & $\begin{array}{l}\text { Borges, Ana Cláudia Leão } \\
\text { Análise de pilares esbeltos de concreto armado } \\
\text { solicitados a flexo-compressão oblíqua / Ana Cláudia } \\
\text { Leão Borges. -- São Carlos, } 1999 .\end{array}$ \\
\hline & $\begin{array}{l}\text { Dissertação (Mestrado) -- Escola de Engenharia de } \\
\text { São Carlos-Universidade de São Paulo, } 1999 . \\
\text { Área: Engenharia de Estruturas. } \\
\text { Orientador: Prof-. Dr-. Ana Lúcia H. de C. El Debs. }\end{array}$ \\
\hline & $\begin{array}{l}\text { 1. Concreto armado. 2. Pilares. 3. Instabilidade. } \\
\text { 4. Flexo-compressão oblíqua. 5. Momento fletor. } \\
\text { 6. Força normal. 7. Análise não-linear. I. Título. }\end{array}$ \\
\hline
\end{tabular}


FOLHA DE APROVACÃO

Candidata: Engenheira ANA CLAUDIA LEÃO BORGES

Dissertação defendida e aprovada em 08-04-1999

pela Comissão Julgadora:

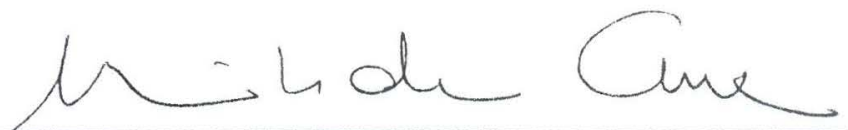

Profa. Doutora ANA LÚCIA HOMCE DE CRESCE EL DEBS (Orientadora)

(Escola de Engenharia de São Carlos - Universidade de São Paulo)

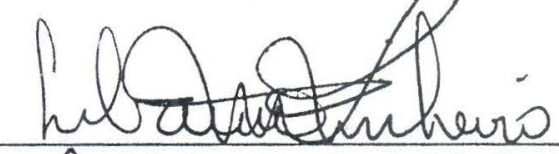

Prof. Doutor LIBÂNIO MIRANDA PINHEIRO

(Escola de Engenharia de São Carlos - Universidade de São Paulo)

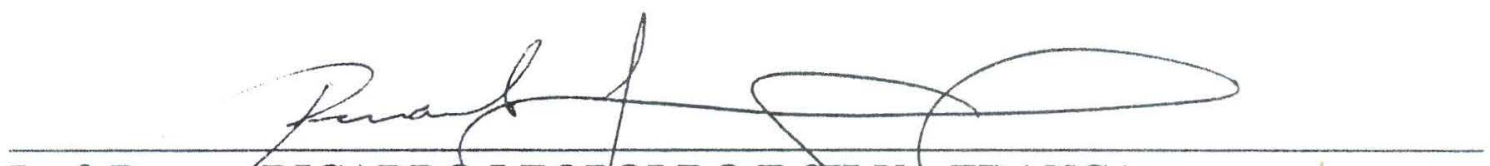

Prof. Doutor RICARDO LEOPOLDO E SHLVA FRANÇA

(Escola Politécnica - Universidade de São Paulo)
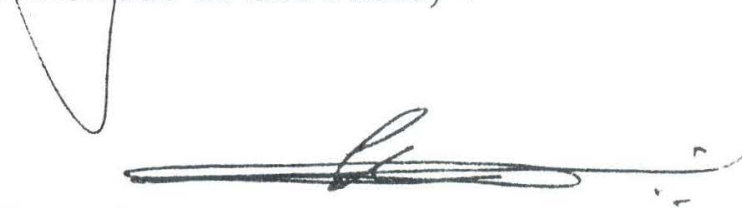

Prof. Titular CARLITO CALIL JUNIOR

Coordenador da Área de Engenharia de Estruturas

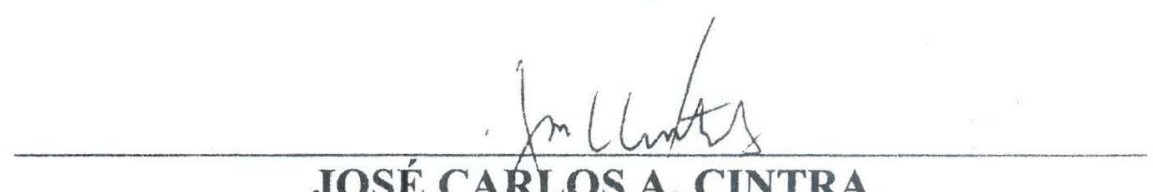

Presidente da Comissåo đe Pós-Graduação da EESC 
Ofereço aos meus pais Leônia e Borges, ao meu marido Érick, e ao meu sobrinho Felipe. 


\section{AGRADECIMENTOS}

À toda minha família, em especial aos meus pais e ao meu marido, pelo carinho e pela confiança em mim depositada, fundamentais para essa conquista.

À professora Ana Lúcia H. de C. El Debs, pela orientação, compreensão e estímulo.

Ao colega Ismael Wilson Cadamuro Jr, cujos conhecimentos foram essenciais para o desenvolvimento deste trabalho.

Ao Professor Pablo Aníbal López Yánez da Universidade Federal da Paraíba, pelos conselhos e recomendações.

A todos aqueles que compõem o Departamento de Estruturas da EESC - USP, às amigas de república, enfim, a todos os amigos que conquistei durante esse período.

Ao CNPq, pelo apoio financeiro. 


\section{SUMÁRIO}

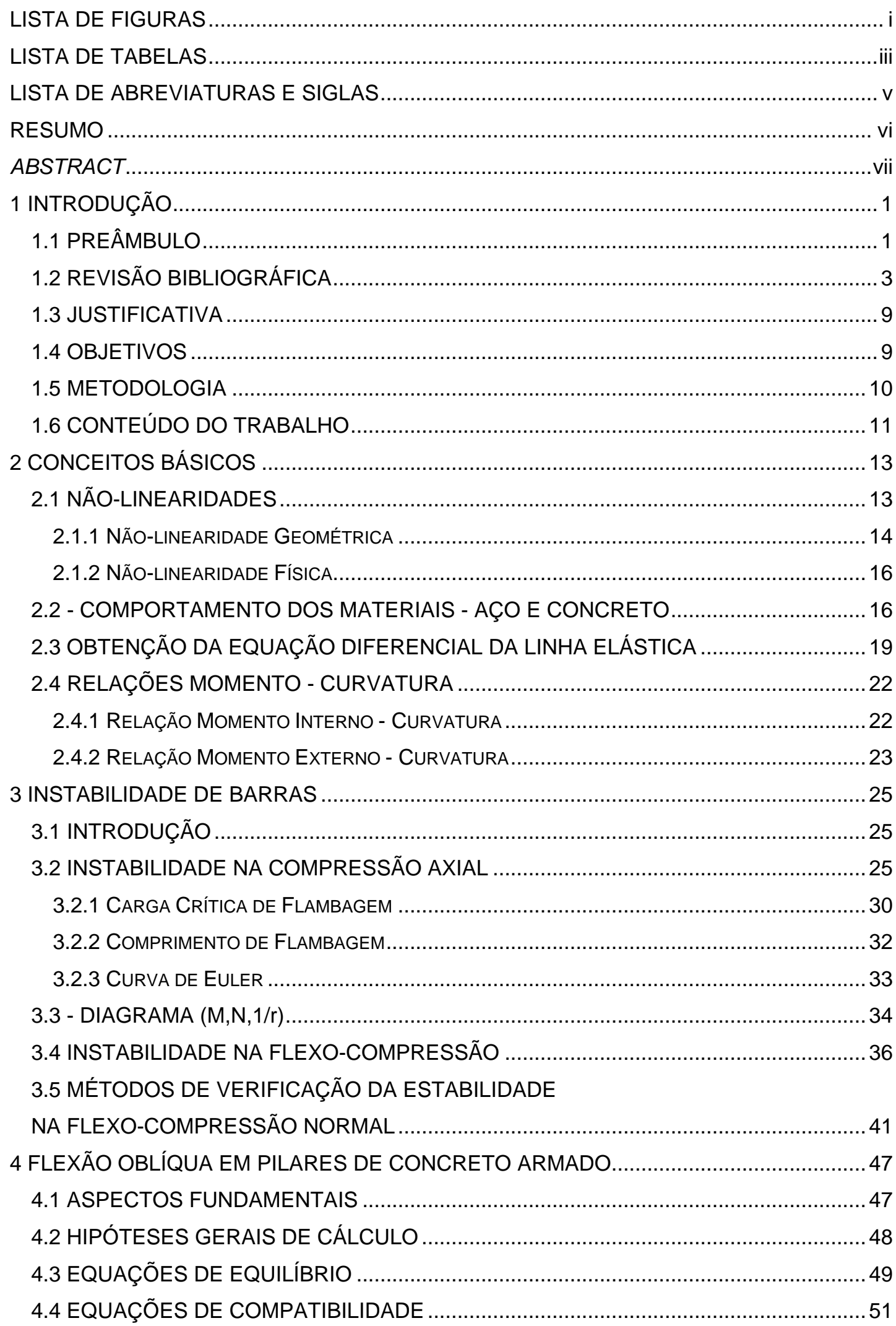


4.5 RELAÇÕES TENSÃO x DEFORMAÇÃO PARA

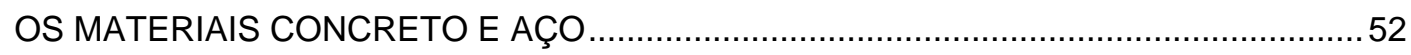

4.6 INSTABILIDADE NA FLEXO-COMPRESSÃO OBLÍQUA ….......................................52

4.7 MÉTODOS DE VERIFICAÇÃO DA ESTABILIDADE .................................................. 53

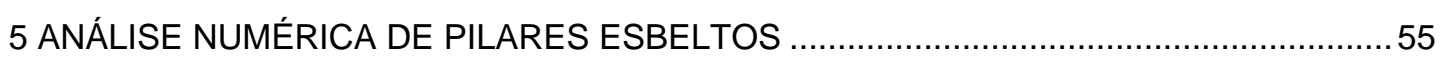

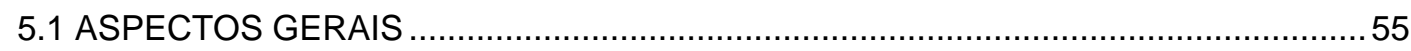

5.2 AFERIÇÃO EXPERIMENTAL DO PROGRAMA ................................................. 56

5.3 ANÁLISE DA FLEXO-COMPRESSÃO NORMAL (FCN) ........................................ 61

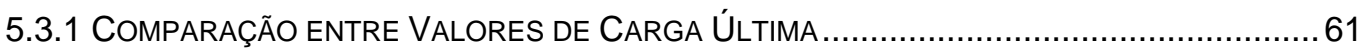

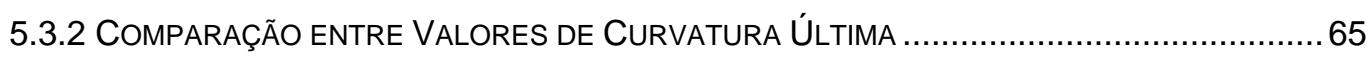

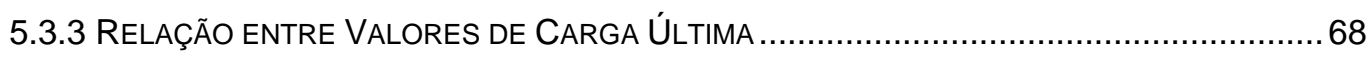

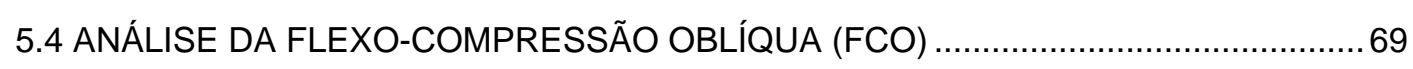

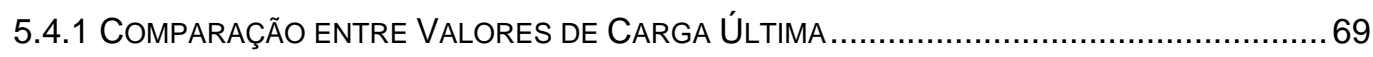

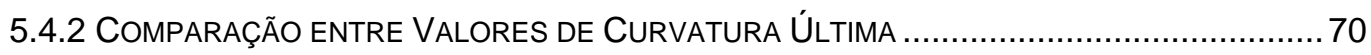

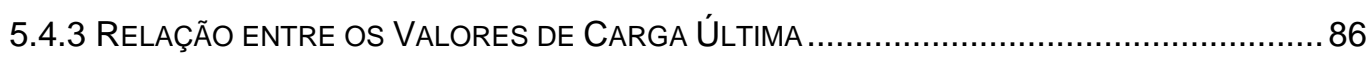

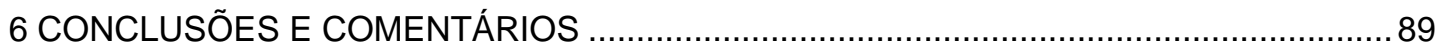

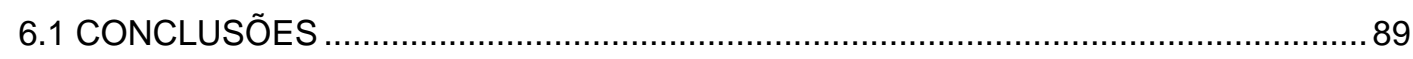

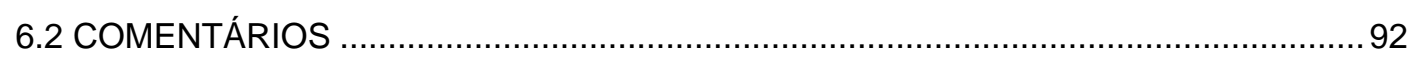

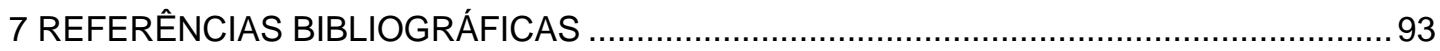




\section{LISTA DE FIGURAS}

FIGURA 01 - Diagrama tensão x deformação de um material não-linear

- trechos de descarregamento 13

FIGURA 02 - Viga biapoiada submetida a carregamento uniformemente distribuído ........... 14

FIGURA 03 - Eixo fletido da viga e esquema de decomposição da reação............................ 14

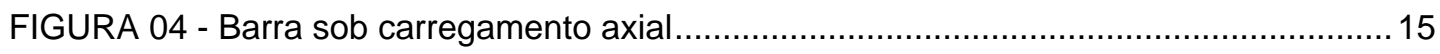

FIGURA 05 - Diagramas tensão $x$ deformação para materiais de comportamento linear e não-linear 16

FIGURA 06 - Diagramas tensão $x$ deformação para concretos de diversas resistências ensaiados a compressão axial. 17

FIGURA 07 - Diagrama tensão x deformação dos aços classe A .....................................17

FIGURA 08 - Diagramas tensão $x$ deformação para o aço classe $A$ segundo a NB-1/82 18

FIGURA 09 - Diagrama tensão $x$ deformação do concreto segundo a NB-1/82 .....................19

FIGURA 10 - Deformação de uma viga fletida de concreto armado sob flexão .....................20

FIGURA 11 - Elemento de barra de comprimento elementar $d x$

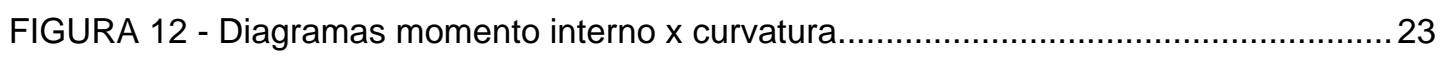

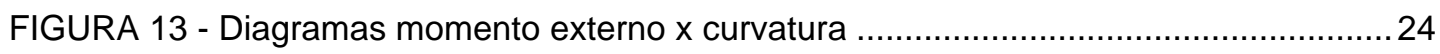

FIGURA 14 - Diagramas momento externo x curvatura - equação simplificada.....................24

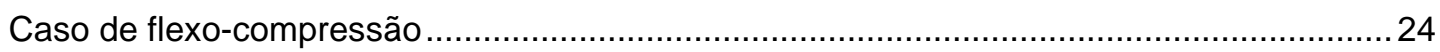

FIGURA 15 - Instabilidade na Compressão Axial

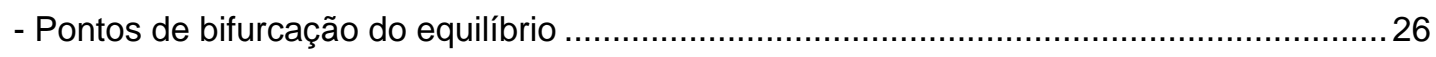

FIGURA 16 - Estabilidade na compressão axial

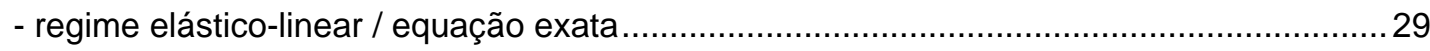

FIGURA 17 - Estabilidade na compressão axia

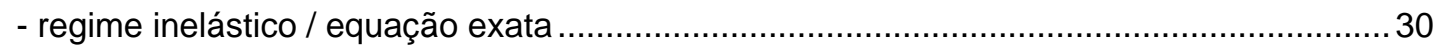

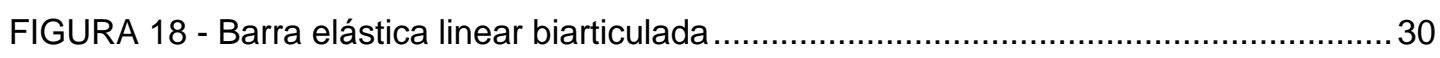

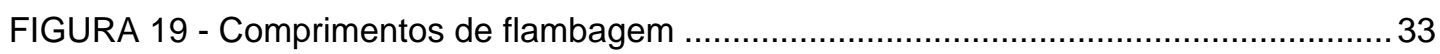

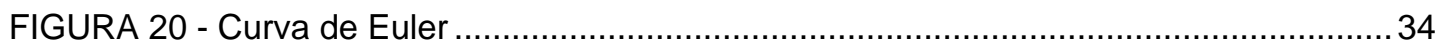

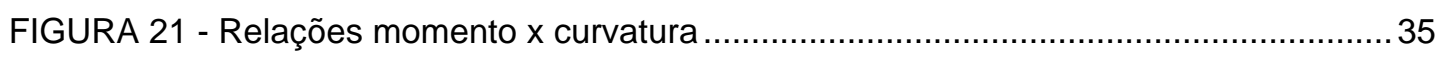

FIGURA 22 - Pilar esbelto submetido a flexo-compressão ................................................ 36

FIGURA 23 - Problema de tensões e de estabilidade sem bifurcação do equilíbrio................38

FIGURA 24 - Diagramas tensão-deformação para materiais de comportamento ....................38

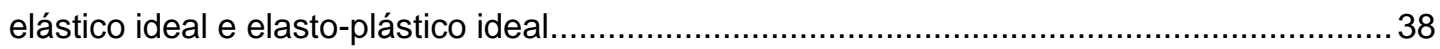

FIGURA 25 - Instabilidade na flexo-compressão - regime elástico ........................................ 40

FIGURA 26 - Instabilidade na flexo-compressão - regime inelástico .................................. 40

FIGURA 27 - Método geral aplicado através do carregamento progressivo ...........................43

FIGURA 28 - Método geral aplicado através de excentricidades progressivas ....................... 44 


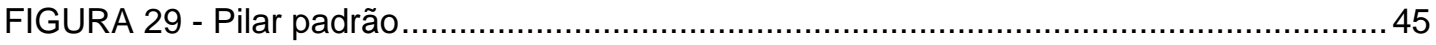

FIGURA 30 - Seção genérica submetida a flexo-compressão oblíqua...............................50

FIGURA 31 - Seção qualquer de concreto armado formada por contornos poligonais .........51

FIGURA 32 - Seção qualquer submetida a flexo-compressão oblíqua..................................52

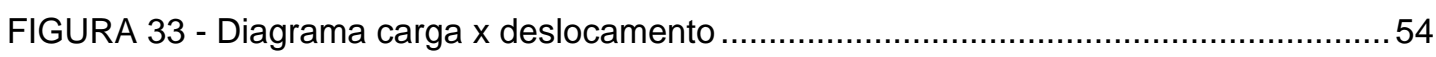

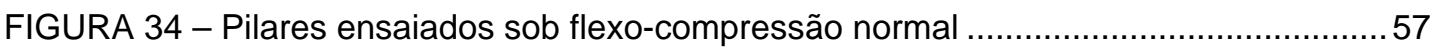

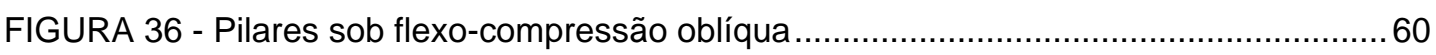

FIGURA 37 - Relação entre valores de carga última dados

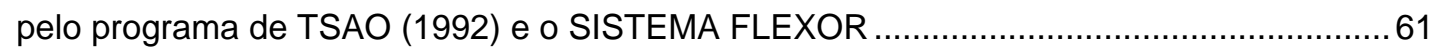

FIGURA 38 - FCN: Esquema das seções transversais dos pilares ensaiados........................62

FIGURA 39 - Gráfico relativo a 1 $1^{\underline{a}}$ e a $3^{\underline{a}}$ séries de pilares da TABELA 08 .............................67

FIGURA 40 - FCO: Esquema das seções transversais dos pilares ensaiados ......................70

FIGURA 41 - Relação entre curvaturas últimas para seção 20x20,

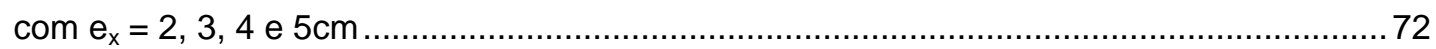

FIGURA 42 - Relação entre curvaturas últimas para seção 20x40,

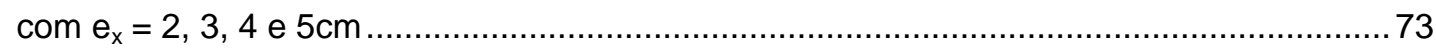

FIGURA 43 - Relação entre curvaturas últimas para seção 20x60,

com $e_{x}=2,3,4$ e $5 \mathrm{~cm}$.

FIGURA 44 - Relação entre curvaturas últimas para seção 20x80,

com $\mathrm{e}_{\mathrm{x}}=2,3$, 4 e $5 \mathrm{~cm}$

FIGURA 45 - Relação entre curvaturas últimas para seção 20×20

com $e_{x}=2 \mathrm{~cm}$, antes e depois da correção

FIGURA 46 - Relação entre curvaturas últimas para seção 20x60

com $e_{x}=2 \mathrm{~cm}$, antes e depois da correção

FIGURA 47 - Relação entre curvaturas últimas para seção 20×20

com $e_{x}=5 \mathrm{~cm}$, antes e depois da correção

FIGURA 48 - Relação entre curvaturas últimas para seção 20x60

com $e_{x}=5 \mathrm{~cm}$, antes e depois da correção

FIGURA 49 - Curva de ajuste da carga última em função da esbeltez. 


\section{LISTA DE TABELAS}

TABELA 01 - Dados e resultados relativos aos pilares ensaiados

- Flexo-compressão normal..

TABELA 02- Dados e resultados para pilares de seção quadrada

- Flexo-compressão oblíqua

TABELA 03 - Dados e resultados para pilares de seção em $L$

- Flexo-compressão oblíqua .

TABELA 04 - FCN: Dados e resultados para pilares de seção retangular

- Cálculo da carga última 63

TABELA 05 - FCN: Dados e resultados para pilares de seção retangular

- Cálculo da carga última.

TABELA 06 - FCN: Dados e resultados para pilares de seção retangular

- Cálculo da carga última

TABELA 07 - FCN: Dados e resultados para pilares de seção retangular

- Cálculo da carga última

TABELA 08 - FCN: Dados e resultados para pilares de seção retangular

- Cálculo da curvatura última

TABELA 09 - FCN: Dados e resultados da série de pilares

- Cálculo da carga última .

TABELA 10 - FCN: Resultados da série de pilares em termos de coeficiente de minoração..

TABELA 11 - FCO: Dados e resultados para pilares de seção retangular

- Cálculo da carga última

TABELA 12 - FCO: Comparação entre os valores de curvatura última para os pilares de seção $20 \times 20$, com $e_{x}=2,3$, 4 e $5 \mathrm{~cm}$.

TABELA 13 - FCO: Comparação entre os valores de curvatura última para os pilares de seção $20 \times 40$ com $e_{x}=2,3$, 4 e $5 \mathrm{~cm}$.

TABELA 14 - FCO: Comparação entre os valores de curvatura última para os pilares de seção $20 \times 60$ com $e_{x}=2,3$, 4 e $5 \mathrm{~cm}$.

TABELA 15 - FCO: Comparação entre os valores de curvatura última para os pilares de seção $20 \times 80$ com $\mathrm{e}_{\mathrm{x}}=2,3,4$ e $5 \mathrm{~cm}$.

TABELA 16 - FCO: Análise dos resultados dos pilares ensaiados com $e_{x}=2 \mathrm{~cm}$

TABELA 17 - FCO: Análise dos resultados dos pilares ensaiados com $e_{\mathrm{X}}=3 \mathrm{~cm}$

TABELA 18 - FCO: Análise dos resultados dos pilares ensaiados 
com $e_{\mathrm{X}}=4 \mathrm{~cm}$ 79

TABELA 19 - FCO: Análise dos resultados dos pilares ensaiados com $\mathrm{e}_{\mathrm{x}}=5 \mathrm{~cm}$ 80

TABELA 20 - FCO: Análise dos resultados dos pilares de seção 20×20 e 20×60, com excentricidades de 2 e $5 \mathrm{~cm}$, após a correção da carga 82

TABELA 21 FCO: Análise dos resultados dos pilares de seção 20×20 e 20×60, com excentricidades de 2 e $5 \mathrm{~cm}$, após a correção da curvatura 85

TABELA 22 - FCO: Dados e resultados da série de pilares

- Cálculo da carga última . 87

TABELA 23 - FCO: Resultados da série de pilares em termos de coeficiente de minoração. .87 


\title{
LISTA DE ABREVIATURAS E SIGLAS
}

\author{
ACl - American Concrete Institute \\ BS - British Standards Institution \\ CEB - Comité Europeén du Béton \\ CG - Centro de gravidade da seção bruta de concreto \\ ELU - Estado limite último de ruptura do concreto comprimido ou de deformação plástica \\ excessiva da armadura tracionada \\ FCN - Flexo-compressão normal \\ FCO - Flexo-compressão oblíqua \\ LN - Linha neutra \\ NB - Norma Brasileira
}




\section{RESUMO}

BORGES, A. C. L. (1999). Análise de pilares esbeltos de concreto armado submetidos a flexo-compressão oblíqua. São Carlos, 1999. 98p. Dissertação (Mestrado) - Escola de Engenharia de São Carlos, Universidade de São Paulo.

Como conseqüência do atual desenvolvimento tecnológico dos materiais aço e concreto, várias pesquisas têm surgido com vistas a um melhor aproveitamento da capacidade desses dois materiais, exigindo um maior conhecimento sobre o comportamento dos elementos, inclusive sobre sua vulnerabilidade a estados limites últimos. Sendo a instabilidade um estado limite último possível de ocorrer em configurações de equilíbrio de peças de concreto armado submetidas a determinadas solicitações normais, seu estudo torna-se fundamental para que seja possível propor soluções estruturais seguras e economicamente viáveis. Este trabalho apresenta a análise de alguns aspectos que interferem no estudo da estabilidade de pilares esbeltos de concreto armado, através de uma abordagem envolvendo aspectos teóricos, como também aspectos práticos oriundos da resolução de exemplos. O estudo é feito com base nos métodos geral e do equilíbrio, com os processos exato e do pilar padrão, através de um software (SISTEMA FLEXOR), desenvolvido por CADAMURO Jr. (1997). O objetivo é testar a viabilidade desses métodos a fim de propor soluções e, com isso, tornar mais amplo e acessível o uso de pilares esbeltos de concreto armado, incentivando a adoção de projetos mais arrojados sem subutilização dos materiais.

Palavras-chave: concreto armado; pilares esbeltos; flexo-compressão oblíqua. 


\section{ABSTRACT}

BORGES, A. C. L. (1999). Analysis of slender reinforced concrete columns subjected to axial load and biaxial bending. São Carlos, 1999. 98p. Dissertação (Mestrado) - Escola de Engenharia de São Carlos, Universidade de São Paulo.

As a consequence of the actual technological development of the materials steel and concrete, many researches have come up with proposal of better use of these two materials capacity, demanding a bigger knowledge about the behaviour of the elements, included your vulnerability to ultimate limit states. Being the instability a possible ultimate limit state of reinforced concrete columns equilibrium configuration, this study has been fundamental to make possible to propose safe and economically reasonable structural solutions. This work presents the analysis of some aspects that interfere in the study of slender reinforced concrete columns stability, through an approach involving theoretical and practical aspects derived from numerical solutions. The scheme is based in the General and Equilibrium Methods with the Exact Process and Model Column Method, through a software (SISTEMA FLEXOR) developed by CADAMURO Jr. (1997). The objective is to testify the practicability of these methods, to propose solutions and to render wider and more practical the use of slender reinforced concrete columns, stimulating the adoption of projects bolders without underutilisation of the materials.

Keywords: reinforced concrete; slender columns; axial load and biaxial bending. 


\section{Capitulo}

\section{INTRODUÇÃO}

\subsection{PREÂMBULO}

Quando os materiais de uso corrente eram o aço doce (CA-25) e o concreto C-15, o problema da instabilidade de pilares praticamente não existia, já que as seções necessárias geravam pilares bastante robustos dos quais os deslocamentos laterais não tinham importância prática.

Com a evolução dos materiais, os aços de alta resistência, como o CA-50, e os concretos de resistências superiores a $30 \mathrm{MPa}$ tornaram-se usuais, e como conseqüência disso, as estruturas tornaram-se mais leves, ou seja, para uma mesma solicitação era possível reduzir as seções transversais, tornando os pilares mais esbeltos. Com isso, os pilares passaram a apresentar um comportamento diferente.

A análise de pilares esbeltos abre espaço para uma discussão extremamente importante, sobre um fenômeno possível de ocorrer em configurações de equilíbrio desses elementos estruturais: a instabilidade. Quando isso ocorre, o pilar não consegue se deformar de modo a permanecer em equilíbrio.

Hoje, os pilares esbeltos tendem a fazer parte do cotidiano do engenheiro projetista, daí a necessidade do conhecimento de procedimentos de dimensionamento e verificação da segurança, simples e ao mesmo tempo confiáveis. Isso tem levado o meio técnico a estudar o fenômeno da instabilidade e, claro, propor soluções.

O estudo da Instabilidade de Barras consiste em uma análise do problema da Estabilidade das Estruturas em âmbito local, analisando o comportamento do pilar entre pavimentos. Sua importância está na análise de barras submetidas a solicitações que produzem tensões normais nas seções transversais do elemento.

São solicitações normais o momento e a força axial agindo isoladamente ou em conjunto, dando origem a solicitações do tipo: compressão axial, flexão 
normal simples, flexão normal composta, flexão oblíqua simples ou flexão oblíqua composta.

Para pilares esbeltos, mesmo pequenas excentricidades causam, com o aumento da carga, deformações por flexão e, por conseguinte, causam tensões de compressão desiguais, até que o concreto no lado comprimido mais solicitado ultrapassa o limite de deformação plástica e rompe. Por causa disso, para determinação da capacidade de carga de pilares esbeltos, deve ser considerada, no concreto armado, a influência de excentricidades não intencionais das cargas, bem como o comportamento inelástico do concreto e o crescimento não-linear das deformações por flexão que caracterizam a chamada Teoria de Segunda Ordem.

Em peças de concreto armado solicitadas à flexão, é usual e geralmente admissível calcular os esforços solicitantes no sistema não deformado, ou seja, segundo a teoria de primeira ordem. As hipóteses dessa teoria, entretanto, devem ser abandonadas quando as deformações tiverem sensível influência sobre os esforços solicitantes, diminuindo, conseqüentemente, a capacidade resistente de uma peça estrutural.

Analisar o comportamento de um pilar de concreto armado com base na teoria de segunda ordem significa considerar a não-linearidade geométrica, ou seja, a posição deformada da estrutura para determinação das solicitações, como também a não-linearidade física do material caracterizada pelo seu comportamento não-linear, observado no diagrama tensão $x$ deformação, que resulta em variações nos valores do módulo de elasticidade e da inércia da seção, de acordo com o nível de solicitação.

Em outras palavras, para pilares esbeltos, é indispensável a análise da sua estabilidade e a consideração, no dimensionamento, além das solicitações iniciais devidas às cargas aplicadas à estrutura e das solicitações devidas às excentricidades acidentais, também os momentos decorrentes dos deslocamentos sofridos pela estrutura por ação desse carregamento, que caracterizam os efeitos de segunda ordem. Além disso, o problema da instabilidade em pilares esbeltos deve ser analisado minuciosamente também pelo fato de se tratar do material concreto armado, por este constituir-se de uma associação entre dois materiais de comportamentos distintos, o aço e o concreto e, portanto, por apresentar dificuldades sérias quando o objetivo é prever o seu comportamento. 


\subsection{REVISÃO BIBLIOGRÁFICA}

Até por volta de 1960, os pilares eram calculados "à flambagem" com grande simplicidade, multiplicando-se a carga de trabalho, suposta axial, por um coeficiente de majoração $\omega$, além do coeficiente de segurança. Era o chamado processo $\omega$ (ômega). Nos casos de flexão composta, calculava-se a armadura para esta solicitação e verificava-se depois o pilar com a força axial agindo isoladamente, majorada por $\gamma_{\mathrm{f}} \mathrm{e} \omega$.

O coeficiente $\omega$ dependia do índice de esbeltez, e tinha como base teórica a consideração da flambagem além do limite de proporcionalidade.

Novas formas de dimensionamento utilizadas na atualidade além de mais complexas, conduzem a áreas de armaduras significativamente maiores, por vezes, até antieconômicas. Devido a essa série de fatos é que há necessidade de estudos nessa área, com o intuito de acompanhar o comportamento desses elementos sob ações crescentes e, com isso, desenvolver ferramentas adequadas para o cálculo.

A análise da Instabilidade de barras é de suma importância, principalmente quando se trata de pilares de grande esbeltez e pilares de seção variável ou irregular, a exemplo de pilares de estruturas de contraventamento de edifícios altos ou de pontes.

Estudos desenvolvidos ao longo dos anos têm aperfeiçoado o dimensionamento dessas peças através de análises envolvendo tipos variados de seções e solicitações. A complexidade envolvida nesse dimensionamento recai no fato do comportamento desses elementos ser tipicamente não-linear, ou seja, além da não-linearidade geométrica, caracterizada pela substancial alteração sofrida pelas solicitações decorrentes dos deslocamentos transversais do eixo do pilar, observa-se, também, a não-linearidade física decorrente das equações constitutivas, não-lineares, do concreto e do aço.

Estudos de grande importância vêm sendo desenvolvidos com o intuito de abordar casos mais gerais e, com isso, abranger uma série de problemas possíveis de ocorrer na prática. Casos como estes são os estudos envolvendo pilares solicitados à flexo-compressão oblíqua, que decorrem da aplicação conjunta de força axial e momento segundo uma direção não coincidente com um eixo de simetria da seção, simetria esta relativa à seção de concreto e à disposição da armadura. Desta análise, pode-se chegar aos casos de flexo-compressão normal, flexão simples ou compressão axial. 
A análise de pilares esbeltos de concreto armado envolvendo seus vários aspectos tem representado uma grande contribuição aos estudos de dimensionamento do concreto armado. Em âmbito mundial, um dos primeiros trabalhos é SAÉNZ \& MARTíN (1963) cujo objetivo é estabelecer, através de resultados experimentais, uma relação entre as resistências de pilares curtos e pilares esbeltos, como também MACGREGOR, BREEN \& PFRANG (1970) que propõem uma análise racional de segunda ordem para revisão do procedimento apresentado no código ACl da época (ACl 1963).

No Brasil, uma grande contribuição vem sendo dada pela Universidade de São Paulo (USP), através dos trabalhos desenvolvidos nessa linha. Nos últimos anos, esse assunto tem sido tratado visando o desenvolvimento de teorias e programas computacionais, com o intuito de determinar o comportamento estrutural dessas peças e, com isso, otimizar seu uso nas obras da construção civil.

BURKE JÚNIOR (1971) estuda o comportamento dos aços tipo B de forma experimental através da determinação de diagramas tensão $\mathrm{x}$ alongamento, além de abordar também, o problema do dimensionamento de peças de seção retangular de concreto armado com armadura lateral além da armadura convencional, através de expressões que permitem a unificação do cálculo da armadura de peças sujeitas a flexão normal composta, que envolve os casos de tração axial, flexo-tração normal, flexão simples, flexo-compressão normal e compressão axial.

AUFIERO (1977) apresenta um estudo sobre estabilidade de pilares solicitados à flexo-compressão normal considerando a influência do comportamento inelástico do material concreto armado, do tipo de carregamento e da esbeltez, para fins de dimensionamento e definição da capacidade de carga, utilizando o processo simplificado do pilar padrão na solução de problemas, cujos resultados são comparados com valores apresentados pelo Boletim de Informação nำ 103 do CEB, utilizando o método geral. Esse trabalho chama a atenção para o verdadeiro significado do fenômeno da flambagem que, para as publicações da época, era considerado como sendo sinônimo de perda de instabilidade na flexocompressão. 
O processo do pilar padrão também consiste no processo utilizado por BUCHAIM (1979), para analisar os conceitos que intervêm na consideração dos efeitos de $2^{a}$ ordem e da instabilidade por divergência do equilíbrio, em pilares de concreto armado sob flexo-compressão.

FORNI (1980) aborda, de maneira muito ampla, o estudo de seções quaisquer no estado limite último, solicitadas à flexo-compressão oblíqua, sem considerar o efeito da fluência. Com base nesse estudo foi desenvolvido um programa para determinação automática da resistência última de seções quaisquer de concreto armado submetidas a solicitações normais; trata-se do programa FOCCA (Flexão Oblíqua Composta no Concreto Armado), elaborado em linguagem FORTRAN.

Em MARCOTTI (1984), apresenta-se uma análise também ampla do problema da instabilidade de pilares de concreto armado submetidos à flexocompressão oblíqua, que inclui o cálculo de diagramas de curvatura e de interação com consideração da esbeltez. Deste trabalho, foi obtido também como subproduto, um programa de cálculo de pilares.

Também sob flexo-compressão oblíqua, seções poligonais quaisquer são estudadas por FRANÇA (1984), que faz um estudo detalhado das relações momento x curvatura.

PAULA (1988) apresenta um estudo sobre estabilidade das configurações de equilíbrio de pilares esbeltos de concreto armado, submetidos à flexocompressão normal e compressão axial, que recai numa simplificação do caso anterior, além de fazer um estudo comparativo entre pilares esbeltos em estado limite último, analisados através de algoritmos e programas elaborados com base no método geral e no processo aproximado do pilar padrão.

Em BORTOLIN (1991) encontram-se aspectos relativos ao dimensionamento de seções transversais retangulares e em $\mathrm{T}$, de concreto armado, submetidas a solicitações normais do tipo flexão simples e flexão oblíqua composta, respectivamente.

MENDES NETO (1991) apresenta um estudo sobre estabilidade de pilares de seção qualquer, solicitados à flexo-compressão oblíqua, através do processo do pilar padrão.

Em FRANÇA (1991) discute-se a questão dos parâmetros que devem ser utilizados para definir o comportamento reológico das peças de concreto armado, necessários para a análise de segunda ordem. Neste trabalho é proposta a troca 
da utilização das relações momento-normal-curvatura por relações momentonormal-rigidez.

Mais recente é o trabalho de CADAMURO Jr. (1997) onde se encontra um estudo geral sobre o dimensionamento de seções isoladas no estado limite último, como também, sobre pilares esbeltos de concreto armado solicitados à flexocompressão oblíqua, levando-se em consideração as não-linearidades física e geométrica e o efeito da fluência, além de seção transversal de forma poligonal qualquer e disposição arbitrária da armadura. Como produto desse trabalho, têmse elaborados e detalhados, vários algoritmos e rotinas computacionais em linguagem FORTRAN que deram origem ao SISTEMA FLEXOR.

Outras publicações como VENTURINI (1989) e VENTURINI \& BORTOLIN (1992) têm contribuído para o estudo de pilares e seu dimensionamento sob solicitações de flexo-compressão normal e oblíqua, respectivamente.

Alguns estudiosos têm incluído em suas publicações sobre os vários aspectos das peças de concreto armado, considerações sobre o fenômeno da instabilidade de pilares esbeltos, como FUSCO (1981), LEONHARDT \& MÖNNIG (1977), SANTOS $(1981,1994)$ e SÜSSEKIND(1987).

Revistas técnicas como o ACl Structural Journal, Journal of Structural Engeneering, The Structural Engineer e Materials and Structures têm, ao longo dos anos, publicado trabalhos sobre o tema, mostrando o interesse e a preocupação de pesquisadores do mundo inteiro, através de trabalhos sobre métodos de análise de pilares como BAZANT, CEDOLIN \& TABBARA (1991), também EL-METWALLY (1994), que apresenta um método numérico para análise de pilares e vigas-colunas de concreto, e RANGAN (1990), cuja contribuição é relativa a um método de cálculo de resistência para pilares esbeltos de concreto armado biapoiados.

GARCIA (1981) estuda o problema da instabilidade lateral de pilares através do processo $\mathrm{P}-\Delta$.

ESPION \& HALLEUX (1988) tratam da relação momento x curvatura de seções de concreto armado sob compressão axial e momento, simultaneamente, assunto também abordado por PRAKHYA \& MORLEY (1990), juntamente com o estudo de diferentes parâmetros que influenciam na relação tensão $\mathrm{x}$ rigidez. 
Aspectos relativos à curva tensão $\mathrm{x}$ deformação do concreto na compressão são abordados em SHEIKH, YEH \& KHOURY (1990) e em SHEIKH \& YEH (1990).

HOROWITZ (1989) descreve um procedimento para otimizar os projetos de pilares submetidos a várias situações de carregamento.

WANG \& HSU (1992) apresentam um estudo completo sobre o comportamento carga-deformação de pilares de concreto armado sujeitos à flexocompressão, assunto também abordado por ZERIS \& MAHIN (1991).

ZENG, DUAN, WANG \& CHEN (1992) apresentam 108 testes com resultados satisfatórios, da comparação entre o método proposto por eles e o método do $\mathrm{ACl}$, para cálculo do módulo de resistência à flexão $(\mathrm{El})$. As expressões propostas, além de simples para uso, são recomendadas para projeto de pilares esbeltos de concreto armado. Nesse mesmo ano foi publicado o trabalho de TSAO (1992) que apresenta uma ferramenta numérica para análise de pilares esbeltos de concreto armado sob flexo-compressão oblíqua, cujos resultados foram verificados através de testes experimentais incluindo seções retangulares e em L.

YAU, CHAN \& SO (1993) apresentam um processo iterativo para escolha da melhor forma de seção transversal para pilares de concreto armado submetidos a flexo-compressão.

ZAK (1993) aborda o problema de seções de concreto armado sujeitas a momento e a carregamento longitudinal, através da consideração de aspectos computacionais do problema da análise da resistência última.

Analisando os estudos desenvolvidos, principalmente na década de 90, percebe-se um aumento da preocupação com o comportamento de pilares, provavelmente em função do desenvolvimento de novos materiais de resistência bastante elevada. Isso se torna evidente, observando-se os últimos trabalhos desenvolvidos para estudo do comportamento de pilares em concreto e aço de alta resistência.

Uma grande contribuição foi dada por CHUANG \& KONG (1995), que apresentam um método numérico para cálculo da carga última de pilares esbeltos de concreto armado sob flexo-compressão normal, levando em consideração tanto a não-linearidade proveniente do material, como também a não-linearidade geométrica. Os valores de carga última obtidos para 127 pilares resultantes de 11 investigações experimentais foram comparados com os valores recomendados pelas normas BS8110 (1985) e EC2 (1992). 
WEERAKOON \& AHMAD (1995) apresentam um modelo não-linear para computador, com o intuito de prever o comportamento de pilares esbeltos de concreto armado submetidos a flexo-compressão oblíqua. Dentre 24 pilares ensaiados na Universidade do Texas, 9 foram escolhidos para terem seus resultados comparados com os resultados obtidos através da análise com 0 modelo.

Também baseado em um método numérico é o trabalho realizado por KIM \& YANG (1995) para prever o comportamento de pilares de concreto armado baseado no método dos elementos finitos, a fim de investigar os efeitos da resistência do concreto e da taxa de armadura longitudinal na relação carga axialmomento fletor.

Nesse mesmo ano surge o trabalho de LIN \& FURLONG (1995), com o propósito de identificar os limites ideais para a taxa de armadura longitudinal em pilares de concreto armado, a fim de controlar a tensão nas barras de aço em serviço.

Em IBRAHIM \& MACGREGOR (1996) apresenta-se uma análise experimental englobando 20 ensaios de pilares curtos de concreto armado sob carga axial com pequena excentricidade, utilizando concretos de alta resistência e de ultra-alta resistência.

Um método numérico para análise de pilares de pórticos de concreto armado foi apresentado por BAZANT \& XIANG (1997), com a proposta de ser mais realista e de fácil aplicação em projetos do que os procedimentos apresentados pelo $\mathrm{ACl}$ e pelo $\mathrm{CEB}$.

CHUANG \& KONG (1997) apresentam 26 resultados experimentais de pilares esbeltos de concreto armado submetidos a flexo-compressão normal cujos valores de carga última foram comparados com os valores recomendados pelas normas ACI318, EC2 e BS8110.

Uma das mais recentes contribuições foi dada por CLAESON \& GYLLTOFT (1998), que apresentam um estudo experimental sobre o comportamento de pilares esbeltos de concreto armado, como também uma análise baseada no método dos elementos finitos. Neste artigo são apresentados 12 resultados provenientes de pilares de seção quadrada sob carga excêntrica monotônica. Paralelamente, aproveitou-se para fazer uma análise do desempenho de concretos de diferentes resistências, com relação à forma de ruína. 


\subsection{JUSTIFICATIVA}

Como visto, uma das conseqüências do atual desenvolvimento tecnológico dos materiais aço e concreto é o surgimento de várias pesquisas com o objetivo de proporcionar um melhor aproveitamento da capacidade desses dois materiais, exigindo assim um maior conhecimento sobre o comportamento dos elementos, incluindo sua vulnerabilidade a estados limites últimos, sejam eles, de ruptura do concreto comprimido, de deformação plástica excessiva ou de instabilidade.

Os dois primeiros, já mais amplamente discutidos, abrem espaço a estudos que esclareçam dúvidas de como cercar o problema da instabilidade, estado limite último que surge quando da análise de peças esbeltas.

Sabendo-se que a instabilidade é um problema presente em configurações de equilíbrio de peças de concreto armado submetidas a determinadas solicitações normais, seu estudo se torna fundamental para que seja possível propor soluções estruturais seguras e economicamente viáveis.

Com base nisso está fundamentada esta pesquisa que aspira contribuir para o estudo da instabilidade no seu caso mais abrangente, o da flexocompressão oblíqua, em pilares de concreto armado pois, apesar de ser um material construtivo dos mais utilizados, apresenta comportamento de difícil descrição. Portanto, tem-se como justificativa para este trabalho a necessidade de estudos com o intuito de tornar acessíveis, a engenheiros projetistas e pesquisadores, procedimentos de cálculo eficazes que contribuam para um melhor aproveitamento da capacidade do material concreto armado através do uso de ferramentas de cálculo já existentes.

\subsection{OBJETIVOS}

Por ser o comportamento dos pilares esbeltos extremamente delicado, do ponto de vista da sua susceptibilidade ao fenômeno da instabilidade, é que engenheiros projetistas tendem a fugir, sempre que possível, dos casos em que $\lambda>80$. O desconhecimento sobre seu real comportamento e sobre a credibilidade dos processos simplificados de verificação torna compreensível que esses casos sejam evitados. O interesse dos pesquisadores que trabalham nesta área é pois, tornar conhecido e acessível aos projetistas o comportamento desses elementos para que deles possa ser aproveitada ao máximo sua capacidade resistente, sem comprometer a segurança. 
Para isso, é necessário testar a viabilidade dos métodos existentes, a fim de propor soluções e, com isso, tornar mais amplo o uso de pilares esbeltos de concreto armado, incentivando a adoção de projetos mais arrojados com um certo grau de confiabilidade que permita a concepção de estruturas mais esbeltas, não permitindo subtilizarão dos materiais.

Com esse intuito, este trabalho tem como proposta estudar o comportamento da pilares de concreto armado, de seção qualquer, solicitados à flexo-compressão oblíqua, que constitui o caso mais geral e também o mais complexo dentre as solicitações normais, observando as não-linearidades física e geométrica, a fim de investigar a validade dos processos aproximados através de uma abordagem envolvendo aspectos teóricos, como também aspectos práticos oriundos da resolução de exemplos.

Para tal, o estudo é feito com base nos métodos geral e do equilíbrio com os processos exato e do pilar padrão, através de um software desenvolvido por CADAMURO Jr. (1997).

O objetivo deste trabalho é, portanto, através da utilização da ferramenta elaborada por CADAMURO Jr. (1997) e da análise de casos reais, propor sistemáticas de cálculo que possam contribuir de alguma forma para o bom uso dos pilares esbeltos de concreto armado.

\subsection{METODOLOGIA}

Para o estudo da estabilidade de pilares esbeltos isolados de concreto armado solicitados à flexo-compressão oblíqua segundo uma análise não-linear, física e geométrica, utilizar-se-á o programa computacional desenvolvido por CADAMURO Jr. (1997), disponível no Departamento de Estruturas da Escola de Engenharia de São Carlos - USP.

O software consiste em um programa em linguagem FORTRAN powerstation para uso em praticamente qualquer computador da linha IBM-PC com plataforma WINDOWS 3.x ou superior.

O SISTEMA FLEXOR consiste em um conjunto de subprogramas que permitem o cálculo das armaduras dos pilares pelo processo exato (DIM_EXATO), pelo processo do pilar padrão (DIM_PPADRAO), como também de seções isoladas no estado limite último (DIM_ELU). 
A verificação da estabilidade de pilares se dá através do método do equilíbrio com o processo exato (VERIFIC_EXATO), ou através do método do equilíbrio com o processo do pilar padrão (VERIFIC_PPADRAO), além de atender também aos casos de verificação de seções isoladas (VERIFIC_ELU).

Com algumas adaptações, pode-se utilizar convenientemente o programa para outros fins, como por exemplo, através do programa VERIFIC_EXATO que é baseada no método do equilíbrio com o processo exato, é possível obter um outro programa (GERAL_EXATO) capaz de permitir incrementos no carregamento ou na excentricidade do carregamento do pilar, dando margem à aplicação do método geral que consiste em utilizar, de forma iterativa, o método do equilíbrio.

Para permitir a entrada de dados, os elementos comprimidos são discretizados por elementos de barra, com seção transversal qualquer e disposição aleatória de armadura.

O SISTEMA FLEXOR foi utilizado no processamento de casos representativos, com variação das esbeltezes, das seções transversais (forma e arranjo), e dos processos de cálculo utilizados (exato e aproximado), como ferramenta para investigação da validade dos processos de cálculo existentes.

\subsection{CONTEÚDO DO TRABALHO}

Este trabalho encontra-se dividido em 6 capítulos. O primeiro deles, Introdução, apresenta uma visão geral sobre o assunto, incluindo a citação de trabalhos realizados dentro desta mesma linha de pesquisa, além de apresentar os objetivos, a metodologia e as justificativas relativas a elaboração deste trabalho.

O segundo capítulo, Conceitos Básicos, apresenta um breve estudo sobre temas complementares à pesquisa realizada, como: não-linearidades, comportamento dos materiais, equação diferencial da linha elástica e relações momento x curvatura .

No terceiro capítulo, Instabilidade de Barras, encontram-se aspectos relativos ao problema da instabilidade de pilares sob o ponto de vista tanto da compressão axial, como da flexo-compressão. Já a flexo-compressão oblíqua tem tratamento reservado no quarto capítulo, Flexão Oblíqua em Pilares de Concreto Armado. 
Quanto a análise numérica desenvolvida através do SISTEMA FLEXOR, ela encontra-se descrita no capítulo 5 intitulado Análise Numérica de Pilares Esbeltos.

No sexto capítulo encontram-se as conclusões e comentários, seguido pelas referências bibliográficas. 


\section{Capítulo}

\section{CONCEITOS BÁSICOS}

\subsection{NÃO-LINEARIDADES}

Para o estudo de barras sob carregamento monotônico, o conceito mais importante é o de linearidade, ficando o conceito de elasticidade como essencial ao estudo de barras sob carregamento cíclico.

A linearidade tanto física como geométrica interfere no comportamento das estruturas. Essa interferência é verificada através da relação entre momento e curvatura.

O conceito de linearidade, por vezes, é confundido com o conceito de elasticidade: se é dito que um determinado material tem comportamento elásticolinear, os conceitos elástico e linear são distintos. Uma barra é de material elástico quando, cessada a ação do carregamento aplicado, volta ao comprimento inicial, isso quer dizer que, quando $\sigma$ volta ao valor zero, $\varepsilon$ também o faz, não havendo pois nenhuma deformação residual.

Analisando o diagrama da FIGURA 01 tem-se: se, ao ser descarregado, o caminhamento se der pela curva em traço cheio, o material será elástico, mas, se o caminhamento se der através da linha tracejada, existirá deformação residual, portanto, será o material dito inelástico. O fato do diagrama ser curvo demonstra que o material não é linear, ou seja, não existe proporcionalidade entre tensão e deformação.

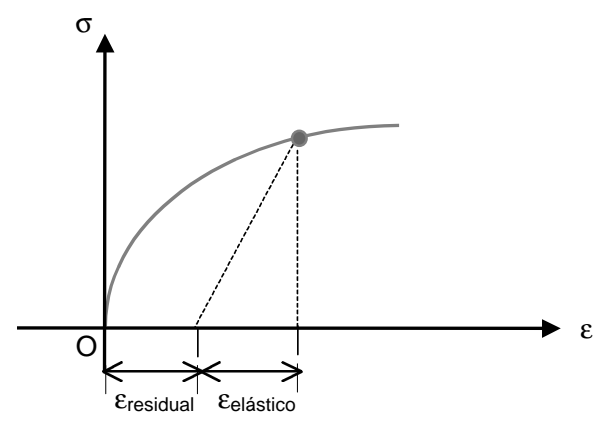

FIGURA 01 - Diagrama tensão x deformação de um material não-linear - trechos de descarregamento 


\subsubsection{NÃO-LINEARIDADE GEOMÉTRICA}

A não-linearidade geométrica é resultante da influência dos deslocamentos no momento total, conhecida como efeito de $2^{\mathrm{a}}$ ordem.

A determinação dos esforços solicitantes ao longo das seções transversais de uma peça é feita, geralmente, supondo a estrutura na sua posição indeformada. Por exemplo, na viga biapoiada da FIGURA 02, tem-se:

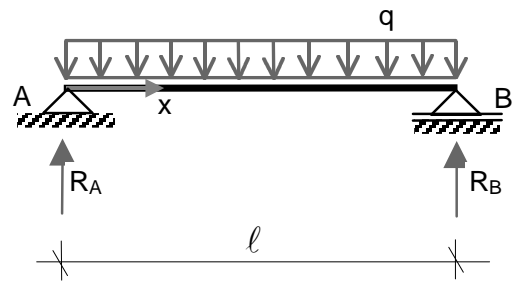

FIGURA 02 - Viga biapoiada submetida a carregamento uniformemente distribuído

$A$ reação em $A$ tem como valor $q \ell / 2$, que é o mesmo valor do esforço cortante logo a direita de $A$. Portanto a solicitação $V_{A}=q \ell / 2$ é proporcional à carga. Fazendo isso, despreza-se a deformação da peça. Diz-se então, que se trata da teoria de $1^{\underline{a}}$ ordem.

Considerando, porém, o eixo fletido da viga, como mostra a FIGURA 03, a seção transversal gira de um ângulo $\phi_{A}$ e a reação $R_{A}$ se decompõe em duas forças que resultam em um esforço cortante $V_{A}$ e em um esforço normal $N_{A}$ :

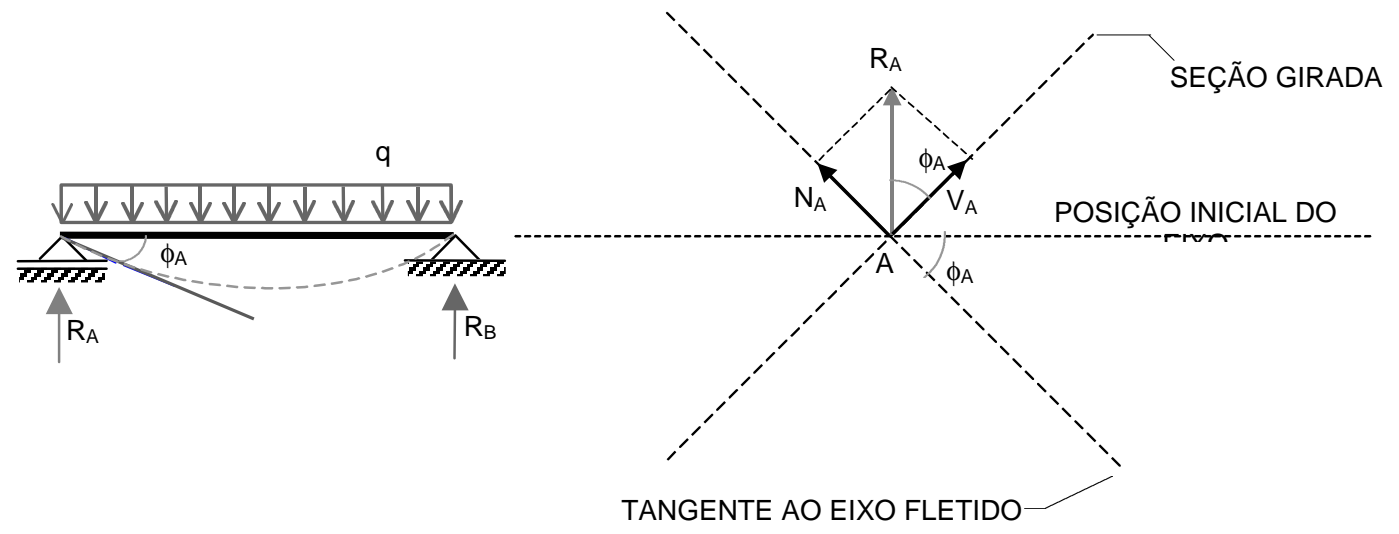

FIGURA 03 - Eixo fletido da viga e esquema de decomposição da reação

Tem-se agora a teoria de $2^{\mathrm{a}}$ ordem. Neste caso os esforços são: 


$$
\begin{aligned}
& \mathrm{V}_{A}=\mathrm{R}_{\mathrm{A}} \cdot \cos \phi_{A} \\
& \mathrm{~N}_{\mathrm{A}}=\mathrm{R}_{\mathrm{A}} \cdot \operatorname{sen} \phi_{A}
\end{aligned}
$$

onde:

$$
\phi_{\mathrm{A}}=\frac{\mathrm{q} \cdot \ell^{3}}{24 \cdot \mathrm{EI}}
$$

portanto:

$$
\mathrm{V}_{\mathrm{A}}=\frac{\mathrm{q} \cdot \ell}{2} \cdot \cos \left(\frac{\mathrm{q} \cdot \ell^{3}}{24 \cdot \mathrm{El}}\right)
$$

e, não haverá proporcionalidade entre $V_{A}$ e $q$.

A rigor, dever-se-ía sempre considerar a posição deformada da estrutura TEORIA DE $2^{\underline{a}}$ ORDEM - para calcular os esforços solicitantes já que isso significa grau mais elevado de aproximação, porém, do ponto de vista prático, a diferença entre os resultados obtidos mediante as teorias de $1^{1 \underline{a}}$ e $2^{\underline{a}}$ ordens pode ser tão pequena que não compense executar um cálculo mais elaborado. Nas vigas usuais, o ângulo $\phi_{A}$ é tão pequeno que se pode fazer $\phi_{A} \cong 0$ de modo que $V_{A}=R_{A}$, como na teoria de $1^{\underline{a}}$ ordem; ou seja, os efeitos de $2^{a}$ ordem são desprezíveis, entretanto existem casos em que a não consideração desses efeitos pode causar discrepâncias consideráveis nos cálculos, como é o caso da barra da FIGURA 04.

Considere-se uma barra carregada axialmente como mostra a FIGURA 04:

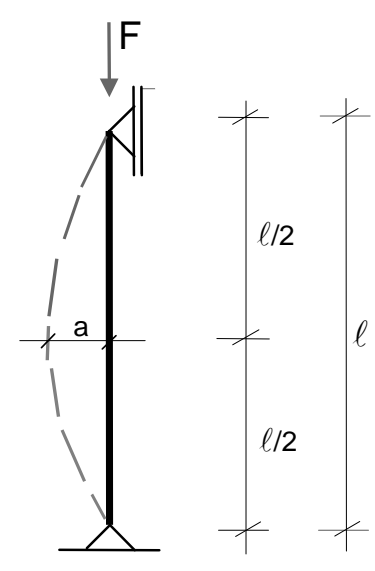

FIGURA 04 - Barra sob carregamento axial

Garantindo-se que a barra tem comportamento elástico-linear até atingir a tensão de escoamento, sabe-se que para valores baixos de $\mathrm{F}$ a barra permanece reta, portanto as flechas são nulas. Fazendo $\mathrm{F}$ crescer, quando se atinge um certo 
valor de $\mathrm{F}$ denominado $\mathrm{F}_{\mathrm{cr}}$ a barra se encurva e o equilíbrio estável só pode ser mantido dessa forma. Para essa nova posição a tensão cresce mais rapidamente para acréscimos pequenos da carga $F_{c r}$. Portanto, do ponto de vista prático, uma determinada carga $F=F_{c r}$ já pode ser considerada de ruína.

\subsubsection{NÃO-LINEARIDADE FíSICA}

A não-linearidade geométrica prova que pode não haver proporcionalidade entre causa e efeito, mesmo quando o material é elástico-linear. O problema se agrava quando o próprio material não é linear, o que caracteriza a não-linearidade física.

O material é linear quando obedece à Lei de Hooke, ou seja, quando a tensão é proporcional à deformação. Caso contrário o material é dito não-linear.

Ao contrário da não-linearidade geométrica, a não-linearidade física é uma propriedade intrínseca do material, e acarreta não proporcionalidade entre causa e efeito mesmo na teoria de $1^{\underline{a}}$ ordem. Considerando-se uma estrutura de concreto armado, a não-linearidade física resulta da resposta não-linear do aço e do concreto. Ver FIGURA 05.

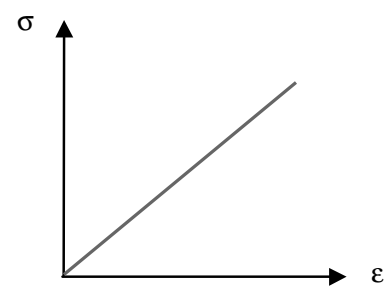

MATERIAL LINEAR

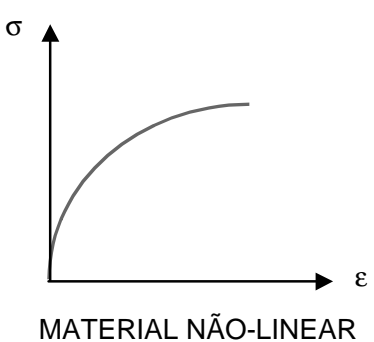

MATERIAL NÃO-LINEAR

FIGURA 05 - Diagramas tensão x deformação para materiais de comportamento linear e não-linear

\section{2 - COMPORTAMENTO DOS MATERIAIS - AÇO E CONCRETO}

O concreto armado, como resultado da associação de dois materiais estruturais, o aço e o concreto, apresenta comportamento de difícil descrição.

O diagrama tensão x deformação do concreto não é linear e é variável para as várias classes de resistência.

Considera-se o concreto como um material elasto-plástico, mas que apresenta um comportamento aproximadamente elástico-linear para tensões até $30 \%$ de sua máxima tensão de compressão. Este valor máximo de tensão de 
compressão representa o valor a partir do qual se inicia a plastificação que, graficamente, é traduzida pelo trecho descendente da curva tensão x deformação.

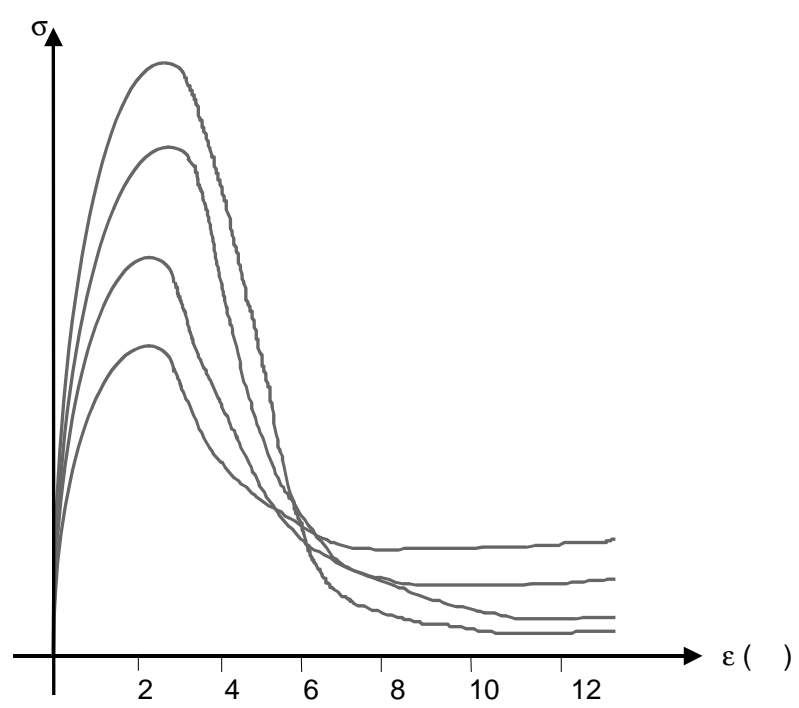

FIGURA 06 - Diagramas tensão x deformação para concretos de diversas resistências ensaiados a compressão axial

Observando a FIGURA 06, tem-se a idéia de que o pico das tensões no concreto ocorre em torno da deformação 2 independente da classe do concreto considerado. No entanto, sabe-se que a forma da curva tensão $x$ deformação depende de vários fatores como: idade do concreto, velocidade e duração de aplicação do carregamento entre outros, além da resistência do concreto.

Os aços usados na construção civil, atualmente, são os aço classe A, laminados a quente e resfriados ao ar livre. Caracterizam-se por apresentar um diagrama tensão $x$ deformação linear até ser atingida a tensão de escoamento, a partir da qual forma-se um patamar de escoamento bem definido, como mostra a FIGURA 07.

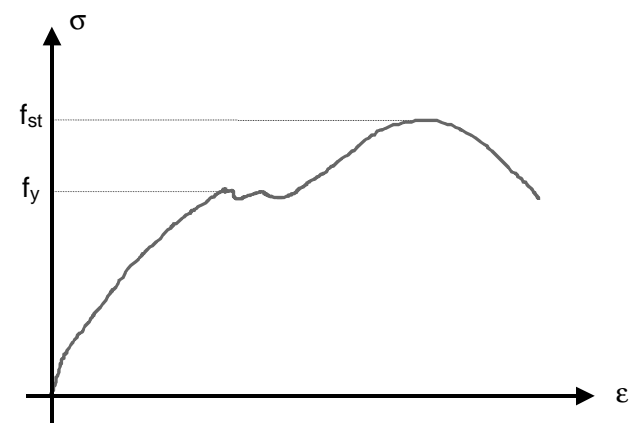

FIGURA 07 - Diagrama tensão x deformação dos aços classe A 
Sabendo disso, deve-se escolher um diagrama de cálculo que apresente a melhor concordância possível com dados experimentais, e que garanta suficiente segurança à sua utilização.

A seguir serão mostrados os gráficos correspondentes ao comportamento do concreto e do aço considerados pela NB-1/82. Antes disso deve-se ressaltar que estes diagramas não são únicos, outros diagramas são apresentados por outras normas, inclusive alguns deles até mais adequados.

A NB-1/82 adota um diagrama de cálculo simplificado para o aço classe A, admitindo ser este um material elasto-plástico perfeito, cujas tensões e deformações são limitadas pelos valores correspondentes ao concreto, por tratarse de aço para concreto armado. O diagrama está mostrado na FIGURA 08.

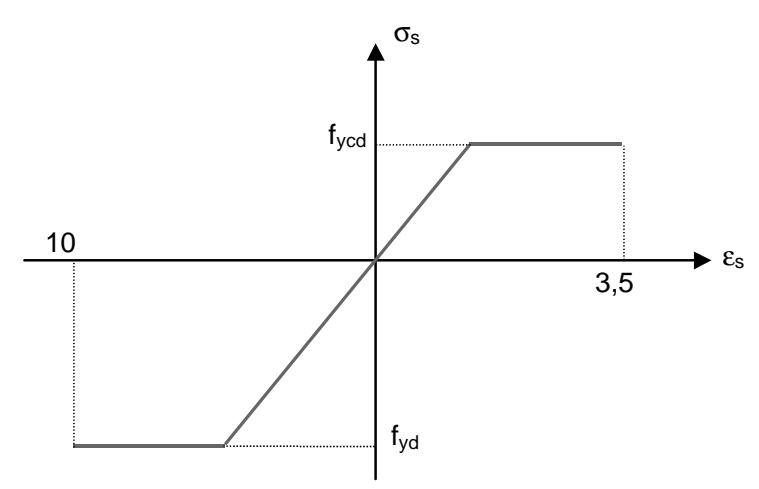

FIGURA 08 - Diagramas tensão x deformação para o aço classe A segundo a NB-1/82

A NB-1/82 adota o diagrama simplificado parábola-retângulo para o concreto apresentado na FIGURA 09, para dimensionamento de peças de concreto armado de seção qualquer no estado limite último. Este diagrama é assim chamado por ser composto de uma parábola do $2^{\circ}$ grau entre os valores de $\varepsilon$ de zero a 2 , cuja ordenada é $0,85 . f_{c d}$, e de um trecho reto correspondente aos valores de $\varepsilon$ entre 2 e 3,5 . 


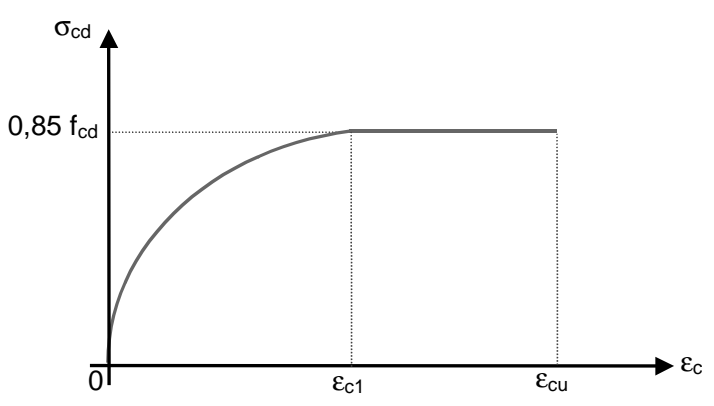

FIGURA 09 - Diagrama tensão x deformação do concreto segundo a NB-1/82

\subsection{OBTENÇÃO DA EQUAÇÃO DIFERENCIAL DA LINHA ELÁSTICA}

A configuração deformada de equilíbrio de uma barra é denominada linha elástica. Ela surge devido ao fato das seções transversais ao longo da barra se deformarem. Daí, desprezando-se as deformações axiais, e admitindo-se a hipótese de manutenção das seções planas, é possível, com o auxílio da FIGURA 10, chegar à equação diferencial da linha elástica.

Considere-se a viga de vão $\ell$ da FIGURA 10 submetida a flexão devido à ação da carga F; o eixo da viga, inicialmente retilíneo e horizontal, deforma-se e assume a forma curva.

Para conhecer a forma desta curva, ou seja, a equação $y=f(x)$ que determina esta curva, considere-se um elemento dx da barra. Após a deformação, as seções transversais distantes $d x$ entre si, inicialmente paralelas, giram de um ângulo $d \theta$.

Tendo-se admitido que o material obedece à Lei de Hooke, a curvatura numa seção genérica é dada pela expressão:

$$
\frac{1}{r}=-\frac{M}{E l}
$$

onde o primeiro membro representa a curvatura do eixo da barra na configuração deformada. Uma vez que o momento $M$ varia ao longo da barra, a linha elástica terá uma curvatura variável.

Resta agora, a partir da FIGURA 10, estabelecer uma relação entre os deslocamentos y e o valor do momento $M$, através da dedução do valor da curvatura $1 / r$ em função destes deslocamentos. 


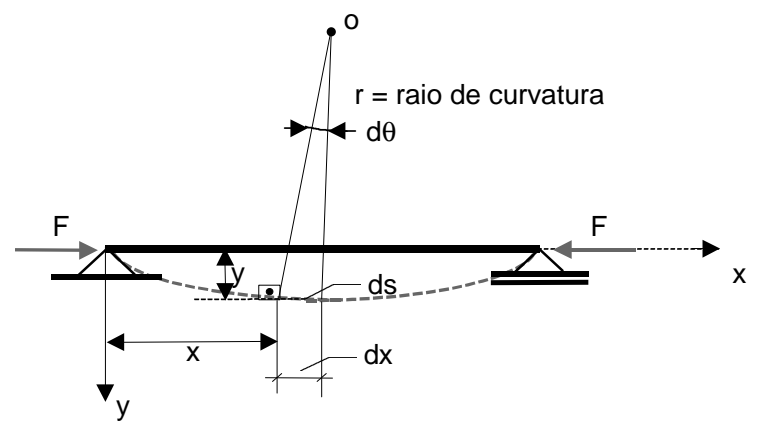

FIGURA 10 - Deformação de uma viga fletida de concreto armado sob flexão

Tem-se então:

$\mathrm{ds}=\mathrm{rd} \theta$

donde $\frac{1}{r}=\frac{d \theta}{d s}=\frac{d \theta}{d x} \cdot \frac{d x}{d s}$

Por outro lado;

$\operatorname{tg} \theta=\frac{d y}{d x} \rightarrow \theta=\operatorname{arctg}\left(\frac{d y}{d x}\right)$

Derivando (07) em relação a x, tem-se:

$\frac{d \theta}{d x}=\frac{1}{1+\left(\frac{d y}{d x}\right)^{2}} \cdot \frac{d^{2} y}{d x^{2}}$

e ainda

$$
d s^{2}=d x^{2}+d y^{2}
$$

resultando em:

$$
\frac{d s}{d x}=\left[1+\left(\frac{d y}{d x}\right)^{2}\right]^{\frac{1}{2}}
$$

Portanto, substituindo (09) e (11) em (07) tem-se:

$$
\frac{1}{r}=\frac{\frac{d^{2} y}{d x^{2}}}{\left[1+\left(\frac{d y}{d x}\right)^{2}\right]^{3 / 2}}=-\frac{M}{E I}
$$

que é a equação diferencial completa da linha elástica. 
Algumas simplificações podem ser feitas ao considerar $\mathrm{dy} / \mathrm{dx}$ pequeno, chegando-se à equação simplificada da linha elástica, que tem a seguinte forma:

$$
\frac{1}{r}=\frac{d^{2} y}{d x^{2}}=-\frac{M}{E l}
$$

Uma outra forma de obter a equação simplificada é considerar rotações muito pequenas de forma que, com grande aproximação, se tenha:

$$
d s \cong d x \text { e } \theta \cong \operatorname{tg} \theta \text { tal que } \theta \cong \frac{d y}{d x}
$$

e portanto;

$$
\frac{1}{r}=\frac{d \theta}{d s}=\frac{d \theta}{d x}=\frac{d \cdot\left(\frac{d y}{d x}\right)}{d x}=\frac{d^{2} y}{d x^{2}}=-\frac{M}{E l}
$$

Essas simplificações podem ser feitas porque $d y / d x$, e em particular o seu quadrado, para barras que se deformam pouco, são pequenos em relação à unidade, podendo ser desprezadas sem que haja diferenças que comprometam os resultados a serem obtidos.

Uma outra forma de obter as curvaturas é através das deformações. Para tal, considere-se um elemento de barra de comprimento $d x$ e, admitindo-se que a barra esteja em equilíbrio após a deformação e que $\varepsilon$ seja a deformação relativa de uma fibra genérica distante $z$ do eixo que passa pelo CG da seção solicitada por uma tensão $\sigma$, tem-se (FIGURA 11):

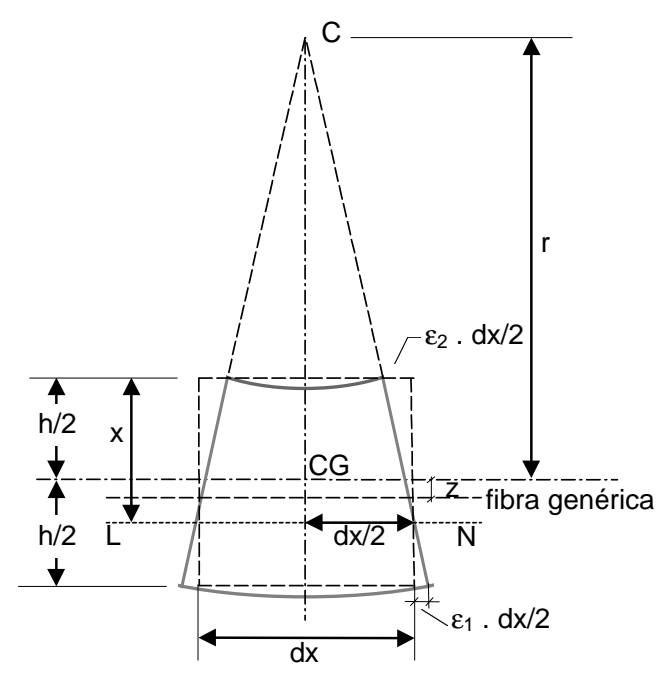

FIGURA 11 - Elemento de barra de comprimento elementar dx 
Da condição de permanência das seções planas:

$$
\frac{-\varepsilon_{1} \cdot \frac{d x}{2}}{h-x}=\frac{\varepsilon_{2} \cdot \frac{d x}{2}}{x}=\frac{\frac{d x}{2} \cdot(1-\varepsilon)}{r+z}
$$

ou;

$$
\frac{-\varepsilon_{1}}{\mathrm{~h}-\mathrm{x}}=\frac{\varepsilon_{2}}{\mathrm{x}}=\frac{1-\varepsilon}{\mathrm{r}+\mathrm{z}}=\frac{\varepsilon_{2}-\varepsilon_{1}}{\mathrm{~h}}
$$

As expressões anteriores podem ser simplificadas pelo fato de que $\varepsilon<<1$ e $\mathrm{z}<<$ r, então tem-se:

$$
\frac{1-\varepsilon}{r+z}=\frac{1}{r}
$$

Com essa simplificação, pode-se reescrever a equação anterior da seguinte forma:

$$
\frac{1}{r}=\frac{\varepsilon_{2}-\varepsilon_{1}}{h}
$$

No caso de uma viga de concreto armado, com deformações extremas $\varepsilon_{\mathrm{c}}$ no concreto comprimido e $\varepsilon_{\mathrm{s}}$ na armadura de tração, resulta;

$$
\frac{1}{\mathrm{r}}=\frac{\varepsilon_{\mathrm{c}}-\varepsilon_{\mathrm{s}}}{\mathrm{d}}
$$

A equação (15) é uma expressão geral da curvatura, escrita em função das deformações, válida para casos de flexão composta com LN não só dentro como fora da seção, exigindo para a dedução apenas a validade da lei de Bernoulli que considera que as seções permanecem planas após a flexão.

\subsection{RELAÇÕES MOMENTO - CURVATURA}

As relações momento x curvatura são expressões que envolvem grandezas intimamente ligadas aos conceitos de não-linearidade. No caso da relação momento interno x curvatura, o conceito mais importante é o de não-linearidade física e, no caso da relação momento externo x curvatura, é o de não-linearidade geométrica, como será visto a seguir.

\subsubsection{RelaçÃo Momento Interno - CuRVATURA}

Para materiais de comportamento elástico-linear, a cada configuração da elástica corresponde uma certa distribuição de momentos fletores, ou seja, em cada seção tem-se:

$$
\mathrm{M}_{\text {int }}=\frac{1}{r} \cdot \mathrm{El}
$$


o que corresponde a dizer que, graficamente, o diagrama é linear.

Para materiais de comportamento não-linear, como é o caso do concreto armado, não há proporcionalidade entre tensão e deformação sendo necessário, portanto, obter o momento interno através do cálculo direto da resultante das tensões correspondentes ao momento, devido ao fato de que a não-linearidade física do material acarreta não-linearidade entre momento interno e curvatura, ou seja, o resultado é um diagrama curvo, ver FIGURA 12.
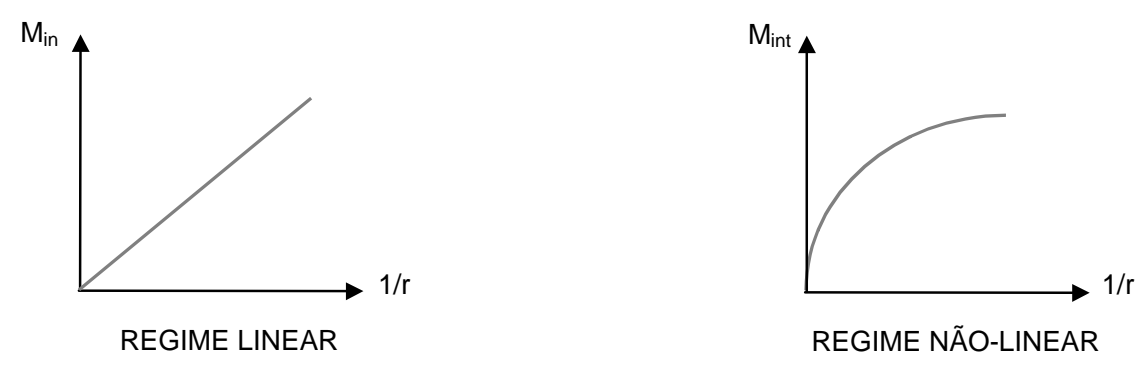

FIGURA 12 - Diagramas momento interno x curvatura

\subsubsection{Relação Momento Externo - Curvatura}

Tanto na compressão axial como na flexo-compressão o uso da equação diferencial completa da linha elástica afeta diretamente o momento externo.

Para a compressão axial, só é possível considerar os efeitos de $2^{\mathrm{a}}$ ordem quando da utilização da equação completa que possibilita o cálculo dos deslocamentos que surgem para cargas maiores que a crítica. Na flexocompressão é possível, através da equação simplificada, obter valores para os deslocamentos embora não sejam estes os verdadeiros.

Para os dois casos a expressão do momento externo depende dos valores dos deslocamentos que são obtidos a partir das equações diferenciais.

Para a compressão axial, tem-se:

$$
\mathrm{M}_{\mathrm{ext}}=\mathrm{F} \cdot \mathrm{y}
$$

e, para flexo-compressão:

$$
\mathrm{M}_{\text {ext }}=\mathrm{F} \cdot\left(\mathrm{e}_{\mathrm{i}}+\mathrm{y}\right)
$$

onde y representa o valor do deslocamento num ponto qualquer ao longo da altura da barra, e e excentricidade inicial. 
Considerando as expressões (17) e (18), e a expressão (12) que contém a equação completa da linha elástica, chega-se a uma relação momento externo $x$ curvatura não-linear, cujos diagramas têm a forma indicada nas FIGURAS 13a e $13 b$.

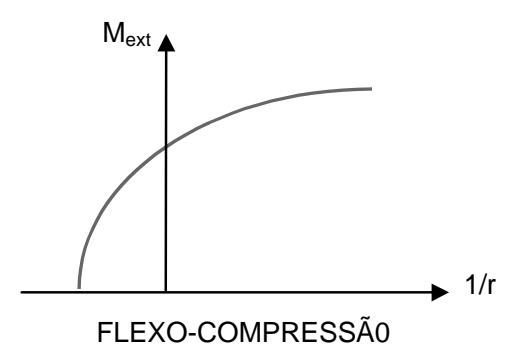

(a)

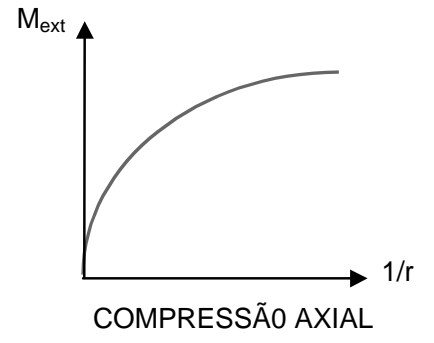

(b)

FIGURA 13 - Diagramas momento externo x curvatura

Com a utilização da equação simplificada, expressão (13), só é possível chegar a alguma relação na flexão composta, e que resultará em uma relação linear, como mostra a FIGURA 14.

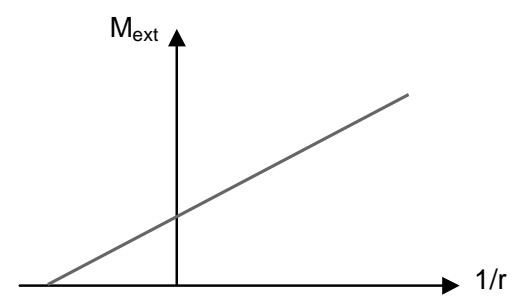

FIGURA 14 - Diagramas momento externo x curvatura - equação simplificada Caso de flexo-compressão 


\section{Capítulo}

\section{INSTABILIDADE DE BARRAS}

\subsection{INTRODUÇÃO}

O problema da instabilidade tem grande importância no estudo de pilares. Existem diversos tipos de instabilidade que podem ocorrer em configurações de equilíbrio, um exemplo é o caso da flambagem que ocorre exclusivamente na compressão axial.

No caso de pilares de concreto armado, a instabilidade é um estado limite último que ocorre nas peças submetidas a flexo-compressão, como conseqüência de um carregamento que cessa sua capacidade portante antes que a estrutura atinja a ruína por ruptura convencional do concreto ou por deformação plástica excessiva da armadura. Portanto, estudos que abrangem os casos de pilares esbeltos que são peças estruturais susceptíveis ao fenômeno da instabilidade, devem levar em consideração o fato de que a peça não deve atingir os estados limites últimos de ruptura convencional do concreto, deformação plástica excessiva da armadura nem tampouco o da instabilidade.

\subsection{INSTABILIDADE NA COMPRESSÃO AXIAL}

O estudo da instabilidade na compressão axial se resume ao estudo da flambagem. Para casos práticos, o estudo da flambagem pode ser considerado desnecessário, porém, teoricamente, o fenômeno constitui-se de uma abordagem simples que auxilia no entendimento do fenômeno da instabilidade. Mesmo difícil de ocorrer na prática, a flambagem para materiais estruturais como o aço e o concreto, é, também, um estado limite último, além do que, serve de ponto de partida para abordagem do problema da instabilidade que atinge seu auge em casos de pilares esbeltos de concreto armado submetidos a flexo-compressão.

Uma barra esbelta sob a ação de carregamento crescente, pode atingir um estado limite a partir do qual se torna impossível mantê-la na posição vertical sob 
equilíbrio estável, ou seja, a partir de um determinado valor de carga pode-se ter duas configurações possíveis de equilíbrio.

Em outras palavras, considerando-se uma barra (FIGURA 15a) inicialmente reta constituída de material elástico-linear sujeita a uma força axial de compressão denominada $\mathbf{F}$ crescente, tem-se, a um determinado valor de $\mathbf{F}$, uma possível mudança na configuração de equilíbrio da estrutura, que pode assumir uma posição deformada.

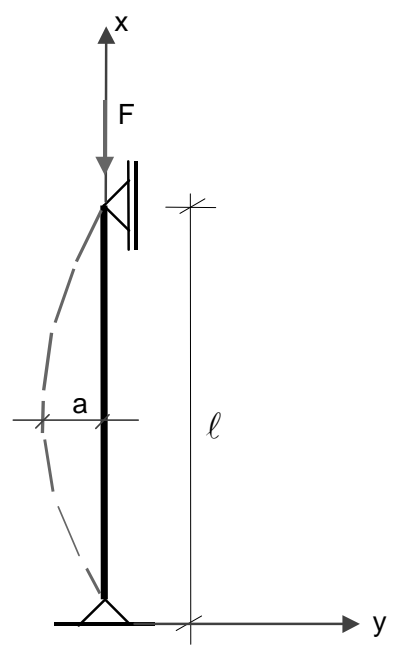

(a)

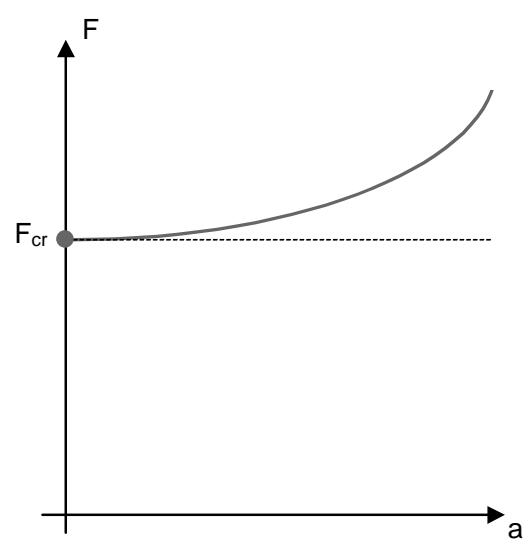

(b)

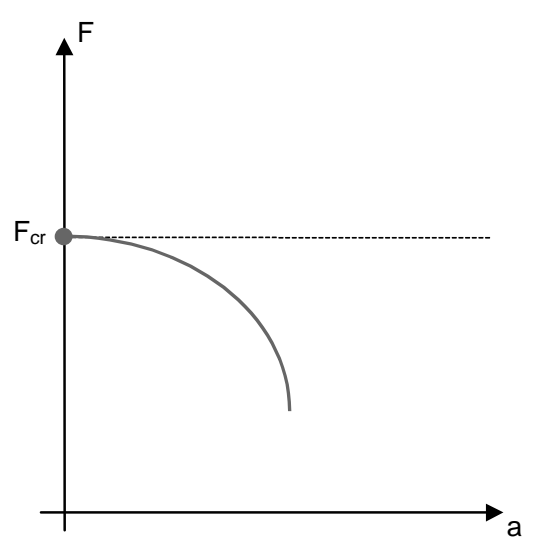

(c)

FIGURA 15 - Instabilidade na Compressão Axial - Pontos de bifurcação do equilíbrio

A carga que leva a estrutura a atingir esse estado limite chama-se carga crítica ou carga de flambagem, $\mathbf{F}_{\mathbf{c r}}$. 
Tomando-se como exemplo a barra da FIGURA 15a nas mesmas condições anteriormente citadas tem-se, FIGURA 15b: para valores de $\mathbf{F}$ entre zero e $\mathbf{F}_{\text {cr }}$, a barra permanece na posição vertical. Para cargas superiores à carga crítica, $\left(F>F_{c r}\right)$, se a barra for geometricamente perfeita e se não houver nenhuma perturbação, a barra continua na posição vertical ou se deformará, assumindo uma nova configuração. A forma estável de equilíbrio para o caso da FIGURA 15a, com $F>F_{c r}$, é representada por uma configuração fletida.

A FIGURA 15b chama a atenção para uma característica fundamental do fenômeno da flambagem que é a presença do ponto de bifurcação do equilíbrio no diagrama que relaciona a carga $\mathbf{F}$ aplicada com o máximo deslocamento transversal a da barra. A flambagem é justamente o fenômeno da aparição de um ponto de bifurcação do equilíbrio para um determinado valor de carga $\mathbf{F}$. Isto se dá porque enquanto $F<F_{c r}$, a tensão normal máxima é proporcional a carga $F$ e é dada pela expressão:

$$
\left|\sigma_{\max }\right|=\frac{F}{A}
$$

onde $\mathrm{A}$ é a área da seção transversal da barra.

A partir do instante em que $\mathbf{F}$ atinge 0 valor de $\mathbf{F}_{\mathrm{cr}}$, a tensão normal máxima passa a crescer mais rapidamente, porque, após a flambagem:

$$
\left|\sigma_{\max }\right|=\frac{\mathrm{F}}{\mathrm{A}}+\frac{\mathrm{F} \cdot \mathrm{a}}{\mathrm{W}}
$$

onde $\mathbf{W}$ é o módulo de resistência à flexão da seção transversal da barra.

Como conseqüência, para materiais estruturais como o concreto e o aço, cargas pouco superiores a $\mathbf{F}_{\mathrm{cr}}$ provocam deslocamentos máximos iguais a frações consideráveis do comprimento da barra.

Tratando-se de uma barra constituída de material não-linear nessas mesmas condições, haverá também bifurcação do equilíbrio como mostra a FIGURA 15c; entretanto, percebe-se que a forma fletida refere-se a valores tais que $\mathrm{F}<\mathrm{F}_{\mathrm{cr}}$, donde se conclui que nesses casos, tem-se, para $\mathrm{F}<\mathrm{F}_{\mathrm{cr}}$, duas formas de equilíbrio possíveis, uma reta estável e uma fletida instável; para $F>F_{c r}$ só existe uma forma de equilíbrio possível, a forma reta que é instável.

A abordagem do problema da flambagem é baseada na teoria da Flambagem Clássica de Euler, cujas deduções e análises são fundamentadas nas relações entre delocamentos e curvaturas através da equação diferencial da linha elástica. 
A determinação dos deslocamentos para cargas superiores à carga crítica exige que seja empregada a expressão exata da linha elástica, ficando a expressão simplificada apenas para obtenção da carga crítica.

A utilização da equação diferencial simplificada é um recurso denominado de linearização, cujo objetivo é determinar mais facilmente o carregamento crítico.

Para análise da estabilidade do equilíbrio consideram-se as equações exata e simplificada da linha elástica e, como simplificação, admite-se que após a flambagem a linha elástica seja senoidal.

$$
y=a \cdot \operatorname{sen} \frac{\pi}{\ell} \cdot x
$$

Da equação simplificada;

$$
\frac{1}{r}= \pm \frac{d^{2} y}{d x^{2}}=-\left(\frac{\pi}{\ell}\right)^{2} \cdot y
$$

chega-se, através do equilíbrio $\left(M_{\mathrm{ext}}=M_{\mathrm{int}}\right)$, ao valor da carga crítica de Euler:

$$
\begin{aligned}
& M_{\text {int }}= \pm \frac{1}{r} \cdot E I=-\left(\frac{\pi}{\ell}\right)^{2} \cdot y \cdot E I \\
& M_{\text {ext }}=F \cdot y \\
& F_{c r}=\frac{\pi^{2}}{\ell^{2}} \cdot \mathrm{EI}
\end{aligned}
$$

Abordando o problema através da equação exata, tem-se, no regime elástico:

$$
\begin{aligned}
& M_{\text {int }}= \pm 1 / r \cdot E l \\
& M_{\text {ext }}=F \cdot y
\end{aligned}
$$

onde y é calculado a partir da curvatura $1 / r$ dada pela expressão (12), nela substituindo a expressão considerada para o andamento dos deslocamentos, dada pela equação (21):

$$
\frac{1}{r}=\frac{-\left(\frac{\pi}{\ell}\right)^{2} \cdot y}{\left[1+\left(\frac{\pi}{\ell}\right)^{2} \cdot\left(a^{2}-y^{2}\right)\right]^{3 / 2}}
$$


Conforme se mostra na FIGURA 16, enquanto subsiste o regime elástico, as funções $M_{\text {ext }}$ e $M_{\text {int }}$ cruzam-se obrigatoriamente num ponto, o qual corresponde à configuração estável de equilíbrio.

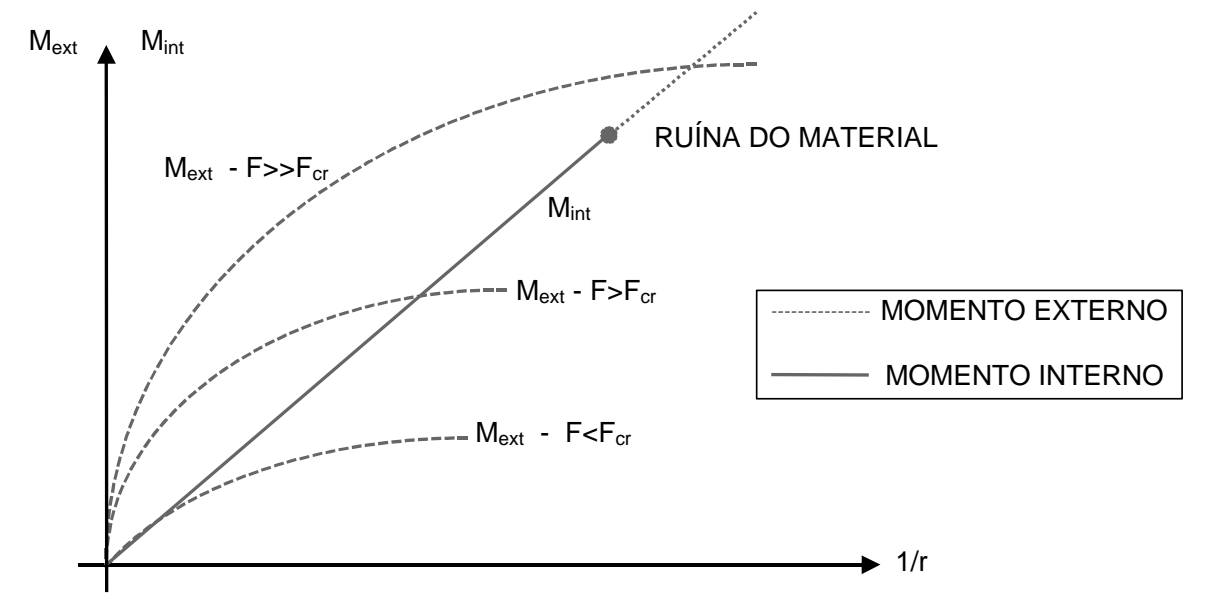

FIGURA 16 - Estabilidade na compressão axial - regime elástico-linear / equação exata

A estabilidade do equilíbrio é garantida pelo andamento retilíneo da função $M_{\text {int }}$, a qual sempre interceptará a curva de $M_{\text {ext }}$ para valores de $F$ maiores que $F_{c r}$.

Note-se porém, que o equilíbrio somente poderá existir de fato se antes não ocorrer a ruína do material.

Para materiais de comportamento não-linear, a função $M_{\text {int }}$ deixa de ter um andamento retilíneo, (FIGURA 17). Desse modo, se a curva de $M_{\text {int }}$ tiver um andamento convergente com a curva de $\mathrm{M}_{\text {ext }}$ correspondente a um certo valor de $\mathbf{F}$ maior que $\mathbf{F}_{\mathrm{cr}}$, então será possível o equilíbrio estável da configuração fletida de equilíbrio, desde que antes não seja atingida a ruína do material, situação em que o equilíbrio é estável.

Pelo contrário, se as curvas de $M_{\text {int }}$ e $M_{\text {ext }}$ tiverem um andamento divergente, elas não se cruzarão, não existindo equilíbrio estável para $F>F_{c r}$. Neste caso, tem-se uma situação de equilíbrio instável. 

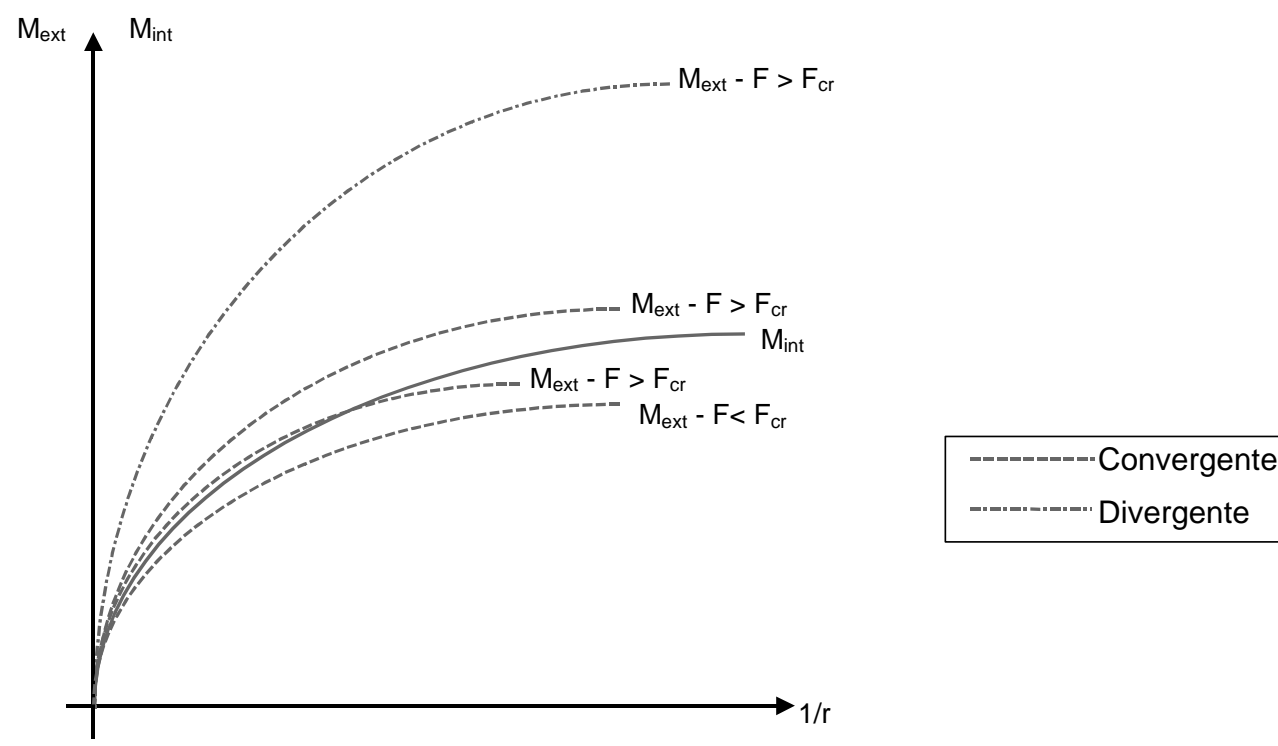

FIGURA 17 - Estabilidade na compressão axial - regime inelástico / equação exata

\subsubsection{Carga Crítica de Flambagem}

Os casos elementares do problema de flambagem são abordados mediante o estudo do Caso Fundamental de Flambagem de Barras Prismáticas. Essa análise abre espaço a obtenção da carga crítica através da equação aproximada da linha elástica para barras com outras condições de contorno.

Seja uma barra ideal suposta inicialmente reta e axialmente comprimida, FIGURA 18. A barra é constituída de material de comportamento elástico-linear, bastante esbelta, ou seja, a tensão crítica é menor que o limite de proporcionalidade, e é articulada nas duas extremidades.

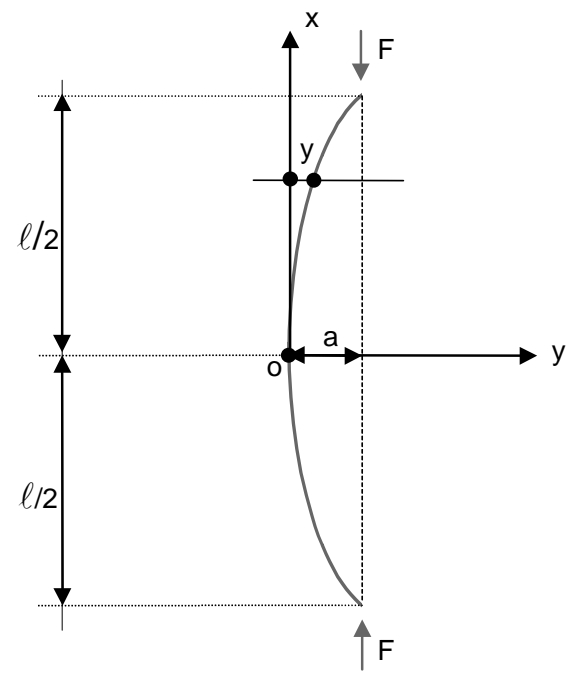

FIGURA 18 - Barra elástica linear biarticulada 
Enquanto $\mathbf{F}$ assume valores menores que o valor crítico, a barra permanece reta, submetida apenas a compressão axial. Quando $\mathbf{F}$ se iguala à carga crítica, ocorre bifurcação do equilíbrio. Esta carga, também chamada carga de Euler, é definida como a força axial suficiente para manter a barra nesse novo estado de equilíbrio.

Através da equação exata da linha elástica, equação (12), é possível determinar as flechas quando $F>F_{c r}$, ou seja, quando o momento vale $\mathrm{M}=-\mathrm{F}(\mathrm{a}-\mathrm{y})$. Porém, em muitos casos, a integração é trabalhosa. Por isso, quando o objetivo é apenas a determinação da carga crítica, o uso da expressão simplificada, equação (13), é suficiente, ficando indeterminadas as flechas.

Para o caso da FIGURA 18 tem-se:

$$
\frac{d^{2} y}{d x^{2}}=-\frac{M}{E l}
$$

onde $\mathrm{M}=-\mathrm{F}(\mathrm{a}-\mathrm{y})$. Então a equação terá a seguinte forma:

$$
\frac{d^{2} y}{d x^{2}}=\frac{F}{E l} a-\frac{F}{E l} y
$$

chamando $\mathrm{K}^{2}=\frac{\mathrm{F}}{\mathrm{El}}$ tem-se;

$$
\frac{d^{2} y}{d x^{2}}+K^{2} y=K^{2} a
$$

A solução geral da equação (29) é a seguinte:

$$
\mathrm{y}=\mathrm{C}_{1} \cos \mathrm{Kx}+\mathrm{C}_{2} \operatorname{sen} \mathrm{Kx}+\mathrm{a}
$$

onde $\mathrm{C}_{1}$ e $\mathrm{C}_{2}$ são constantes de integração determinadas pelas condições de contorno da barra, que são:

- para $x=0 ; y=0$ e $\frac{d y}{d x}=0$ então $C_{1}=-a$ e $C_{2}=0$ e, portanto:

$$
y=a(1-\cos K x)
$$

- para $x=\ell / 2, y=0$, então:

$$
a \cos K \frac{\ell}{2}=0
$$

mas $a \neq 0$, caso contrário não haveria flexão, então:

$\cos K \frac{\ell}{2}=0$

Para que esta igualdade seja verdadeira, tem-se: 


$$
\begin{aligned}
& K \frac{\ell}{2}=(2 n-1) \frac{\pi}{2} \operatorname{com} n=1,2,3, \ldots . . \text { Então; } \\
& K=(2 n-1) \frac{\pi}{\ell}
\end{aligned}
$$

Daí, sabendo que $\mathrm{F}=\mathrm{K}^{2} \mathrm{El}$ então;

$$
F=(2 n-1)^{2} \frac{\pi^{2} E I}{\ell^{2}} \text { com } n=1,2,3, \ldots
$$

O menor valor do arco que verifica a equação (32) é $K=\pi / \ell$, portanto o menor valor de carga capaz de levar a barra da FIGURA 18 a atingir um estado limite a partir do qual a forma reta de equilíbrio é instável é:

$$
\mathrm{F}_{\mathrm{cr}}=\frac{\pi^{2} \mathrm{El}}{\ell^{2}}
$$

equação esta semelhante a equação (25) obtida do equilíbrio $M_{\text {ext }}=M_{\text {int }}$.

A partir deste valor da carga (carga de Euler), surge a configuração fletida de equilíbrio estável, que só é determinada com o emprego da expressão exata da curvatura.

Na equação (34), o denominador representa o quadrado do comprimento de flambagem, para o caso estudado. Para quaisquer outras condições de contorno, chega-se à mesma carga crítica, diferindo apenas no valor de $\ell$. Sendo assim, ela pode ser reescrita da seguinte forma:

$$
F_{c r}=\frac{\pi^{2} E I}{\ell_{e}^{2}}
$$

onde $\ell_{\mathrm{e}}$ vale $\ell$, neste caso, em particular.

\subsubsection{Comprimento de Flambagem}

Para a determinação do comprimento de flambagem de um pilar considerase sua deformada de flambagem quando o mesmo encontra-se submetido ao carregamento mais desfavorável. O comprimento de flambagem determinante corresponde, como indica a FIGURA 19, à distância entre pontos de inflexão da deformada de flambagem do pilar.

Conforme o grau de engastamento, o ponto de inflexão situa-se mais ou menos próximo do nó, podendo inclusive coincidir com o mesmo em alguns casos. Portanto, o valor de $\ell_{\mathrm{e}}$ varia de 0,5 a 2 , para os casos mais usuais de vinculações. 


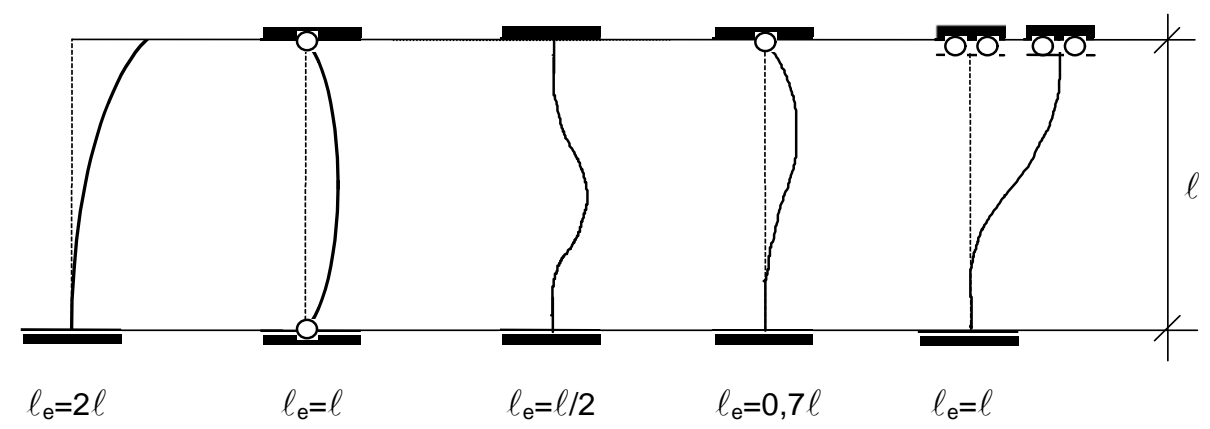

FIGURA 19 - Comprimentos de flambagem

\subsubsection{Curva de Euler}

As expressões que determinam o valor de $\mathbf{F}_{\mathrm{cr}}$ foram obtidas com base na hipótese de que o problema permanece no regime elástico. Para tanto a tensão máxima de compressão $(\sigma)$ na barra, decorrente de sua solicitação, não deve exceder o limite de proporcionalidade $\sigma_{p}$ do material, ou seja; $\sigma \leq \sigma_{p}$.

No instante em que $\mathbf{F}$ atinge o valor $\mathbf{F}_{\mathrm{cr}}$, a tensão $\sigma$ será $\sigma_{\mathrm{cr}}$, que valerá, em valor absoluto:

$$
\sigma_{\mathrm{cr}}=\frac{\mathrm{F}_{\mathrm{cr}}}{\mathrm{A}}=\frac{\pi^{2} \mathrm{El}}{\mathrm{A} \ell_{\mathrm{e}}^{2}}
$$

Fazendo $\lambda=\frac{\ell_{\mathrm{e}}}{\mathrm{i}}$, onde o denominador é o raio de giração que vale $\sqrt{\frac{\mathrm{I}}{\mathrm{A}}}$, tem-se:

$$
\sigma_{\mathrm{cr}}=\frac{\pi^{2} \mathrm{E}}{\lambda^{2}}
$$

$\lambda$ é chamado índice de esbeltez da barra.

Conhecendo-se o módulo de elasticidade do material $(E)$ e o seu limite de proporcionalidade $\sigma_{\mathrm{p}}$, pode-se determinar $\lambda_{\ell \mathrm{im}}$ da seguinte forma:

$$
\frac{\pi^{2} E}{\lambda^{2}} \leq \sigma_{p} \rightarrow \lambda \geq \pi \sqrt{\frac{E}{\sigma_{p}}}
$$

portanto, $\lambda_{\text {lim }}=\pi \sqrt{\frac{E}{\sigma_{p}}}$ 
Então as expressões de $\mathbf{F}_{\mathrm{cr}}$ só são válidas para barras de material elástico com índice de esbeltez $\lambda \geq \lambda_{\text {lim }}$, caso contrário a tensão de compressão atinge 0 valor $\sigma_{p}$ antes que ocorra a flambagem, ou seja, passa-se ao regime inelástico.

A forma de representar esse fenômeno graficamente se dá mediante a curva de Euler, que consiste em um diagrama de $\sigma_{\mathrm{cr}} \times \lambda$, como está mostrado na FIGURA 20.

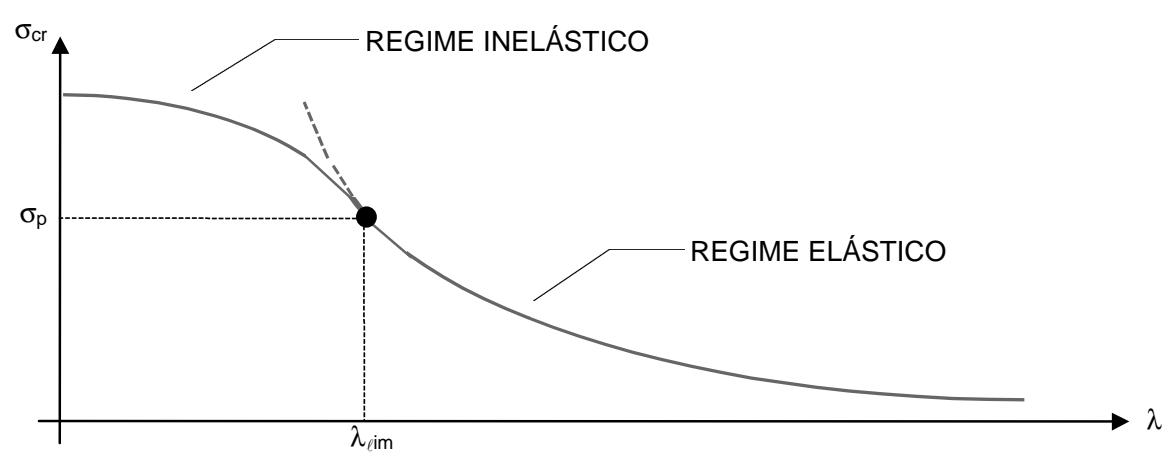

FIGURA 20 - Curva de Euler

Observe-se que a curva se aproxima, assintoticamente, do eixo das abcissas, ou seja, $\sigma_{\mathrm{cr}}$ tende a zero a medida que $\lambda$ cresce, o que significa que quanto mais esbelta é a barra, menor é o valor da carga crítica.

\section{3 - DIAGRAMA (M,N,1/r)}

A análise de problemas de instabilidade, como de outros problemas da Engenharia, baseia-se em equações de equilíbrio e de compatibilidade. Essas equações referem-se a estados de deformação desde solicitações muito baixas até atingir a ruína, seja por esgotamento da resistência do concreto ou deformação excessiva da armadura, seja por perda de estabilidade. Isso se dá porque os diagramas de $\varepsilon$ numa seção podem não pertencer aos domínios de deformação mas, ser constituídos por uma reta qualquer correspondente a uma situação de serviço ou a uma fase intermediária entre uma situação de serviço e uma de ruína.

Para análise de problemas envolvendo peças de concreto armado submetidas a flexo-compressão, faz necessária a consideração da teoria de $2^{a}$ ordem e, para tanto, é essencial descobrir uma relação entre a curvatura e os esforços. Essa relação é feita através de diagramas de interação força normal momento fletor - curvatura. Esses diagramas são a ferramenta básica de qualquer cálculo de verificação da estabilidade. 
Embora seja o diagrama ( $M, N, 1 / r)$ de execução trabalhosa, a idéia é muito simples: a curvatura está relacionada com as deformações; estas ligam-se às tensões através das equações constitutivas; conhecidas as tensões, a deformação $\varepsilon_{c}$ e a curvatura $1 / r$, tem-se todos os elementos para calcular o esforço normal e o momento fletor. Portanto, existe uma relação entre essas três grandezas que, graficamente é representada pelo diagrama ( $M, N, 1 / r)$.

Considere-se um pilar esbelto de concreto armado, sendo conhecidos: dimensões, quantidade e distribuição da armadura, tipo de aço e concreto e vinculações, sujeito a força de compressão excêntrica N. Do estudo feito até então, conclui-se ser de fundamental importância determinar o máximo momento interno que a seção pode desenvolver em função da curvatura da deformada naquela mesma seção.

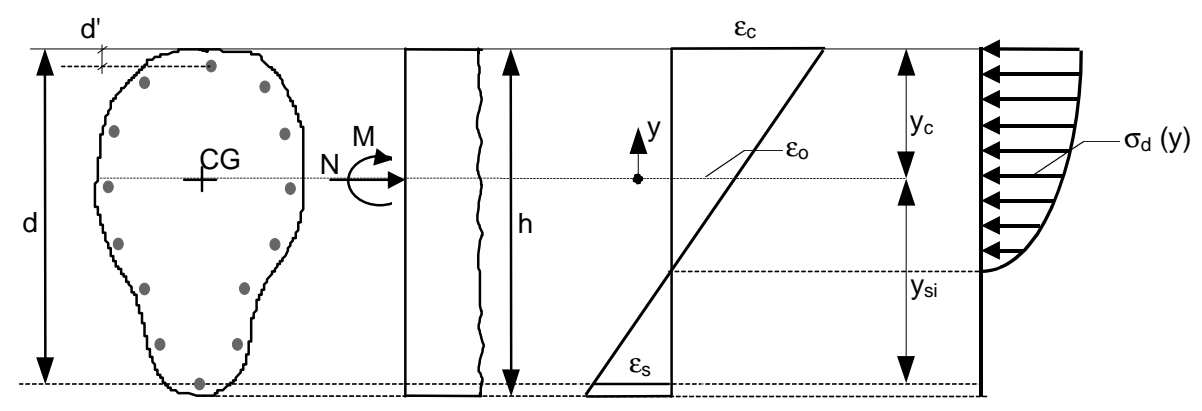

FIGURA 21 - Relações momento x curvatura

Seja a seção fletida da FIGURA 21 com armadura conhecida. Conforme a equação (15):

$$
\frac{1}{r}=\frac{\varepsilon_{\mathrm{c}}-\varepsilon_{\mathrm{s}}}{\mathrm{d}}
$$

ou ainda:

$$
\frac{1}{r}=\frac{\left|\varepsilon_{\mathrm{c}}\right|+\left|\varepsilon_{\mathrm{s}}\right|}{\mathrm{d}}
$$

Por semelhança de triângulos, tem-se:

$$
\begin{aligned}
& \left|\varepsilon_{\mathrm{c}}\right|=\left|\varepsilon_{0}+\frac{\mathrm{y}_{\mathrm{c}}}{\mathrm{r}}\right| \\
& \left|\varepsilon_{\mathrm{s}}\right|=\left|\varepsilon_{\mathrm{o}}-\frac{\mathrm{y}_{\mathrm{si}}}{\mathrm{r}}\right|
\end{aligned}
$$


Os estados limites últimos relativos ao material não serão atingidos, enquanto forem obedecidos os limites:

$$
\begin{aligned}
& \left|\varepsilon_{\mathrm{c}}\right|=\left|\varepsilon_{\mathrm{o}}+\frac{\mathrm{y}_{\mathrm{c}}}{\mathrm{r}}\right| \leq 3,5 \% \\
& \left|\varepsilon_{\mathrm{s}}\right|=\left|\varepsilon_{\mathrm{o}}-\frac{\mathrm{y}_{\mathrm{si}}}{\mathrm{r}}\right| \leq 10 \%
\end{aligned}
$$

Assim, a seção, para uma dada curvatura 1/r, não esgotará sua capacidade resistente enquanto não se chegar a um valor $\left(\varepsilon_{0}\right)_{\max }$ tal que faça ser atingida, no concreto ou no aço, suas deformações específicas limites. Desse modo, para cada par de valores $\left(1 / r, \varepsilon_{0}\right)$ tem-se definidos os valores de cálculo dos esforços $N_{d}$ e $M_{d}$ capazes de serem resistidos pela seção.

Desta forma, estabelece-se para cada curvatura arbitrada $\left(1 / r_{i}\right)$, os vários pares de valores $\left(M_{d}, N_{d}\right)$ correspondentes a essa curvatura, ou seja, obtém-se, para uma dada curvatura, os grupos de valores interligados $\left(1 / r_{i}, M_{d}, N_{d}\right)$, referentes as variações de $\varepsilon_{0}$, até se atingir $\varepsilon_{0, \max }$. Feito isso, tem-se conhecido o terno $(\mathrm{M}, \mathrm{N}, 1 / \mathrm{r})$. Adotando-se outros valores da curvatura e mantendo-se fixos os demais dados, obtém-se o diagrama $(\mathrm{M}, \mathrm{N}, 1 / \mathrm{r})$.

\subsection{INSTABILIDADE NA FLEXO-COMPRESSÃO}

Considere uma barra esbelta, como mostra a FIGURA 22, constituída de material de comportamento elástico-linear (FIGURA 24a), carregada com uma determinada excentricidade $\mathbf{e}_{\mathbf{i}}$ de primeira ordem. Para valores crescentes de $\mathbf{F}, \mathbf{a}$ barra assume, desde o início, a forma fletida e haverá sempre uma configuração de equilíbrio estável para cada valor de $\mathbf{F}$.

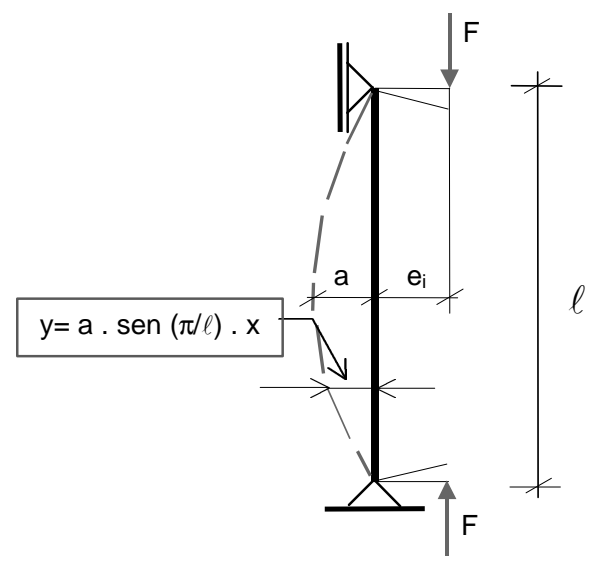

FIGURA 22 - Pilar esbelto submetido a flexo-compressão 
As expressões dos momentos externo e interno são:

$$
\begin{aligned}
M_{\text {ext }} & =P \cdot\left(e_{i}+y\right) \\
\frac{M_{\text {int }}}{E l} & =\frac{1}{r}
\end{aligned}
$$

Sabendo-se que $M_{\text {ext }}=M_{\text {int }}$, é condição de equilíbrio para cada seção da barra, tem-se:

$$
\frac{1}{r}=\frac{d^{2} y}{d x^{2}}=-\frac{P \cdot\left(e_{i}+y\right)}{E l}
$$

Fazendo $\frac{\mathrm{P}}{\mathrm{El}}=\mathrm{K}^{2}$, e desenvolvendo a equação (44) como feito anteriormente, chega-se a :

$$
\frac{d^{2} y}{d x^{2}}+K^{2} y+K^{2} e_{i}=0
$$

que tem como solução:

$$
y=C_{1} \operatorname{sen} K x+C_{2} \cos K x-e_{i}
$$

A flecha máxima, impondo-se as condições de contorno, é dada por:

$$
\mathrm{a}=\frac{1-\cos \mathrm{K} \ell}{\cos \mathrm{K} \ell}
$$

Como se pode observar, o uso da expressão simplificada da curvatura na flexão composta em regime elástico-linear permite o cálculo das flechas da configuração de equilíbrio. No entanto, quando o valor de $\cos K \ell$ tende a zero, tal uso leva a uma indeterminação como mostra a equação (47). As flechas tendem ao infinito levando-se a idéia de que a carga crítica de Euler teria algum significado físico na flexo-compressão, mas isso nada mais é do que um defeito de linearização.

Usando-se a expressão exata da curvatura, tem-se:

$$
\frac{1}{r}=\frac{\frac{d^{2} y}{d x^{2}}}{\left[1+\left(\frac{d y}{d x}\right)^{2}\right]^{\frac{3}{2}}}=-K^{2} y-K^{2} e
$$

A partir dessa expressão, prova-se que tal idéia não é correta. Na flexocompressão de pilares não há bifurcação do equilíbrio. Enquanto o material permanecer no regime elástico não haverá problema de instabilidade; a configuração fletida será uma configuração de equilíbrio estável e a ruína será atingida por falha do material. 


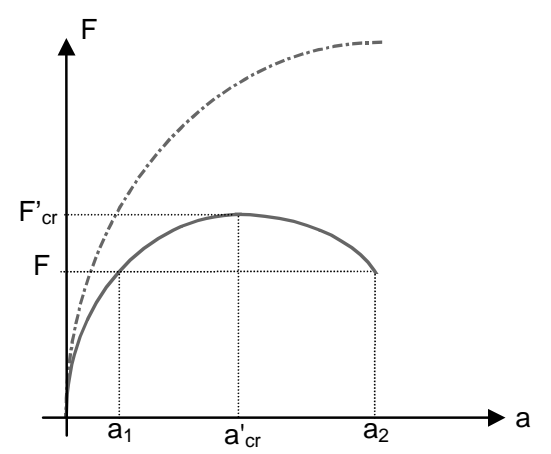

FIGURA 23 - Problema de tensões e de estabilidade sem bifurcação do equilíbrio

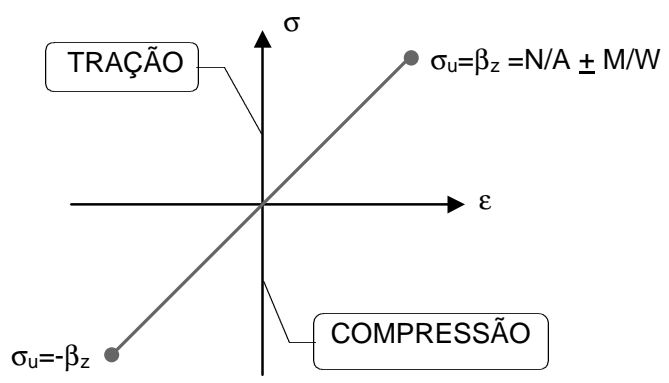

(a)

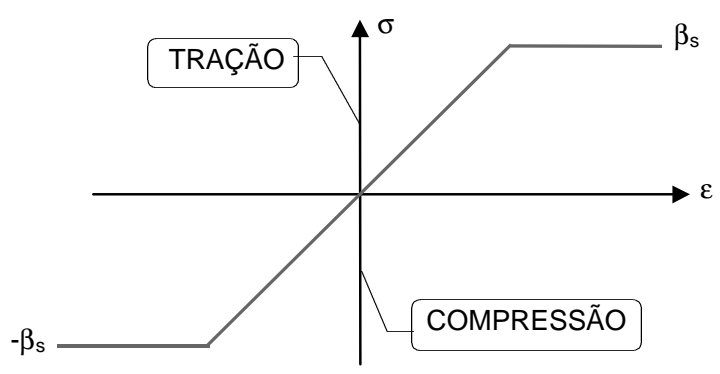

(b)

FIGURA 24 - Diagramas tensão-deformação para materiais de comportamento elástico ideal e elasto-plástico ideal

No caso mostrado na FIGURA 22, a cada carga $\mathbf{F}$ corresponderá uma certa deformação a, caso mostrado na linha tracejada da FIGURA 23. F pode ser aumentada até a tensão no bordo da seção comprimida, correspondente ao maior momento que recebe a contribuição das parcelas $\mathrm{N}=\mathrm{F}$ e $\mathrm{M}=\mathrm{F} .(\mathrm{e}+\mathrm{a})$, atingir o valor limite $\sigma_{\mathrm{u}}$. Trata-se pois, de um problema de tensões.

Admitindo-se para a barra com carga excêntrica da FIGURA 22 um estado elasto-plástico ideal, FIGURA 24b, o comportamento resistente modifica-se totalmente após ser atingido o limite de escoamento na seção transversal de máxima solicitação.

No domínio elástico $\left(\sigma_{\mathrm{e}} \leq \beta_{\mathrm{s}}\right)$, o momento interno que a seção é capaz de absorver, e que resiste ao momento externo, pode ainda aumentar, assim como o momento externo $M=F \cdot(e+a)$ que cresce com o aumento do deslocamento a. Entretanto, o momento interno cresce lentamente logo que o limite de escoamento 
seja atingido no bordo e a plastificação avance para o interior da peça. A capacidade resistente é esgotada quando a linha contínua da FIGURA 23 alcança o seu máximo, o valor $\mathbf{F}_{c r}^{\prime}$ que representa a carga crítica.

Para cargas menores que a carga crítica e deformações menores que a correspondente deformação crítica, o estado de equilíbrio ainda é estável; para $\mathrm{F}=\mathrm{F}_{\mathrm{cr}}^{\prime}$, com $\mathrm{a}=\mathrm{a}_{\mathrm{cr}}^{\prime}$, o equilíbrio pode ser indiferente. Nesse último estado, $a$ plastificação da seção transversal é tão avançada que, para um aumento insignificante $\Delta \mathrm{F}$ de $\mathrm{F}_{\mathrm{cr}}^{\prime}$, o momento interno cresce menos que o momento externo. Para $F>F_{c r}^{\prime}$ não é possível qualquer equilíbrio, e a barra atinge a ruína; o valor $F_{c r}^{\prime}$ é denominado carga-limite e nada tem a ver com o valor $\boldsymbol{F}_{\mathrm{cr}}$ denominado de carga crítica de Euler que corresponde à instabilidade na compressão axial.

Aumentando-se a deformação além de $\mathbf{a}_{\mathrm{cr}}^{\prime}$, o equilíbrio só será possível quando a carga $\mathbf{F}$ for reduzida simultaneamente. Esse ramo descendente da curva carga-deformação caracteriza o estado de equilíbrio instável, visto que pequenas perturbações conduzem de imediato à ruína da barra.

Para valores de $F<F_{c r}^{\prime}$ existem pois duas situações de equilíbrio, uma estável com $\mathrm{a}=\mathrm{a}_{1}$ e outra instável com $\mathrm{a}=\mathrm{a}_{2}$. Visto que a curva carga-deformação tem variação contínua, trata-se de um problema de estabilidade sem bifurcação do equilíbrio.

Admitindo-se inicialmente que a barra tenha uma linha elástica senoidal, como indicado na FIGURA 22, e que a equação da linha elástica tem a forma aproximada, tem-se:

$$
\frac{1}{r}= \pm \frac{d^{2} y}{d x^{2}}=-\left(\frac{\pi}{\ell}\right)^{2} \cdot y
$$

donde

$$
y=\left(\frac{\ell}{\pi}\right)^{2} \cdot \frac{1}{r}
$$

Enquanto perdurar a validade da equação diferencial aproximada (as rotações $\mathrm{dy} / \mathrm{dx}$ deverão ser desprezíveis em face da unidade), o momento externo $M_{\text {ext }}$ será uma função linear da curvatura da seção. De fato, pois sendo $e_{i} a$ excentricidade inicial de $1^{\underline{a}}$ ordem, tem-se: 


$$
M_{e x t}=F \cdot\left(e_{1}+y\right)=F \cdot e_{i}+F \cdot\left(\frac{\ell}{\pi}\right)^{2} \cdot \frac{1}{r}
$$

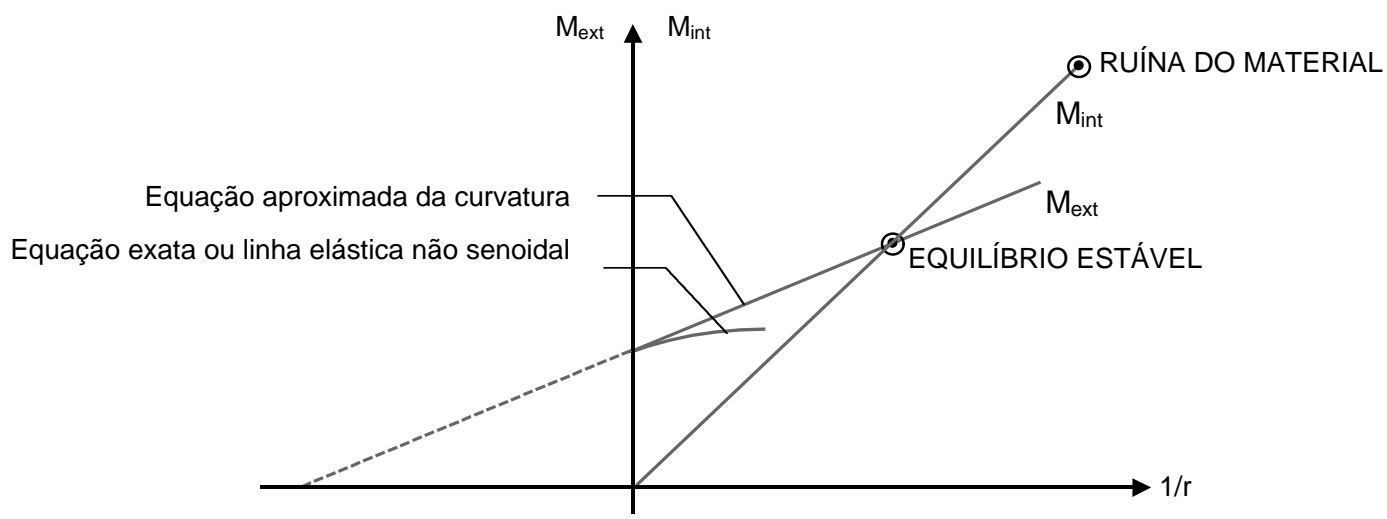

FIGURA 25 - Instabilidade na flexo-compressão - regime elástico

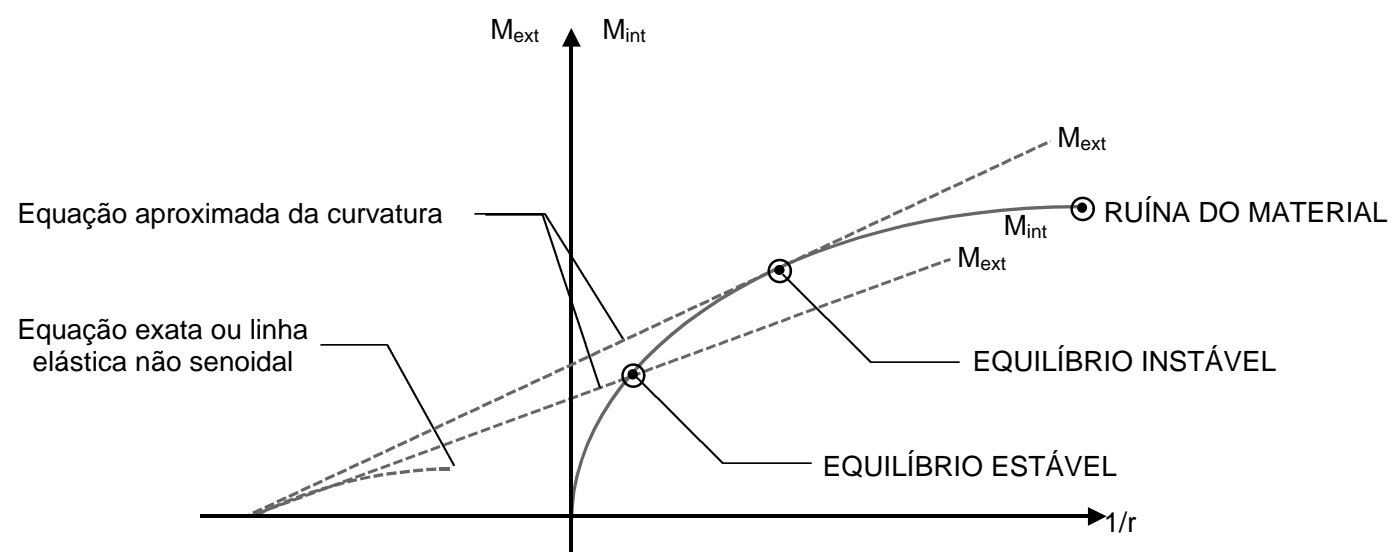

FIGURA 26 - Instabilidade na flexo-compressão - regime inelástico

Para ser verificada a estabilidade das formas de equilíbrio, considere-se a possibilidade de ser mantido o equilíbrio, dado pela condição explicitada na expressão (52) quando é dado um acréscimo a $M_{\text {ext }}$ :

$$
\mathrm{M}_{\mathrm{ext}}=\mathrm{M}_{\mathrm{int}}
$$

Enquanto a barra permanecer no regime elástico, sempre haverá uma configuração de equilíbrio estável pois $M_{\text {int }}$ também será função linear das curvaturas. Nesse caso, uma situação de ruína somente poderá ser alcançada por ruptura do material, FIGURA 25. Pelo contrário, se for ultrapassado o regime de 
proporcionalidade o diagrama de $\mathrm{M}_{\text {int }}$ passará a ser curvo, surgindo então um novo fenômeno de instabilidade.

Na FIGURA 26, esse fenômeno de instabilidade na flexão composta é caracterizado pela existência de uma carga crítica para a qual a reta do $M_{\text {ext }}$ é tangente à curva do $\mathrm{M}_{\text {int. }}$ Para valores de carga menores que o valor crítico é possível o equilíbrio estável e para valores de carga maiores que o valor crítico, o equilíbrio é impossível.

Observe-se que o emprego da expressão completa da curvatura ou a consideração de uma lei não-senoidal para a linha elástica altera os resultados anteriores. Devido ao fato de que, abandonando-se as hipóteses simplificadoras a expressão do $M_{\text {ext }}$ deixa de ser linear em função de $1 / r$, conseqüentemente, altera a circunstância de existir necessariamente o equilíbrio estável enquanto $M_{\text {int }}$ for função linear de $1 / r$.

A perda de linearidade do material é condição suficiente, porém não necessária, para permitir o desencadeamento do fenômeno de instabilidade na flexo-compressão, desde que a barra seja suficientemente esbelta. No caso de barras curtas, estas tenderão a romper por flexão composta devido ao fato de que a solicitação tende a ser maior que a capacidade resistente.

Num regime de grandes deformações, quando as rotações não forem desprezíveis, existirá uma relação não-linear entre a curvatura $1 / r$ e as flechas y, sendo então também possível a instabilidade na flexo-compressão.

\subsection{MÉTODOS DE VERIFICAÇÃO DA ESTABILIDADE NA FLEXO- COMPRESSÃO NORMAL}

A análise da estabilidade pode ser feita, de acordo com a consideração das não-linearidades física e geométrica, através de métodos aproximados ou do método geral.

Segundo o Texto para Revisão da NB-1 (1997) o método geral consiste na análise da $2^{\mathrm{a}}$ ordem efetuada com discretização adequada da barra, consideração da relação momento-curvatura real em cada seção, e consideração da nãolinearidade geométrica de maneira não aproximada.

Considerar a relação momento-curvatura real está relacionada a consideração da não-linearidade física, enquanto que considerar a não-linearidade geométrica de maneira não aproximada significa calcular a curvatura a partir dos deslocamentos reais da estrutura. 
Quanto aos métodos aproximados, o Texto para Revisão da NB-1 (1997) descreve dois métodos que podem ser utilizados, cujas aproximações são relativas a não-linearidade geométrica que é considerada supondo-se a deformada da barra como senoidal, e a não-linearidade física que é considerada através de uma expressão aproximada da curvatura na seção crítica, no caso do "Método do Pilar Padrão com Curvatura Aproximada" como é denominado pela norma. Outro método aproximado pode ser utilizado melhorando-se a forma de tratar a nãolinearidade física, que é feita considerando-se como valor da curvatura na seção crítica aqueles obtidos a partir de diagramas $(\mathrm{M}, \mathrm{N}, 1 / \mathrm{r})$ específicos para o caso, este método é denominado pela norma de "Método do Pilar Padrão acoplado a diagramas $(\mathrm{M}, \mathrm{N}, 1 / \mathrm{r})$ ".

De acordo com esses métodos propostos pela NB-1 é necessário esclarecer a relação existente entre essa nomenclatura e a nomenclatura utilizada neste trabalho.

A nomenclatura utilizada neste trabalho acompanha a nomenclatura utilizada para dar nome aos programas que compõem o SISTEMA FLEXOR. Aqui, denomina-se de método o método geral e o método do equilíbrio, este último não é muitas vezes considerado como método devido ao fato de que pode ser considerado como caso particular do método geral. Neste trabalho ele é considerado como método por necessitar de rotina própria, do ponto de vista computacional, para a solução de problemas.

Quanto ao que está sendo chamado neste trabalho de processo, tem-se os processos exato e do pilar padrão, que estão relacionados à consideração da nãolinearidade geométrica. $O$ processo exato permite calcular a curvatura em cada seção do pilar a partir dos deslocamentos reais nessas seções, enquanto que o processo do pilar padrão considera que a linha elástica seja senoidal.

Quanto à não-linearidade física, nenhuma nomenclatura especial é utilizada pelo fato de que nenhuma simplificação é feita, sendo considerada portanto, sempre através da relação momento-curvatura real.

Justificada então a nomenclatura adotada, tem-se que para determinação da carga crítica o método a se utilizar é o método geral, que consiste em estudar o comportamento das estruturas de concreto armado à medida que se dá o aumento do carregamento ou da excentricidade do carregamento, na barra. O método geral juntamente com o processo exato é aplicável a qualquer tipo de pilar, inclusive nos casos em que as dimensões da peça, a armadura ou a força aplicada, são 
variáveis ao longo do seu comprimento. Todavia, para a maioria dos casos, sua aplicação torna-se trabalhosa exigindo a utilização de processos numéricos através de microcomputadores.

A utilização do processo exato é justificada pela qualidade dos seus resultados que são os que mais se aproximam do comportamento real da estrutura, devido ao fato de que considera a não-linearidade geométrica de maneira bastante precisa.

O princípio do processo é procurar, para um determinado elemento submetido a uma situação particular de carregamento, uma posição deformada estável. Essa posição corresponde a um estado de equilíbrio entre esforços e solicitações, respeitada a compatibilidade entre curvaturas, deformações e posição da linha neutra, além das equações constitutivas dos materiais.

O método geral com o processo exato, quanto ao rigor, faz duas concessões: admite ser a curvatura igual à segunda derivada da equação da linha elástica e, já que para sua execução necessita de processos numéricos, precisa da subdivisão da peça em elementos tornando os resultados dependentes do número de elementos considerado. A precisão será, portanto, tanto maior quanto maior for o número de subdivisões da peça.

Pelo método geral a determinação da carga crítica se dá por etapas. 0 carregamento é aplicado por incrementos progressivos e, para cada etapa, é calculado o deslocamento correspondente de uma determinada seção que corresponde ao deslocamento característico do efeito de $2^{\underline{a}}$ ordem, essencial para cálculo do momento da etapa posterior. O carregamento crítico é obtido através do valor crítico da carga, para o qual tende assintoticamente o diagrama carga $x$ deslocamento (FIGURA 27).

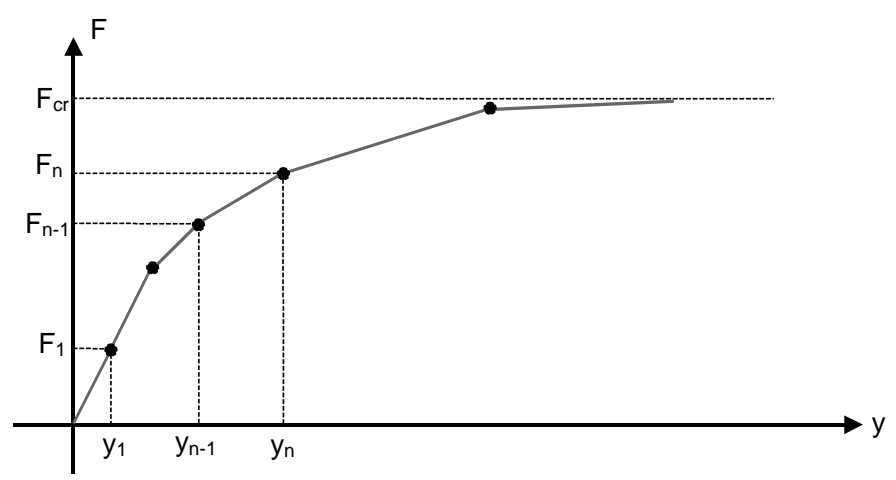

FIGURA 27 - Método geral aplicado através do carregamento progressivo 
Percebe-se que para aplicação do método geral através de acréscimos de carga, basta ter-se à mão uma ferramenta para o cálculo dos deslocamentos que para o caso de peças isostáticas, é suficiente o conhecimento dos diagramas (M, $N, 1 / r)$.

Outra forma de aplicação do método geral se dá através de acréscimos de excentricidade. Neste processo o cálculo obedece à mesma seqüência, com a diferença de que, ao invés de excentricidades constantes e variação do módulo da força aplicada, tem-se cargas constantes e variação dos valores das excentricidades de $1^{\text {a }}$ ordem. $O$ valor crítico da excentricidade é obtido como o valor assintótico do diagrama excentricidade $x$ deslocamento (FIGURA 28).

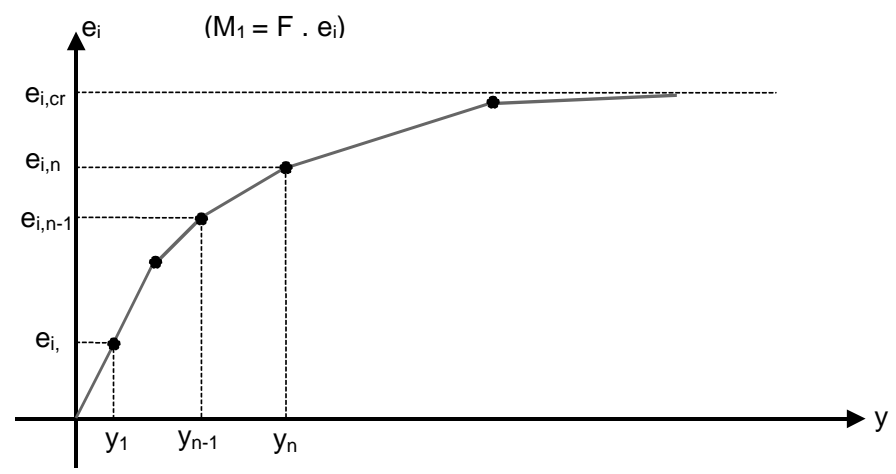

FIGURA 28 - Método geral aplicado através de excentricidades progressivas

Devido ao montante de cálculos que envolve a aplicação do processo exato, relativo ao cálculo das deformações que se dá via integração do diagrama de curvaturas, surgiu o processo do pilar padrão.

O pilar padrão consiste em um conceito simplificado aplicável a barras de seção transversal constante, inclusive a armadura, ao longo de todo o seu comprimento. Baseia-se na suposição de que a linha elástica da barra seja senoidal, o que resulta em linha elástica e curvaturas proporcionais.

Por definição o pilar padrão é um pilar perfeitamente engastado na base e livre no topo, com uma distribuição de curvaturas tal que a flecha no topo possa ser determinada pela relação (53), como mostra a FIGURA 29:

$$
a=\frac{\ell_{e}^{2}}{10} \cdot\left(\frac{1}{r}\right)_{\text {base }}
$$




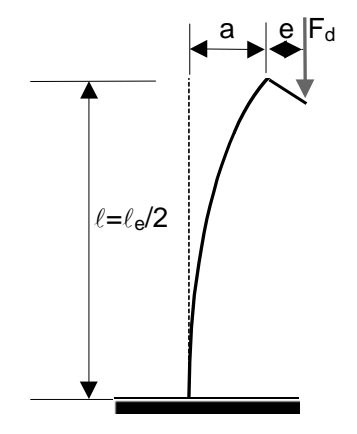

FIGURA 29 - Pilar padrão

Graficamente, o processo do pilar padrão consiste em construir um diagrama $(M, 1 / r)$ relativo à seção de base, a partir do diagrama $(M, N, 1 / r)$ dessa mesma seção, sem a necessidade de integração das curvaturas ao longo do comprimento do pilar. Desse novo diagrama, para uma dada força $\mathbf{F}$ e, tendo-se como deslocamento no topo o valor dado pela equação (53), pode-se obter o momento de $2^{\underline{a}}$ ordem e, conseqüentemente, o momento interno disponível para as solicitações de $1^{\underline{a}}$ ordem correspondente ao estado limite último de instabilidade, para um certo comprimento de flambagem $\ell_{\mathrm{e}}$.

A desvantagem do processo do pilar padrão reside no fato de que seus resultados são precisos apenas nos casos em que a seção é constante, inclusive armadura, e o carregamento não é composto por cargas transversais, ou seja, o método do pilar padrão só conduz a bons resultados se a linha elástica for muito próxima da senoidal. Para os casos em que isso não acontece, pode-se optar pelo processo do pilar padrão melhorado, cujo objetivo é estender a aplicação do processo a casos de barras submetidas a carregamento transversal, através de uma correção no método, resultado de uma linearização do diagrama ( $M, N, 1 / r)$.

Pelo método geral, a determinação da carga crítica demonstrada graficamente exige o traçado de uma curva, seja ela carga $x$ deslocamento, no caso de carregamento progressivo, ou excentricidade $x$ deslocamento, no caso de excentricidades progressivas. Já o processo do pilar padrão exige apenas 0 traçado do diagrama momento x curvatura que é de obtenção mais simples do que os demais.

Um outro método que permite a verificação da estabilidade é o método do equilíbrio. Este método consiste em garantir a segurança contra o estado limite de instabilidade através da verificação de que, sob a ação do carregamento de cálculo 
ou da excentricidade de cálculo, o deslocamento de uma seção de referência corresponde a uma configuração estável de equilíbrio.

O método do equilíbrio também pode ser aplicado através de processos aproximados como é o caso do processo do pilar padrão. Neste caso, trata-se de um método aproximado de verificação da estabilidade em que se considera o deslocamento na extremidade livre do pilar como função da curvatura da base.

Em resumo, com o método do equilíbrio a verificação da segurança contra o estado limite último de instabilidade é feita através da constatação da existência de um estado possível de equilíbrio, onde o esforço é maior do que a solicitação, portanto, o método garante a segurança mas não dá a melhor solução.

O intuito da aplicação do método do equilíbrio é reduzir o problema ao cálculo de apenas um ponto do diagrama ação x deslocamento. Já o método geral tem o compromisso de analisar cada ponto do diagrama ação $\mathrm{x}$ deslocamento. Portanto, pode-se perceber que o método geral consiste em se aplicar várias vezes o método do equilíbrio. 


\section{Capítulo

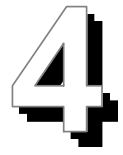

\section{FLEXÃO OBLÍQUA EM PILARES DE CONCRETO ARMADO}

\subsection{ASPECTOS FUNDAMENTAIS}

Pilares são elementos estruturais submetidos a solicitações normais, ou seja, são elementos submetidos a solicitações que produzem tensões normais em suas seções transversais.

A principal solicitação normal que ocorre em pilares de edifício é a flexocompressão pela necessidade de se considerar no mínimo excentricidades acidentais quando da aplicação do carregamento, para suprir falhas como imperfeições geométricas construtivas e erros de avaliação dos esforços. A flexocompressão normal, associação de momento e força axial cuja direção da linha neutra é conhecida e normal ao plano de atuação do momento, em geral, ocorre como simplificação decorrente da não consideração da flexo-compressão oblíqua. Esta última consiste no caso de solicitação normal composta de momento e força axial em que não se conhece, a priori, a direção da linha neutra.

A flexão oblíqua ocorre em várias situações: em seções que não apresentam plano de simetria, em seções simétricas quanto à forma mas com armaduras assimétricas ou em seções simétricas quanto à forma e distribuição da armadura mas com plano de atuação do momento fletor não coincidente com o plano de simetria da seção. Esse tipo de solicitação é aquela a que se encontra submetida a maioria dos pilares e vigas submetidas a cargas laterais além das verticais, portanto, sendo este o caso mais geral de solicitação normal, é alvo dos estudos mais abrangentes de dimensionamento e verificação de pilares.

No estudo da flexão oblíqua, para uma dada seção de concreto armado, sendo conhecidas sua forma, a posição e a área de cada barra da armadura, existem dois problemas básicos; são eles: 
$\left.1^{\circ}\right)$ sendo dada uma situação de solicitação composta pelo terno $\left(N, M_{x}, M_{y}\right)$ tal que não ultrapasse a capacidade resistente da seção, o problema é descobrir qual o correspondente estado de deformações e, conseqüentemente, o estado de tensão caracterizado pela posição da linha neutra e por sua curvatura;

$2^{\circ}$ ) assumindo-se um estado de deformações compatível com os limites de resistência da seção pela fixação da linha neutra e sua curvatura, o problema é encontrar os esforços que equilibram as solicitações.

O segundo problema é aquele já visto quando da discussão sobre a obtenção do diagrama (N, M, 1/r). A solução pode ser obtida diretamente da aplicação das equações de equilíbrio e de compatibilidade, e das relações tensão $x$ deformação do concreto e do aço. A partir do estado de deformações, obtém-se a deformação $\varepsilon_{i}$ em qualquer fibra do concreto, e a deformação $\varepsilon_{\text {si }}$ para qualquer barra da armadura. Com esses valores nos diagramas tensão $\mathrm{x}$ deformação do aço e do concreto, obtém-se o estado de tensão a partir do qual se obtêm os esforços. A solução é alcançada iterativamente, adotando-se um estado inicial de tensão e, daí, determinando-se os valores correspondentes dos esforços. Caso estes não coincidam, a menos de uma tolerância, com as solicitações, adota-se novo estado de tensão, e repete-se o processo até que a tolerância seja atingida.

Quanto ao primeiro problema, sua solução não é direta pois a partir das solicitações não é possível determinar o estado de deformação ou de tensões sem cair em uma solução iterativa semelhante à solução do segundo problema.

Percebe-se que para a solução desse tipo de problema é necessária a utilização das equações de compatibilidade, equações de equilíbrio e equações constitutivas dos materiais, ou melhor, a solução de qualquer problema, incluindo os da Mecânica dos Sólidos Deformáveis, deve satisfazer às hipóteses de cálculo e as equações de equilíbrio, de compatibilidade e constitutivas dos materiais.

\subsection{HIPÓTESES GERAIS DE CÁLCULO}

Descrevem-se a seguir as hipóteses gerais relativas ao estado limite último:

$\Rightarrow$ Solidariedade dos materiais concreto e aço: o comportamento solidário entre as barras de aço da armadura e o concreto que as envolve garante que a deformação em cada barra da armadura seja igual à do concreto que lhe é adjacente;

$\Rightarrow$ Manutenção da forma plana da seção: baseia-se na hipótese de Bernoulli que admite, até o estado limite último, a manutenção da forma plana da seção 
transversal ao longo do processo de deformação, quando submetida a solicitações normais. Como conseqüência dessa hipótese, admite-se uma distribuição plana de deformações normais;

$\Rightarrow$ Permanência da forma da seção transversal: considera-se que, mesmo após sofrer deformações, a forma da seção transversal permanece inalterada;

$\Rightarrow$ Inexistência de tensões e deformações iniciais ou residuais: hipótese que exclui do estudo peças em concreto protendido;

$\Rightarrow$ Pequenos deslocamentos: hipótese que permite considerar como válida a equação diferencial simplificada da linha elástica;

$\Rightarrow$ Consideração da fluência: é feita através da Teoria Linear da Fluência;

$\Rightarrow$ Encurtamentos de ruptura do concreto: o concreto é considerado rompido quando atinge um determinado valor último $\left(\varepsilon_{\mathrm{cu}}\right)$, justificado experimentalmente, cujo valor não depende do tipo de concreto, e sim do tipo de solicitação. $O$ encurtamento de ruptura do concreto, para seções inteiramente comprimidas, é considerado como $\varepsilon_{\mathrm{cu}}=2$ na fibra situada a uma distância de 3/7 da altura da seção em relação a borda mais comprimida, e para seções não inteiramente comprimidas é de $\varepsilon_{\mathrm{cu}}=3,5$ na fibra mais comprimida;

$\Rightarrow$ Alongamento último da armadura tracionada: para peças de concreto armado, convenciona-se como valor último de alongamento da armadura 0 valor $\varepsilon_{\mathrm{su}}=10$. Este valor, também justificado experimentalmente, quando atingido, provoca fissuras exageradas que prejudicam o comportamento da estrutura.

\subsection{EQUAÇÕES DE EQUILÍBRIO}

Dada uma seção qualquer de concreto armado (FIGURA 30), cheia ou vazada, submetida a flexo-compressão oblíqua, denomina-se a carga axial como $\mathrm{N}$ e o momento como $M$, que é dado por suas componentes $M_{x}$ e $M_{y}$. 


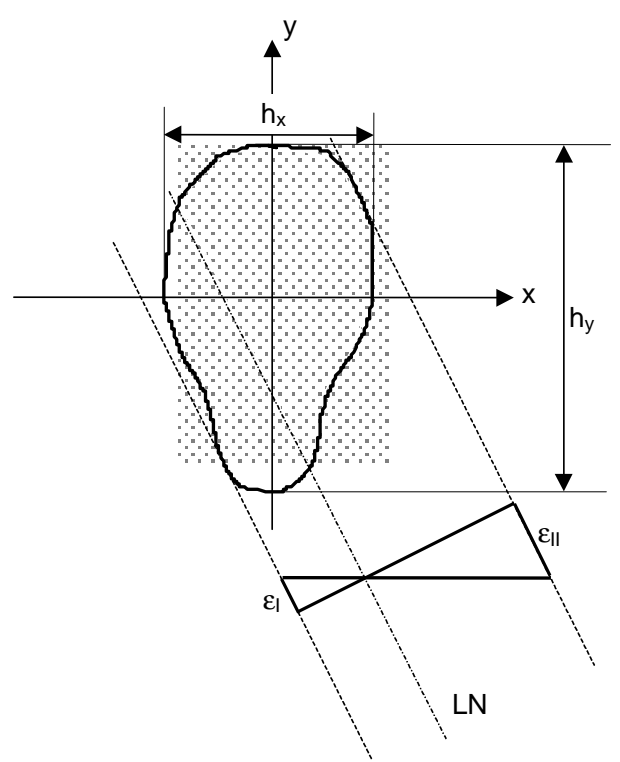

FIGURA 30 - Seção genérica submetida a flexo-compressão oblíqua

Submetida a esse conjunto de solicitações, a seção encontra-se sujeita a tensões e deformações. Essas tensões são responsáveis pelos esforços que surgem em oposição ao carregamento atuante de modo a garantir o equilíbrio da seção. As equações de equilíbrio são:

$$
\begin{aligned}
& N=\iint_{A_{c}} \sigma_{c} \cdot d x \cdot d y+\sum_{i=1}^{n} A_{s i} \cdot\left(\sigma_{s d}\right)_{i} \\
& M_{x}=-\left(\iint_{A_{c}} \sigma_{c d} \cdot y \cdot d x \cdot d y+\sum_{i=1}^{n} A_{s i} \cdot \sigma_{s d i} \cdot y_{s i}\right) \\
& M_{y}=\iint_{A_{c}} \sigma_{c d} \cdot x \cdot d x \cdot d y+\sum_{i=1}^{n} A_{s i} \cdot \sigma_{s d i} \cdot x_{s i}
\end{aligned}
$$

onde:

$\mathrm{A}_{\mathrm{c}}=$ área de concreto da seção transversal, admitida como igual à área da seção geométrica da seção transversal;

$\sigma_{\mathrm{cdi}}=$ tensão normal numa fibra genérica do concreto, de coordenadas x e y;

$\mathrm{A}_{\mathrm{si}}=$ área de uma barra de aço genérica i;

$\sigma_{\text {sdi }}=$ tensão normal numa barra de aço genérica $\mathrm{i}$;

$\mathrm{n}=$ número de barras de aço da armadura. 
O cálculo analítico das integrais das equações (54), (55) e (56) é praticamente inexeqüível; portanto, para obter a solução, uma saída é a discretização do problema transformando-se as integrais em somatórias.

Na FIGURA 31, é apresentada uma seção de concreto armado submetida a flexão oblíqua, resultante da transformação do contorno em uma forma poligonal.

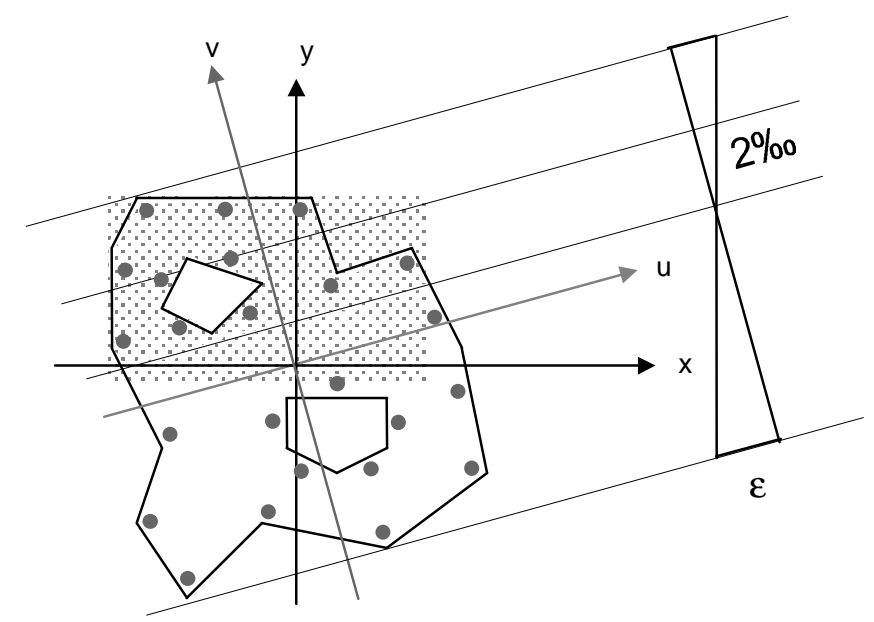

FIGURA 31 - Seção qualquer de concreto armado formada por contornos poligonais

\subsection{EQUAÇÕES DE COMPATIBILIDADE}

Considerando como válida a hipótese das seções planas, tem-se como resultado uma distribuição plana de deformações normais ao longo da seção transversal, como mostra a FIGURA 31.

A distribuição plana pode ser dada pela equação:

$$
\varepsilon=a \cdot v+b
$$

onde $a$ e b são constantes a serem definidas, e $v$ a coordenada de um ponto genérico da seção transversal sobre um eixo perpendicular a linha neutra.

Para determinação completa do estado de deformação da seção é necessário conhecer três parâmetros, são eles: o ângulo que a linha neutra (LN) forma com o eixo horizontal da seção $(\alpha)$, a curvatura majorada adimensional $(\theta)$ explicitada na equação (58), e uma deformação não nula de um ponto qualquer da seção transversal. Rotacionando o sistema de referência de um ângulo $\alpha$, tornamse necessários apenas dois parâmetros, número que pode ainda ser reduzido a um, se for considerado o estado limite último, que por si só já constitui um parâmetro. 


$$
\theta=1000 \cdot \frac{\mathrm{h}_{\alpha}}{\mathrm{r}}
$$

\subsection{RELAÇÕES TENSÃO x DEFORMAÇÃO PARA OS MATERIAIS CONCRETO E AÇO}

O diagrama tensão $\mathrm{x}$ deformação do concreto é considerado como sendo uma seqüência de polinômios de graus arbitrários, a fim de permitir uma maior flexibilidade às equações, não restringindo a análise a um determinado tipo de diagrama específico. Quanto ao aço, considera-se tanto o comportamento do aço tipo A como o do tipo B, de acordo com as recomendações da NB-1/82.

\subsection{INSTABILIDADE NA FLEXO-COMPRESSÃO OBLÍQUA}

Tendo-se uma barra submetida a um determinado carregamento tal que produza flexo-compressão oblíqua em suas seções transversais, o eixo da barra sofre deformações que, no caso de barras esbeltas, provocam o surgimento de excentricidades significativas responsáveis pelo efeito de $2^{\underline{a}}$ ordem, importantes para o estudo do comportamento dessas barras devido ao fato de que podem ocasionar a instabilidade.

Em virtude da deformação de uma barra sob flexão oblíqua, tem-se o plano de flexão variável a cada seção da barra.

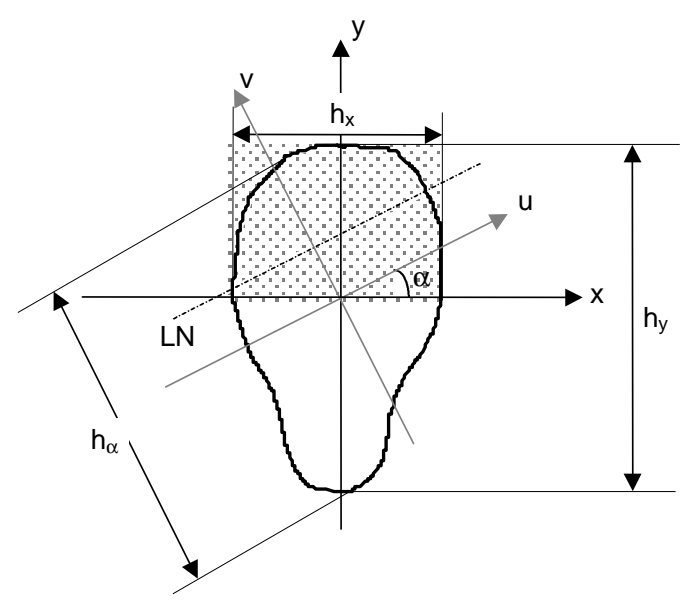

FIGURA 32 - Seção qualquer submetida a flexo-compressão oblíqua

Numa barra de seção qualquer, como mostra a FIGURA 32, tendo-se a direção da linha neutra e o valor da curvatura na direção perpendicular a ela, chega-se facilmente aos valores de curvatura nas direções x e y, ou seja: 


$$
\begin{aligned}
& \frac{1}{r_{x}}=\frac{1}{r_{\alpha}} \cdot \operatorname{sen} \alpha \\
& \frac{1}{r_{y}}=\frac{1}{r_{\alpha}} \cdot \cos \alpha
\end{aligned}
$$

Essas equações são fruto da relação existente entre as maiores dimensões da seção, nas direções x e y, e a maior dimensão na direção perpendicular a linha neutra.

$$
\mathrm{h}_{\alpha}=\mathrm{h}_{\mathrm{x}} \cdot \cos \alpha+\mathrm{h}_{\mathrm{y}} \operatorname{sen} \alpha
$$

Também na flexo-compressão oblíqua podem ser determinados os diagramas (M, N, 1/r) analogamente ao que é feito na flexo-compressão normal, com o detalhe de que, no caso da flexão oblíqua devem-se considerar dois momentos fletores, $M_{x}$ e $M_{y}$, e a direção da linha neutra como incógnitas, ou seja, a flexão oblíqua torna o trabalho mais complexo envolvendo um número maior de parâmetros.

A obtenção do diagrama parte da pré-fixação de um valor para a inclinação da linha neutra $(\alpha)$. A partir deste valor, adota-se um valor para a curvatura $1 / r_{\alpha} \mathrm{e}$ para a deformação ao nível do centro de gravidade, perpendicular à direção da linha neutra, através dos quais se torna possível encontrar o valor da resultante de compressão no concreto e da resultante de tração no aço, donde se obtém os esforços.

\subsection{MÉTODOS DE VERIFICAÇÃO DA ESTABILIDADE}

Pelo método geral a determinação da carga crítica na flexo-compressão oblíqua pode ser feita da mesma forma abordada na flexo-compressão normal, ou seja, pode ser aplicado através do processo exato ou do processo do pilar padrão.

A diferença básica entre o cálculo da carga crítica na flexo-compressão normal e na flexo-compressão oblíqua está no fato de que, neste último, existem dois momentos fletores quando da variação da posição da linha neutra. Portanto, sendo basicamente a aplicação feita da mesma forma, parte-se do mesmo princípio, do cálculo do diagrama carga $x$ deslocamento ou do diagrama excentricidade $\mathrm{x}$ deslocamento, do pilar.

Como visto, o método geral através do carregamento progressivo consiste em determinar o diagrama carga $x$ deslocamento do pilar. Para construção desse diagrama, as ações crescem em cada etapa, a partir das quais são determinados 
os deslocamentos nas direções $\mathrm{x}$ e $\mathrm{y}, \mathrm{w}_{\mathrm{x}}$ e $\mathrm{w}_{\mathrm{y}}$ respectivamente, como mostra a FIGURA 33.

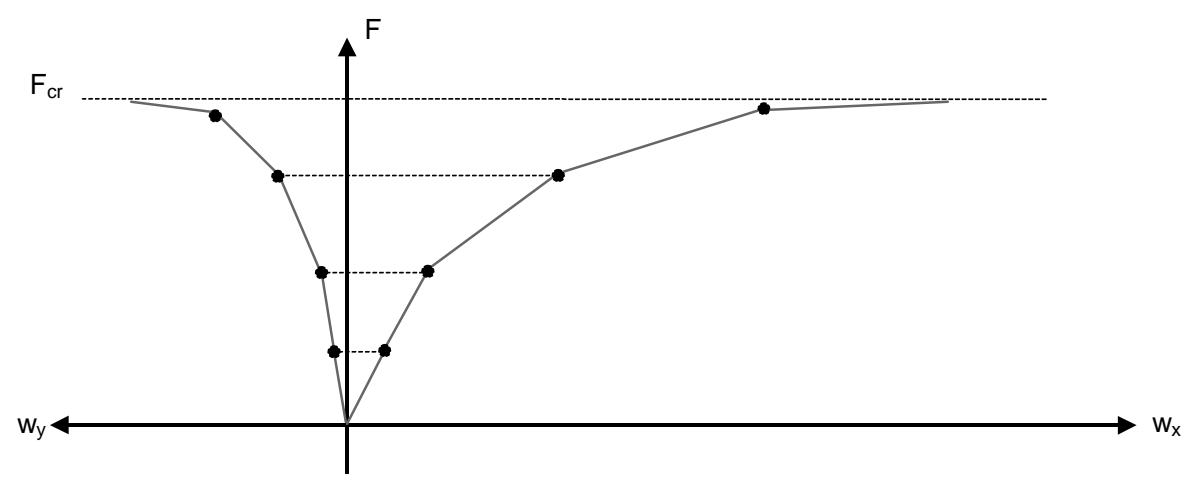

FIGURA 33 - Diagrama carga x deslocamento

A carga crítica será determinada como sendo o valor que primeiro tender a uma assíntota paralela aos eixos dos deslocamentos.

Quanto à aplicação do método geral com o processo do pilar padrão, segue-se o conceito de que a linha elástica seja senoidal; isso significa que está sendo admitido que o eixo da barra seja uma curva plana contida num plano perpendicular à linha neutra da seção de base. Essa hipótese de perpendicularismo exige que a linha neutra de todas as seções tenham sempre a mesma direção, o que não acontece num caso geral de flexão oblíqua, onde o plano de flexão varia de seção para seção caracterizando o eixo deformado da barra como uma curva reversa.

As vantagens da adoção do processo do pilar padrão continuam sendo relativas à simplificação do cálculo dos deslocamentos, já que a hipótese da linha elástica senoidal elimina a integração da equação diferencial do eixo deformado da barra ao longo de todo o seu comprimento e, conseqüentemente, torna a obtenção do momento de $2^{\underline{a}}$ ordem imediata como função exclusiva da curvatura.

Obtidos os momentos de $2^{\underline{a}}$ ordem, pode-se chegar ao máximo valor disponível para o momento de $1^{\underline{a}}$ ordem que será também função apenas da curvatura, para um dado valor de força normal e para uma dada inclinação da linha neutra.

Da mesma forma que o método geral, o método do equilíbrio pode ser aplicado à flexão oblíqua tanto através do processo exato quanto do processo do pilar padrão, como forma de verificação da estabilidade das configurações de equilíbrio. 


\section{Capítulo}

\section{ANÁLISE NUMÉRICA DE PILARES ESBELTOS}

\subsection{ASPECTOS GERAIS}

Os resultados obtidos provêm da resolução de exemplos com base na análise de pilares isolados, através da utilização do software SISTEMA FLEXOR, que compreende um conjunto de programas de dimensionamento e verificação da estabilidade de seções isoladas e de pilares, considerando o estado limite de instabilidade. Os programas baseiam-se nos métodos geral e do equilíbrio, e nos processos exato e do pilar padrão.

A escolha quanto a utilização de um ou outro sub-programa que compõe o SISTEMA FLEXOR depende exclusivamente do tipo de análise que o usuário pretende realizar. A escolha do método é feita com base no que se procura verificar, ou seja, se o interesse está no valor da carga última ou se apenas se pretende verificar se uma determinada solicitação corresponde ou não a uma situação de equilíbrio.

Quanto ao processo, a escolha depende do grau de precisão que se deseja obter através dos resultados. Vale salientar que para determinados tipos de pilar que não se enquadram nas exigências de aplicação do processo do pilar padrão, não há outro processo a ser aplicado senão o exato.

A utilização dos programas é simples. A entrada de dados e a saída de resultados se dá via arquivo. No caso da entrada de dados o arquivo armazena inúmeras seqüências de dados executando apenas a primeira delas, que deve estar de acordo com o programa a utilizar escolhida pelo usuário.

A entrada de dados contém, basicamente, para cada seção transversal em estudo, as seguintes informações: condições de vinculação, solicitações, (carga axial e momentos nas direções x e y), número de nós da poligonal de concreto, número de barras da armadura, coeficiente de fluência, resistência de cálculo do concreto, resistência de cálculo do aço, classe do aço, módulo de elasticidade do aço, coordenadas $\mathrm{x}$ e y dos nós da poligonal de concreto e das barras da 
armadura. Outras informações são requeridas de acordo com o programa escolhido, e estão relacionadas ao tipo de análise, (dimensionamento, verificação), e ao processo que se deseja utilizar na análise (exato, pilar padrão).

É importante ressaltar que as vinculações permitidas, ou seja, as condições de contorno do pilar nas direções $x$ e y são do tipo: pilar biapoiado, pilar rigidamente engastado na base e livre no topo e pilar elasticamente engastado na base e livre no topo. Neste último caso, devem ser fornecidos ao programa os valores dos coeficientes de mola considerados nas direções $\mathrm{x}$ e y do engaste elástico.

Quanto à saída de resultados, os componentes básicos são: deslocamentos das seções nas direções $x$ e y, relação entre os momentos de $1^{\underline{a}}$ e de $2^{\underline{a}}$ ordens, além da área mínima necessária para a seção transversal da armadura, no caso de dimensionamento, ou do tipo e seção de ruína, no caso de verificação da estabilidade.

A etapa que compreendeu a investigação numérica foi iniciada com a aferição experimental do programa e, após obter êxito nessa fase, foi iniciada a fase de estudo sobre a flexo-compressão normal em pilares de vários índices de esbeltez e, seguindo esse estudo, foram estudados casos de pilares submetidos a flexo-compressão oblíqua.

\subsection{AFERIÇÃO EXPERIMENTAL DO PROGRAMA}

$\mathrm{Na}$ fase de aferição experimental do programa, foram resolvidos exemplos de pilares submetidos à flexo-compressão normal e à flexo-compressão oblíqua.

Os primeiros resultados obtidos relativos à flexo-compressão normal são decorrentes da comparação entre valores de carga última, disponíveis em CHUANG \& KONG (1997), como resultado da experimentação prática de 26 pilares esbeltos de concreto armado de características diversas.

Para tal, foi utilizada uma versão modificada do programa VERIFIC_EXATO do SISTEMA FLEXOR, chamado de GERAL_EXATO, que permite o cálculo iterativo da carga última, cujo incremento é dado pelo usuário na entrada de dados. Essa alteração foi feita de forma muito simples, com o objetivo de aplicar o método geral, que consiste na aplicação sucessiva do método do equilíbrio, juntamente com o processo exato. 
Os ensaios apresentados no artigo mencionado foram divididos nas séries A, B, C e HB, de acordo com a resistência do aço utilizado. Dentro de cada série, houve variação nos valores de resistência à compressão $\left(f_{c y}\right)$, no comprimento $(L)$, na taxa geométrica de armadura, $\left(A_{s} / \mathrm{bh}\right)$, no valor da excentricidade da carga aplicada (e), como também nas dimensões da seção transversal (b e h), conforme consta da TABELA 01.

Os pilares ensaiados têm seção retangular, como mostra a FIGURA 34. Possuem índices de esbeltez entre 50 e 110 na direção mais crítica, (direção x), direção esta em que é aplicada a excentricidade à carga caracterizando a flexocompressão normal, com valores de $50 \mathrm{~mm}$ para primeira metade dos pilares de cada série, e $100 \mathrm{~mm}$ para o restante, com exceção apenas no caso da série $C$, em que as excentricidades foram de 30 e $60 \mathrm{~mm}$, respectivamente.

Os valores de d' foram obtidos a partir da soma do diâmetro das barras da armadura mais 3 centímetros de cobrimento.
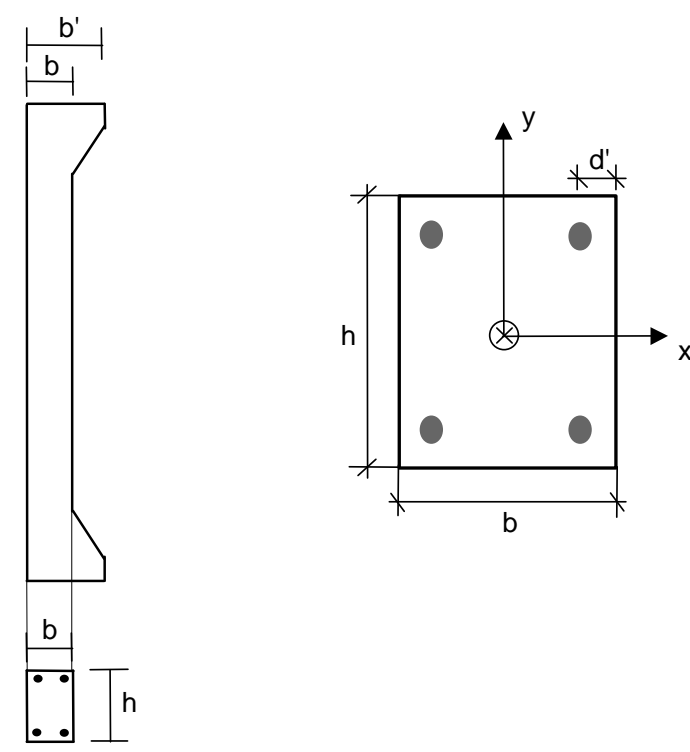

FIGURA 34 - Pilares ensaiados sob flexo-compressão normal

Em CHUANG \& KONG (1997) também são apresentados para os pilares ensaiados, além dos resultados experimentais, os resultados de carga última utilizando os processos indicados pelas normas ACI318, EC2 e BS8110, com a finalidade de compará-los com os valores fornecidos pelos ensaios, não entrando em discussão os coeficientes de segurança adotados por cada uma delas. 
Os valores indicados na TABELA 01, referentes às características dos pilares ensaiados, também foram utilizados como dados de entrada no SISTEMA FLEXOR através do programa GERAL_EXATO. Esses resultados também encontram-se na TABELA 01.

O Gráfico da FIGURA 35 apresenta de forma esquemática, a relação existente entre os valores encontrados através dos procedimentos de cálculo utilizado pelas normas citadas anteriormente, como também através do SISTEMA FLEXOR (programa GERAL_EXATO), com os valores experimentais tomados como valores-base de cálculo.

Como a comparação foi feita sobre os valores característicos, a discussão gira em torno dos procedimentos de cálculo. Com base nisso, constata-se que os procedimentos adotados pela norma BS8110 e pelo SISTEMA FLEXOR (programa GERAL_EXATO) são os que se apresentam mais próximos entre si, como também dos valores experimentais.

TABELA 01 - Dados e resultados relativos aos pilares ensaiados - Flexo-compressão normal

\begin{tabular}{|c|c|c|c|c|c|c|c|c|c|c|c|}
\hline $\begin{array}{c}\text { Pilar } \\
\mathrm{n}^{\circ}\end{array}$ & $\begin{array}{c}\lambda \\
\mathrm{adm}\end{array}$ & $\begin{array}{c}\mathbf{b} \\
\mathrm{cm}\end{array}$ & $\begin{array}{c}\mathbf{h} \\
\mathrm{cm}\end{array}$ & $\begin{array}{c}\mathbf{A s}_{\mathbf{s}} / \mathbf{b h} \\
\%\end{array}$ & $\begin{array}{c}\boldsymbol{f}_{\mathrm{cy}} \\
\mathrm{kN} / \mathrm{cm}^{2}\end{array}$ & $\begin{array}{c}\boldsymbol{f}_{\mathrm{y}} \\
\mathrm{kN} / \mathrm{cm}^{2}\end{array}$ & $\begin{array}{l}\mathbf{P}_{\mathrm{ACl}} \\
\mathrm{kN}\end{array}$ & $\begin{array}{l}P_{\mathrm{BS}} \\
\mathrm{kN}\end{array}$ & $\begin{array}{l}P_{\mathrm{EC} 2} \\
\mathrm{kN}\end{array}$ & $\begin{array}{c}\text { PfLex } \\
\mathrm{kN}\end{array}$ & $\begin{array}{c}P_{\text {EXP }} \\
k N\end{array}$ \\
\hline $1 \mathrm{~A}$ & 52 & 20 & 30 & 3.27 & 2.49 & 49.3 & 887 & 1041 & 987 & 986 & 1286 \\
\hline $2 \mathrm{~A}$ & 59 & 20 & 30 & 3.27 & 3.06 & 49.3 & 891 & 1103 & 1026 & 1009 & 1181 \\
\hline $3 \mathrm{~A}$ & 62 & 20 & 30 & 3.27 & 2.62 & 49.3 & 803 & 991 & 918 & 890 & 1082 \\
\hline $4 \mathrm{~A}$ & 66 & 20 & 30 & 3.27 & 2.58 & 49.3 & 764 & 956 & 874 & 843 & 1197 \\
\hline $5 \mathrm{~A}$ & 52 & 20 & 30 & 3.27 & 2.64 & 49.3 & 583 & 670 & 643 & 644 & 888 \\
\hline $6 \mathrm{~A}$ & 59 & 20 & 30 & 3.27 & 3.22 & 49.3 & 603 & 710 & 666 & 708 & 904 \\
\hline $7 \mathrm{~A}$ & 62 & 20 & 30 & 3.27 & 2.62 & 49.3 & 539 & 630 & 590 & 580 & 852 \\
\hline $8 \mathrm{~A}$ & 66 & 20 & 30 & 3.27 & 2.42 & 49.3 & 507 & 595 & 555 & 541 & 815 \\
\hline $9 \mathrm{~B}$ & 59 & 20 & 30 & 1.34 & 2.98 & 51.9 & 621 & 768 & 647 & 702 & 1088 \\
\hline $10 \mathrm{~B}$ & 62 & 20 & 30 & 1.34 & 3.37 & 51.9 & 626 & 798 & 654 & 722 & 989 \\
\hline $11 \mathrm{~B}$ & 66 & 20 & 30 & 1.34 & 3.18 & 51.9 & 579 & 735 & 594 & 657 & 1046 \\
\hline $12 \mathrm{~B}$ & 59 & 20 & 30 & 1.34 & 3.09 & 51.9 & 394 & 436 & 377 & 390 & 477 \\
\hline $13 \mathrm{~B}$ & 62 & 20 & 30 & 1.34 & 3.40 & 51.9 & 390 & 433 & 368 & 387 & 480 \\
\hline $14 \mathrm{~B}$ & 66 & 20 & 30 & 1.34 & 3.60 & 51.9 & 380 & 423 & 353 & 377 & 461 \\
\hline $15 \mathrm{C}$ & 95 & 12 & 20 & 3.35 & 3.37 & 52.0 & 161 & 234 & 157 & 183 & 531 \\
\hline $16 \mathrm{C}$ & 104 & 12 & 20 & 3.35 & 3.41 & 52.0 & 143 & 210 & 138 & 162 & 485 \\
\hline $17 \mathrm{C}$ & 110 & 12 & 20 & 3.35 & 3.55 & 52.0 & $\#$ & 199 & 129 & 153 & 333 \\
\hline $18 \mathrm{C}$ & 95 & 12 & 20 & 3.35 & 3.41 & 52.0 & 123 & 162 & 121 & 126 & 205 \\
\hline $19 \mathrm{C}$ & 104 & 12 & 20 & 3.35 & 3.32 & 52.0 & 111 & 148 & 107 & 112 & 320 \\
\hline $20 \mathrm{C}$ & 110 & 12 & 20 & 3.35 & 3.50 & 52.0 & $\#$ & 144 & 103 & 108 & 255 \\
\hline $21 \mathrm{HB}$ & 59 & 20 & 30 & 1.34 & 7.70 & 53.1 & 985 & 1472 & 1120 & 1400 & 1801 \\
\hline $22 \mathrm{HB}$ & 62 & 20 & 30 & 1.34 & 7.58 & 53.1 & 907 & 1366 & 1004 & 1295 & 1477 \\
\hline $23 \mathrm{HB}$ & 66 & 20 & 30 & 1.34 & 7.63 & 53.1 & 844 & 1282 & 907 & 1217 & 1572 \\
\hline $24 \mathrm{HB}$ & 59 & 20 & 30 & 1.34 & 7.53 & 53.1 & 535 & 607 & 495 & 536 & 706 \\
\hline $25 \mathrm{HB}$ & 62 & 20 & 30 & 1.34 & 7.67 & 53.1 & 513 & 581 & 466 & 511 & 646 \\
\hline $26 \mathrm{HB}$ & 66 & 20 & 30 & 1.34 & 7.69 & 53.1 & 487 & 553 & 436 & 485 & 608 \\
\hline
\end{tabular}




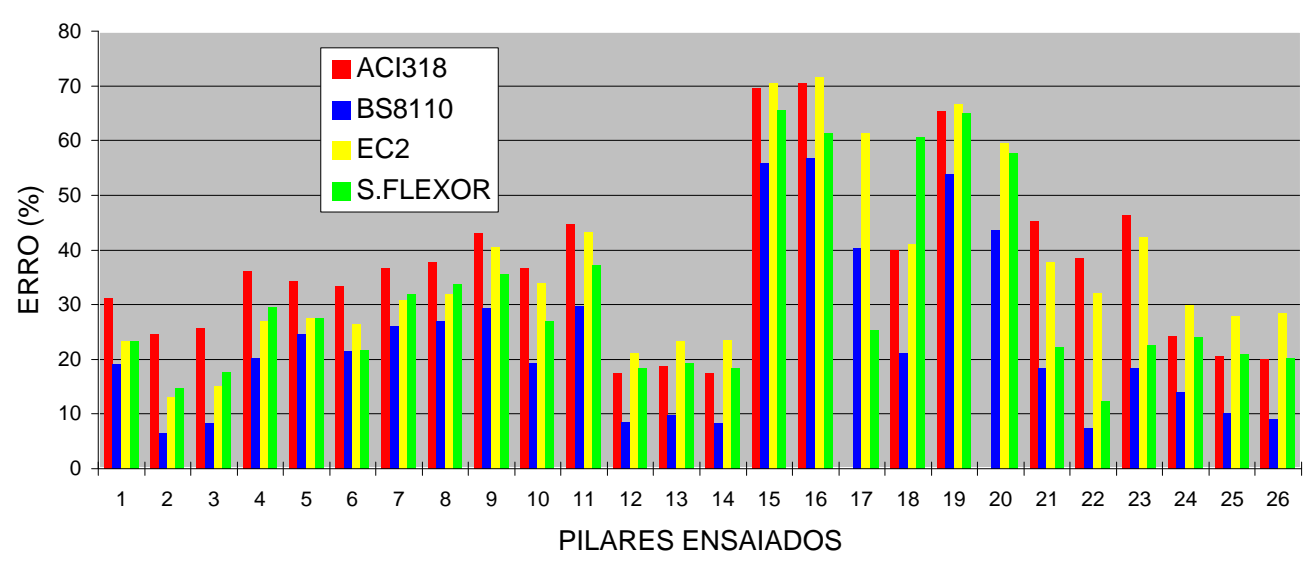

FIGURA 35 - Relação entre valores de carga última dados pelas normas e pelo programa SISTEMA FLEXOR

Com o intuito de aferir o programa com relação ao tratamento da flexocompressão oblíqua, foram feitos ensaios numéricos da mesma forma descrita anteriormente, com 14 exemplares, incluindo pilares de seção quadrada (série C) e de seção em $L$ (série $B$ ), ensaiados experimental e numericamente por TSAO (1992). Esses exemplares apresentam as características descritas nas TABELAS 02 e 03 e na FIGURA 36.

Também encontram-se nas TABELAS 02 e 03 os resultados obtidos através do SISTEMA FLEXOR com o programa GERAL_EXATO. Os resultados, em termos de carga última, foram comparados com os valores experimentais e com os valores obtidos através do programa elaborado por TSAO (1992).

TABELA 02- Dados e resultados para pilares de seção quadrada - Flexo-compressão oblíqua

\begin{tabular}{|c|c|c|c|c|c|c|c|c|c|c|}
\hline $\begin{array}{c}\text { Pilar } \\
\mathrm{n}^{\circ}\end{array}$ & $\begin{array}{c}\lambda_{x}=\lambda_{y} \\
\operatorname{adm}\end{array}$ & $\begin{array}{c}\text { lado } \\
\mathrm{cm}\end{array}$ & $\begin{array}{c}\mathbf{A s}_{\mathbf{s}} / \mathbf{b h} \\
\%\end{array}$ & $\begin{array}{c}\boldsymbol{f}_{\mathrm{c}} \\
\mathrm{kN} / \mathrm{cm}^{2}\end{array}$ & $\begin{array}{c}\boldsymbol{f}_{\mathrm{y}} \\
\mathrm{kN} / \mathrm{cm}^{2}\end{array}$ & $\begin{array}{l}\mathbf{e}_{\mathbf{x}} \\
\mathrm{cm}\end{array}$ & $\begin{array}{l}\mathbf{e}_{\mathrm{y}} \\
\mathrm{cm}\end{array}$ & $\begin{array}{c}\text { PtSAO }_{\text {TN }} \\
\text { kN }\end{array}$ & $\begin{array}{c}\text { PfLeX } \\
\mathrm{kN}\end{array}$ & $\begin{array}{c}P_{\text {EXP }} \\
k N\end{array}$ \\
\hline C1 & 55.43 & 7.62 & 4.9 & 1.91 & 54.47 & 0.97 & 2.35 & 65.21 & 70.00 & 69.04 \\
\hline C2 & 55.43 & 7.62 & 4.9 & 1.86 & 54.47 & 1.80 & 1.80 & 62.76 & 66.00 & 57.03 \\
\hline C3 & 55.43 & 7.62 & 4.9 & 2.90 & 54.47 & 3.59 & 3.59 & 45.35 & 47.00 & 39.99 \\
\hline C4 & 55.43 & 7.62 & 4.9 & 2.55 & 42.06 & 1.80 & 1.80 & $\begin{array}{l}73.24 \\
\end{array}$ & 72.00 & 84.78 \\
\hline C5 & 55.43 & 7.62 & 4.9 & 2.55 & 42.06 & 1.94 & 4.69 & 46.02 & 43.00 & 47.64 \\
\hline C6 & 55.43 & 7.62 & 4.9 & 2.55 & 42.06 & 0.97 & 2.35 & 75.38 & 75.00 & 83.23 \\
\hline
\end{tabular}


TABELA 03 - Dados e resultados para pilares de seção em L - Flexo-compressão oblíqua

\begin{tabular}{|c|c|c|c|c|c|c|c|c|c|c|}
\hline $\begin{array}{c}\text { Pilar } \\
\mathrm{n}^{\circ}\end{array}$ & $\begin{array}{c}\lambda_{\mathbf{x}} \\
\mathrm{cm}\end{array}$ & $\begin{array}{c}\lambda_{\mathbf{y}} \\
\mathrm{cm}\end{array}$ & $\begin{array}{c}\text { As/Ac } \\
\%\end{array}$ & $\begin{array}{c}\boldsymbol{f}_{\mathrm{c}} \\
\mathrm{kN} / \mathrm{cm}^{2}\end{array}$ & $\begin{array}{c}\boldsymbol{f}_{\mathbf{y}} \\
\mathrm{kN} / \mathrm{cm}^{2}\end{array}$ & $\begin{array}{c}\mathbf{e}_{\mathbf{x}} \\
\mathrm{cm}\end{array}$ & $\begin{array}{c}\mathbf{e}_{\mathbf{y}} \\
\mathrm{cm}\end{array}$ & $\begin{array}{c}\text { PTSAO }_{\text {TS }} \\
\mathrm{KN}\end{array}$ & $\begin{array}{c}\text { P }_{\text {FLEX }} \\
\mathrm{kN}\end{array}$ & $\begin{array}{c}\text { P }_{\text {EXP }} \\
\mathrm{kN}\end{array}$ \\
\hline B1 & 58.06 & 15.33 & 4.0 & 2.48 & 43.44 & 1.61 & 3.45 & $\#$ & 59.00 & $\#$ \\
\hline B2 & 58.06 & 15.33 & 4.0 & 2.51 & 43.44 & 2.15 & 4.61 & 46.75 & 47.00 & 45.59 \\
\hline B3 & 58.06 & 15.33 & 4.0 & 2.68 & 43.44 & 2.69 & 2.69 & 52.96 & 53.00 & 57.04 \\
\hline B4 & 58.06 & 15.33 & 4.0 & 2.68 & 44.13 & 3.59 & 3.59 & 41.95 & 42.00 & 45.00 \\
\hline B5 & 58.06 & 15.33 & 4.0 & 2.93 & 44.13 & 0.90 & 0.90 & 114.95 & 118.00 & 128.21 \\
\hline B6 & 58.06 & 15.33 & 4.0 & 2.93 & 44.13 & 1.80 & 1.80 & 74.54 & 76.00 & 71.49 \\
\hline B7 & 58.06 & 15.33 & 4.0 & 2.92 & 44.13 & 1.55 & 2.01 & 77.40 & 79.00 & 71.45 \\
\hline B8 & 58.06 & 15.33 & 4.0 & 2.92 & 44.13 & 3.09 & 4.03 & 44.77 & 42.00 & 46.80 \\
\hline
\end{tabular}
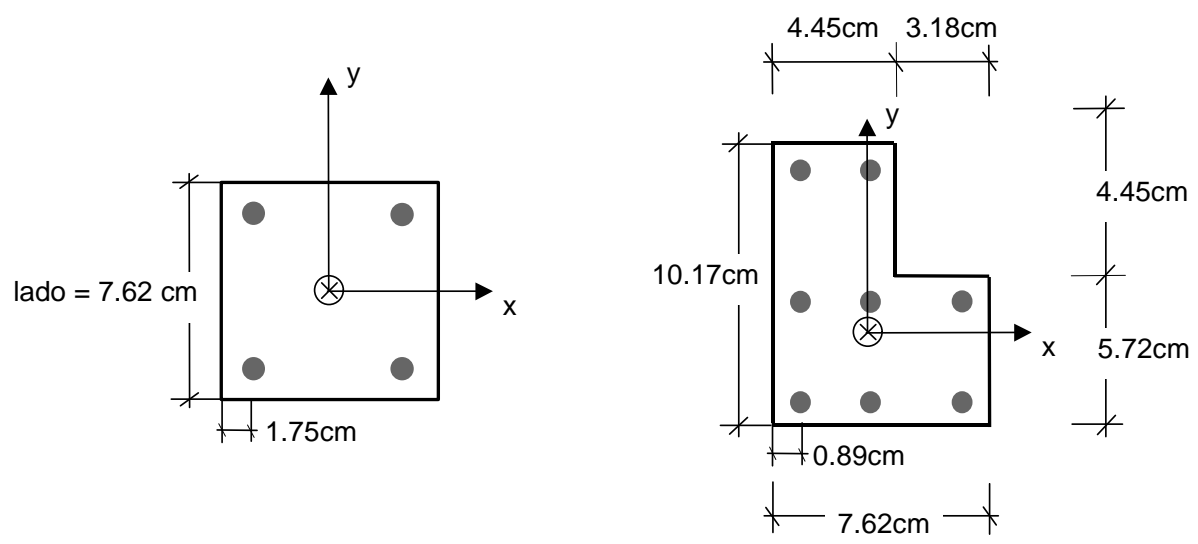

FIGURA 36 - Pilares sob flexo-compressão oblíqua

Os resultados obtidos a partir do programa elaborado por TSAO (1992) estão identificados na TABELA 02 pela coluna $\mathrm{P}_{\text {TSAO. Ao lado desta, encontram-se }}$ os resultados obtidos através do SISTEMA FLEXOR ( $\left.P_{\text {FLEX }}\right)$ pelo programa GERAL_EXATO, e os resultados experimentais $\left(P_{\text {EXP }}\right)$.

Os valores de $f_{c}$ que se encontram nas TABELAS 02 e 03, são relativos a corpos-de-prova cilíndricos com dimensões 3in x 6in, não compatíveis com os corpos-de-prova utilizados pela norma brasileira para cálculo da resistência à compressão do concreto. Com base nisso, acredita-se que a resistência, se medida a partir de corpos-de-prova de $15 \mathrm{~cm} \times 30 \mathrm{~cm}$, assumiria valores menores e, portanto o SISTEMA FLEXOR, que considera a resistência medida a partir da análise desse tipo de corpo-de-prova, deve apresentar valores sensivelmente mais elevados de carga, quando comparado ao programa elaborado por TSAO(1992).

O Gráfico da FIGURA 37 apresenta, também de forma esquemática, a relação existente entre os valores encontrados através do programa elaborado por 
TSAO(1992) e pelo SISTEMA FLEXOR através do programa GERAL_EXATO, com os valores experimentais tomados como valores-base de cálculo.

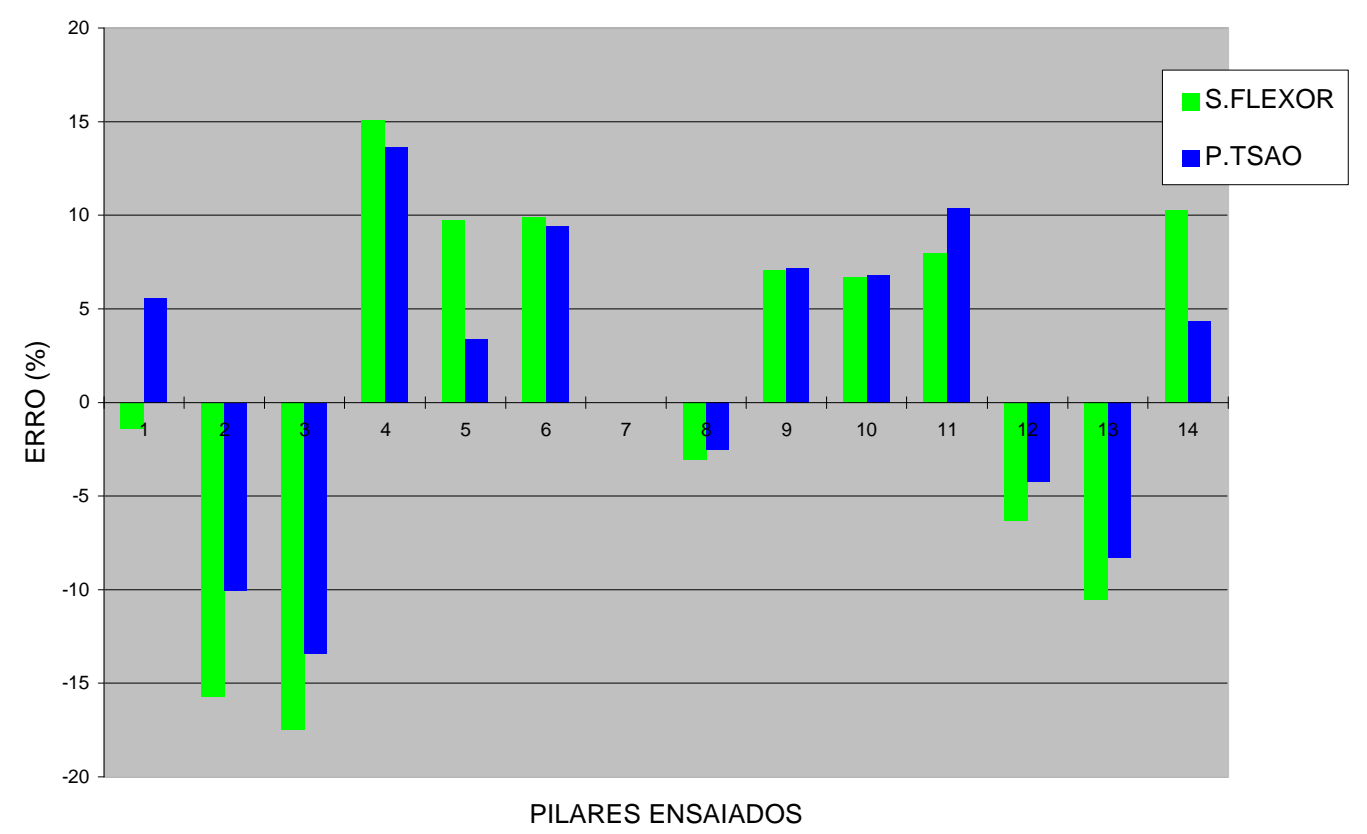

FIGURA 37 - Relação entre valores de carga última dados pelo programa de TSAO (1992) e o SISTEMA FLEXOR

\subsection{ANÁLISE DA FLEXO-COMPRESSÃO NORMAL (FCN)}

Com o intuito de detectar problemas e definir parâmetros no estudo da flexo-compressão, o estudo foi iniciado através da análise da flexo-compressão normal, por ser este um caso particular da flexo-compressão oblíqua.

Dentro do estudo da flexo-compressão normal foi resolvida uma série de exemplos com o intuito de verificar os limites de validade de aplicação do processo simplificado do Pilar Padrão, adotado pela NB1, indicado apenas para pilares limitados pela geometria e pelo índice de esbeltez.

\subsubsection{Comparação entre Valores de Carga Última}

Para iniciar o estudo, o parâmetro escolhido foi a carga última. Para pilares de índices de esbeltez os mais diversos, foi calculado o valor da carga última pelo SISTEMA FLEXOR, através dos programas GERAL_EXATO e GERAL_PPADRAO. 
Os valores utilizados para análise da carga última estão apresentados nas TABELAS 04, 05, 06 e 07, com a relação entre os valores, explicitada através de porcentagem relativa ao valor obtido com o processo exato.

O esquema dos arranjos adotados para a distribuição da armadura dos pilares das TABELAS 04, 05, 06, 07 e 08 encontram-se na FIGURA 38. Os valores de d' variam de acordo com o raio da barra de armadura adotada, sendo seus valores calculados a partir da soma do raio mais $3 \mathrm{~cm}$.

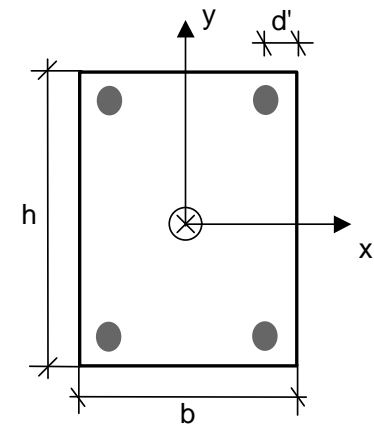

(a) TABELAS 04 e 08

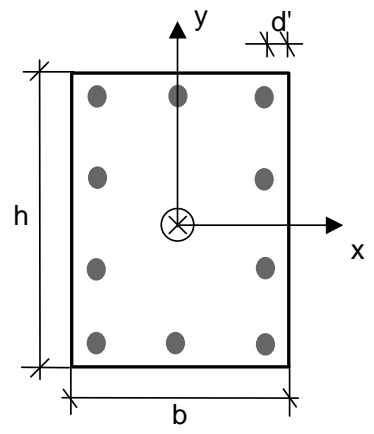

(b) TABELAS 05, 06 e 07

FIGURA 38 - FCN: Esquema das seções transversais dos pilares ensaiados 
TABELA 04 - FCN: Dados e resultados para pilares de seção retangular - Cálculo da carga última

\begin{tabular}{|c|c|c|c|c|c|c|c|c|c|}
\hline $\begin{array}{c}\text { Pilar } \\
\mathrm{n}^{\circ}\end{array}$ & $\begin{array}{c}\lambda \mathrm{x} \\
\mathrm{adm} .\end{array}$ & $\begin{array}{c}\text { Seção } \\
\mathrm{cm} \times \mathrm{cm}\end{array}$ & $\begin{array}{c}f_{\mathrm{cd}} \\
\mathrm{kN} / \mathrm{cm}^{2}\end{array}$ & $\begin{array}{c}f_{\mathrm{yd}} \\
\mathrm{kN} / \mathrm{cm}^{2}\end{array}$ & $\begin{array}{c}\mathbf{e}_{\mathbf{x}} \\
\mathrm{cm}\end{array}$ & $\begin{array}{c}\text { As } \\
\mathrm{cm}^{2}\end{array}$ & $\begin{array}{c}\mathbf{P}_{\mathrm{u}(\text { PPADRAO }} \\
\text { ) } \\
\mathrm{kN}\end{array}$ & $\begin{array}{c}\mathbf{P}_{\mathrm{u}(\text { EXATO) }} \\
\mathrm{kN}\end{array}$ & $\begin{array}{c}\text { Diferença } \\
\%\end{array}$ \\
\hline 01 & 60.6 & $20 \times 30$ & 2.78 & 43.48 & 5.0 & 6.91 & 646 & 635 & 1.73 \\
\hline 02 & 69.3 & $20 \times 30$ & 2.78 & 43.48 & 5.0 & 6.91 & 565 & 553 & 2.17 \\
\hline 03 & 77.9 & $20 \times 30$ & 2.78 & 43.48 & 5.0 & 6.91 & 490 & 479 & 2.30 \\
\hline 04 & 86.6 & $20 \times 30$ & 2.78 & 43.48 & 5.0 & 6.91 & 424 & 415 & 2.17 \\
\hline 05 & 95.3 & $20 \times 30$ & 2.78 & 43.48 & 5.0 & 6.91 & 367 & 359 & 2.23 \\
\hline 06 & 103.9 & $20 \times 30$ & 2.78 & 43.48 & 5.0 & 6.91 & 319 & 312 & 2.24 \\
\hline 07 & 112.6 & $20 \times 30$ & 2.78 & 43.48 & 5.0 & 6.91 & 279 & 273 & 2.20 \\
\hline 08 & 121.2 & $20 \times 30$ & 2.78 & 43.48 & 5.0 & 6.91 & 245 & 240 & 2.08 \\
\hline 09 & 57.7 & $12 \times 20$ & 2.91 & 43.48 & 3.0 & 3.53 & 291 & 287 & 1.39 \\
\hline 10 & 72.2 & $12 \times 20$ & 2.91 & 43.48 & 3.0 & 3.53 & 233 & 228 & 2.19 \\
\hline 11 & 86.6 & $12 \times 20$ & 2.91 & 43.48 & 3.0 & 3.53 & 185 & 181 & 2.21 \\
\hline 12 & 101.0 & $12 \times 20$ & 2.91 & 43.48 & 3.0 & 3.53 & 147 & 144 & 2.08 \\
\hline 13 & 115.5 & $12 \times 20$ & 2.91 & 43.48 & 3.0 & 3.53 & 118 & 115 & 2.61 \\
\hline 14 & 129.9 & $12 \times 20$ & 2.91 & 43.48 & 3.0 & 3.53 & 96 & 94 & 2.13 \\
\hline 15 & 144.4 & $12 \times 20$ & 2.91 & 43.48 & 3.0 & 3.53 & 79 & 78 & 1.28 \\
\hline 16 & 158.8 & $12 \times 20$ & 2.91 & 43.48 & 3.0 & 3.53 & 66 & 65 & 1.54 \\
\hline 17 & 173.2 & $12 \times 20$ & 2.91 & 43.48 & 3.0 & 3.53 & 56 & 55 & 1.82 \\
\hline 18 & 187.6 & $12 \times 20$ & 2.91 & 43.48 & 3.0 & 3.53 & 48 & 48 & 0.00 \\
\hline 19 & 202.1 & $12 \times 20$ & 2.91 & 43.48 & 3.0 & 3.53 & 42 & 41 & 2.44 \\
\hline 20 & 60.6 & $20 \times 30$ & 6.49 & 43.48 & 5.0 & 8.95 & 1280 & 1250 & 2.40 \\
\hline 21 & 69.3 & $20 \times 30$ & 6.49 & 43.48 & 5.0 & 8.95 & 1096 & 1069 & 2.53 \\
\hline 22 & 77.9 & $20 \times 30$ & 6.49 & 43.48 & 5.0 & 8.95 & 933 & 909 & 2.64 \\
\hline 23 & 86.6 & $20 \times 30$ & 6.49 & 43.48 & 5.0 & 8.95 & 795 & 774 & 2.71 \\
\hline 24 & 95.3 & $20 \times 30$ & 6.49 & 43.48 & 5.0 & 8.95 & 681 & 662 & 2.87 \\
\hline 25 & 103.9 & $20 \times 30$ & 6.49 & 43.48 & 5.0 & 8.95 & 588 & 571 & 2.98 \\
\hline 26 & 112.6 & $20 \times 30$ & 6.49 & 43.48 & 5.0 & 8.95 & 511 & 496 & 3.02 \\
\hline 27 & 121.2 & $20 \times 30$ & 6.49 & 43.48 & 5.0 & 8.95 & 447 & 434 & 3.00 \\
\hline & & & & & & & & & \\
\hline
\end{tabular}

TABELA 05 - FCN: Dados e resultados para pilares de seção retangular - Cálculo da carga última

\begin{tabular}{|c|c|c|c|c|c|c|c|c|c|}
\hline $\begin{array}{c}\text { Pilar } \\
\mathrm{n}^{0}\end{array}$ & $\begin{array}{c}\lambda \\
\operatorname{adm} .\end{array}$ & $\begin{array}{l}\text { Seção } \\
\mathrm{cm} \times c m\end{array}$ & $\begin{array}{c}\boldsymbol{f}_{\text {cd }} \\
\mathrm{kN} / \mathrm{cm}^{2}\end{array}$ & $\begin{array}{c}\boldsymbol{f}_{\mathbf{y d}} \\
\mathrm{kN} / \mathrm{cm}^{2}\end{array}$ & $\begin{array}{l}e_{x} \\
\mathrm{~cm}\end{array}$ & $\begin{array}{l}\text { As } \\
\mathrm{cm}^{2}\end{array}$ & $\begin{array}{c}\text { Pu(PPADRAO } \\
\text { ) } \\
\text { kN }\end{array}$ & $\begin{array}{c}\mathbf{P}_{\mathbf{u}(\text { EXATO })} \\
k N\end{array}$ & $\begin{array}{c}\text { Diferença } \\
\%\end{array}$ \\
\hline 01 & 77.9 & $20 \times 30$ & 2.30 & 43.48 & 5.0 & 19.62 & 668 & 653 & 2.30 \\
\hline 02 & 86.6 & $20 \times 30$ & 2.30 & 43.48 & 5.0 & 19.62 & 586 & 576 & 1.74 \\
\hline 03 & 95.3 & $20 \times 30$ & 2.30 & 43.48 & 5.0 & 19.62 & 518 & 509 & 1.77 \\
\hline 04 & 103.9 & $20 \times 30$ & 2.30 & 43.48 & 5.0 & 19.62 & 460 & 452 & 1.77 \\
\hline 05 & 112.6 & $20 \times 30$ & 2.30 & 43.48 & 5.0 & 19.62 & 411 & 403 & 1.99 \\
\hline 06 & 121.2 & $20 \times 30$ & 2.30 & 43.48 & 5.0 & 19.62 & 368 & 361 & 1.94 \\
\hline 07 & 77.9 & $20 \times 30$ & 2.78 & 43.48 & 5.0 & 8.04 & 530 & 518 & 2.32 \\
\hline 08 & 86.6 & $20 \times 30$ & 2.78 & 43.48 & 5.0 & 8.04 & 461 & 451 & 2.22 \\
\hline 09 & 95.3 & $20 \times 30$ & 2.78 & 43.48 & 5.0 & 8.04 & 401 & 393 & 2.04 \\
\hline 10 & 103.9 & $20 \times 30$ & 2.78 & 43.48 & 5.0 & 8.04 & 350 & 343 & 2.04 \\
\hline 11 & 112.6 & $20 \times 30$ & 2.78 & 43.48 & 5.0 & 8.04 & 307 & 301 & 1.99 \\
\hline 12 & 121.2 & $20 \times 30$ & 2.78 & 43.48 & 5.0 & 8.04 & 270 & 265 & 1.89 \\
\hline 13 & 129.9 & $12 \times 20$ & 2.91 & 43.48 & 3.0 & 8.04 & 113 & 111 & 1.80 \\
\hline 14 & 144.4 & $12 \times 20$ & 2.91 & 43.48 & 3.0 & 8.04 & 95 & 93 & 2.15 \\
\hline 15 & 158.8 & $12 \times 20$ & 2.91 & 43.48 & 3.0 & 8.04 & 81 & 79 & 2.53 \\
\hline 16 & 173.2 & $12 \times 20$ & 2.91 & 43.48 & 3.0 & 8.04 & 69 & 68 & 1.47 \\
\hline 17 & 187.6 & $12 \times 20$ & 2.91 & 43.48 & 3.0 & 8.04 & 60 & 59 & 1.69 \\
\hline 18 & 202.1 & $12 \times 20$ & 2.91 & 43.48 & 3.0 & 8.04 & 53 & 52 & 1.92 \\
\hline 19 & 77.9 & $20 \times 30$ & 6.49 & 43.48 & 5.0 & 8.04 & 901 & 877 & 2.74 \\
\hline 20 & 86.6 & $20 \times 30$ & 6.49 & 43.48 & 5.0 & 8.04 & 767 & 745 & 2.95 \\
\hline 21 & 95.3 & $20 \times 30$ & 6.49 & 43.48 & 5.0 & 8.04 & 656 & 637 & 2.98 \\
\hline 22 & 103.9 & $20 \times 30$ & 6.49 & 43.48 & 5.0 & 8.04 & 566 & 549 & 3.10 \\
\hline 23 & 112.6 & $20 \times 30$ & 6.49 & 43.48 & 5.0 & 8.04 & 492 & 477 & 3.14 \\
\hline 24 & 121.2 & $20 \times 30$ & 6.49 & 43.48 & 5.0 & 8.04 & 431 & 417 & 3.36 \\
\hline
\end{tabular}


TABELA 06 - FCN: Dados e resultados para pilares de seção retangular - Cálculo da carga última

\begin{tabular}{|c|c|c|c|c|c|c|c|c|c|}
\hline $\begin{array}{c}\text { Pilar } \\
\mathrm{n}^{\circ}\end{array}$ & $\begin{array}{c}\lambda \mathrm{x} \\
\mathrm{adm} .\end{array}$ & $\begin{array}{c}\text { Seção } \\
\mathrm{cm} \times \mathrm{cm}\end{array}$ & $\begin{array}{c}\boldsymbol{f}_{\mathrm{cd}} \\
\mathrm{kN} / \mathrm{cm}^{2}\end{array}$ & $\begin{array}{c}\boldsymbol{f}_{\mathbf{y d}} \\
\mathrm{kN} / \mathrm{cm}^{2}\end{array}$ & $\begin{array}{c}\mathbf{e x}_{\mathrm{x}} \\
\mathrm{cm}\end{array}$ & $\begin{array}{c}\text { As } \\
\mathrm{Cm}^{2}\end{array}$ & $\begin{array}{c}\text { Pu} \text { (PPADRAO } \\
\text { ) } \\
\mathrm{kN}\end{array}$ & $\begin{array}{c}\text { Pu(EXAT } \\
\text { o) } \\
\mathrm{kN}\end{array}$ & $\begin{array}{c}\text { Diferença } \\
\%\end{array}$ \\
\hline 01 & 52.0 & $20 \times 30$ & 2.50 & 49.3 & 5.0 & 19.62 & 1016 & 986 & 3.04 \\
\hline 02 & 58.9 & $20 \times 30$ & 3.06 & 49.3 & 5.0 & 19.62 & 1039 & 1009 & 2.97 \\
\hline 03 & 62.4 & $20 \times 30$ & 2.62 & 49.3 & 5.0 & 19.62 & 917 & 890 & 3.03 \\
\hline 04 & 52.0 & $20 \times 30$ & 2.58 & 49.3 & 5.0 & 19.62 & 867 & 843 & 2.85 \\
\hline 05 & 52.0 & $20 \times 30$ & 2.64 & 49.3 & 5.0 & 19.62 & 666 & 644 & 3.42 \\
\hline 06 & 58.9 & $20 \times 30$ & 3.22 & 49.3 & 5.0 & 19.62 & 741 & 708 & 4.66 \\
\hline 07 & 62.4 & $20 \times 30$ & 2.62 & 49.3 & 5.0 & 19.62 & 604 & 580 & 4.14 \\
\hline 08 & 65.8 & $20 \times 30$ & 2.42 & 49.3 & 5.0 & 19.62 & 564 & 541 & 4.25 \\
\hline 09 & 59.9 & $20 \times 30$ & 2.98 & 51.9 & 5.0 & 8.04 & 714 & 702 & 1.71 \\
\hline 10 & 62.4 & $20 \times 30$ & 3.37 & 51.9 & 5.0 & 8.04 & 737 & 722 & 2.08 \\
\hline 11 & 65.8 & $20 \times 30$ & 3.18 & 51.9 & 5.0 & 8.04 & 671 & 657 & 2.13 \\
\hline 12 & 58.9 & $20 \times 30$ & 3.09 & 51.9 & 5.0 & 8.04 & 409 & 390 & 4.87 \\
\hline 13 & 62.4 & $20 \times 30$ & 3.40 & 51.9 & 5.0 & 8.04 & 407 & 387 & 5.17 \\
\hline 14 & 65.8 & $20 \times 30$ & 3.60 & 51.9 & 5.0 & 8.04 & 397 & 377 & 5.31 \\
\hline 15 & 95.3 & $12 \times 20$ & 3.37 & 52.0 & 3.0 & 8.04 & 187 & 183 & 2.19 \\
\hline 16 & 103.9 & $12 \times 20$ & 3.41 & 52.0 & 3.0 & 8.04 & 166 & 162 & 2.47 \\
\hline 17 & 109.7 & $12 \times 20$ & 3.55 & 52.0 & 3.0 & 8.04 & 156 & 153 & 1.96 \\
\hline 18 & 95.3 & $12 \times 20$ & 3.41 & 52.0 & 3.0 & 8.04 & 129 & 126 & 2.38 \\
\hline 19 & 103.9 & $12 \times 20$ & 3.32 & 52.0 & 3.0 & 8.04 & 115 & 112 & 2.68 \\
\hline 20 & 109.7 & $12 \times 20$ & 3.50 & 52.0 & 3.0 & 8.04 & 110 & 108 & 1.85 \\
\hline 21 & 58.9 & $20 \times 30$ & 7.70 & 53.1 & 5.0 & 8.04 & 1436 & 1400 & 2.57 \\
\hline 22 & 62.4 & $20 \times 30$ & 7.58 & 53.1 & 5.0 & 8.04 & 1330 & 1295 & 2.70 \\
\hline 23 & 65.8 & $20 \times 30$ & 7.63 & 53.1 & 5.0 & 8.04 & 1251 & 1217 & 2.79 \\
\hline 24 & 58.9 & $20 \times 30$ & 7.53 & 53.1 & 5.0 & 8.04 & 567 & 536 & 5.78 \\
\hline 25 & 62.4 & $20 \times 30$ & 7.67 & 53.1 & 5.0 & 8.04 & 542 & 511 & 6.07 \\
\hline 26 & 65.8 & $20 \times 30$ & 7.69 & 53.1 & 5.0 & 8.04 & 514 & 485 & 5.98 \\
\hline
\end{tabular}

TABELA 07 - FCN: Dados e resultados para pilares de seção retangular - Cálculo da carga última

\begin{tabular}{|c|c|c|c|c|c|c|c|c|c|}
\hline $\begin{array}{c}\text { Pilar } \\
\mathrm{n}^{\circ}\end{array}$ & $\begin{array}{c}\lambda x \\
\text { adm. }\end{array}$ & $\begin{array}{l}\text { Seção } \\
\mathrm{cm} \times c \mathrm{~cm}\end{array}$ & $\begin{array}{c}\boldsymbol{f}_{\mathrm{cd}} \\
\mathrm{kN} / \mathrm{cm}^{2}\end{array}$ & $\begin{array}{c}\boldsymbol{f}_{\mathrm{yd}} \\
\mathrm{kN} / \mathrm{cm}^{2}\end{array}$ & $\begin{array}{l}\text { ex } \\
\mathrm{cm}\end{array}$ & $\begin{array}{c}\text { As } \\
\mathrm{Cm}^{2}\end{array}$ & $\begin{array}{c}\mathrm{Pu}_{\text {(PPADRAO }} \\
\text { k } \\
\mathrm{kN}\end{array}$ & $\begin{array}{c}P_{u(E X A T} \\
\text { o) } \\
k N\end{array}$ & $\begin{array}{c}\text { Diferença } \\
\%\end{array}$ \\
\hline 01 & 77.9 & $20 \times 30$ & 2.50 & 49.3 & 5.0 & 19.62 & 739 & 725 & 1.93 \\
\hline 02 & 86.6 & $20 \times 30$ & 3.06 & 49.3 & 5.0 & 19.62 & 648 & 638 & 1.57 \\
\hline 03 & 95.3 & $20 \times 30$ & 2.62 & 49.3 & 5.0 & 19.62 & 574 & 563 & 1.95 \\
\hline 04 & 103.9 & $20 \times 30$ & 2.58 & 49.3 & 5.0 & 19.62 & 510 & 500 & 2.00 \\
\hline 05 & 112.6 & $20 \times 30$ & 2.64 & 49.3 & 5.0 & 19.62 & 455 & 446 & 2.02 \\
\hline 06 & 121.2 & $20 \times 30$ & 3.22 & 49.3 & 5.0 & 19.62 & 407 & 399 & 2.01 \\
\hline 07 & 77.9 & $20 \times 30$ & 2.98 & 51.9 & 5.0 & 8.04 & 559 & 546 & 2.38 \\
\hline 08 & 86.6 & $20 \times 30$ & 3.37 & 51.9 & 5.0 & 8.04 & 481 & 471 & 2.12 \\
\hline 09 & 95.3 & $20 \times 30$ & 3.18 & 51.9 & 5.0 & 8.04 & 416 & 407 & 2.21 \\
\hline 10 & 103.9 & $20 \times 30$ & 3.09 & 51.9 & 5.0 & 8.04 & 361 & 353 & 2.27 \\
\hline 11 & 112.6 & $20 \times 30$ & 3.40 & 51.9 & 5.0 & 8.04 & 315 & 308 & 2.27 \\
\hline 12 & 121.2 & $20 \times 30$ & 3.60 & 51.9 & 5.0 & 8.04 & 276 & 270 & 2.22 \\
\hline 13 & 129.9 & $12 \times 20$ & 3.37 & 52.0 & 3.0 & 8.04 & 116 & 114 & 1.75 \\
\hline 14 & 144.4 & $12 \times 20$ & 3.41 & 52.0 & 3.0 & 8.04 & 97 & 96 & 1.04 \\
\hline 15 & 158.8 & $12 \times 20$ & 3.55 & 52.0 & 3.0 & 8.04 & 82 & 81 & 1.23 \\
\hline 16 & 173.2 & $12 \times 20$ & 3.41 & 52.0 & 3.0 & 8.04 & 70 & 69 & 1.45 \\
\hline 17 & 187.6 & $12 \times 20$ & 3.32 & 52.0 & 3.0 & 8.04 & 61 & 60 & 1.67 \\
\hline 18 & 202.1 & $12 \times 20$ & 3.50 & 52.0 & 3.0 & 8.04 & 53 & 52 & 1.92 \\
\hline 19 & 77.9 & $20 \times 30$ & 7.70 & 53.1 & 5.0 & 8.04 & 989 & 959 & 3.13 \\
\hline 20 & 86.6 & $20 \times 30$ & 7.58 & 53.1 & 5.0 & 8.04 & 839 & 813 & 3.20 \\
\hline 21 & 95.3 & $20 \times 30$ & 7.63 & 53.1 & 5.0 & 8.04 & 717 & 694 & 3.31 \\
\hline 22 & 103.9 & $20 \times 30$ & 7.53 & 53.1 & 5.0 & 8.04 & 618 & 597 & 3.52 \\
\hline 23 & 112.6 & $20 \times 30$ & 7.67 & 53.1 & 5.0 & 8.04 & 537 & 518 & 3.67 \\
\hline 24 & 121.2 & $20 \times 30$ & 7.69 & 53.1 & 5.0 & 8.04 & 469 & 453 & 3.53 \\
\hline
\end{tabular}


A partir dessa análise, é possível observar que fatores como taxa de armadura e resistência do concreto exercem influência considerável sobre o comportamento dos pilares.

Também foi verificado que, obedecendo as limitações de geometria, distribuição da armadura e carregamento para aplicação do processo do pilar padrão, as diferenças encontradas no cálculo da carga última entre os processos Exato e do Pilar Padrão foram muito pequenas, chamando a atenção para o fato de que, pela recomendação da NB1, o uso do processo do Pilar Padrão se torna limitado não por causa da consideração da não-linearidade geométrica de forma aproximada considerando que a deformada da barra seja senoidal, mas sim, provavelmente, por causa da consideração da não-linearidade física de forma aproximada, através da expressão recomendada para cálculo da curvatura última na seção crítica.

Como consequência, outros ensaios foram realizados com o intuito de comparar os valores da curvatura última calculados através da norma e através do SISTEMA FLEXOR com o programa VERIFIC_PPADRAO. Esse estudo foi feito da forma descrita a seguir.

\subsubsection{Comparação entre Valores de Curvatura Última}

Para comparar valores de curvatura última segundo dois processos diferentes de cálculo, é necessário fixar todos os outros parâmetros envolvidos, para que apenas o valor curvatura fique livre para variar. Sabendo disso, e com base nos valores de carga última já encontrados e indicados na TABELA 04, foi fixada para cada pilar das 3 séries uma carga de dimensionamento e, através dessa carga, foi possível encontrar o valor da curvatura última correspondente.

Os valores da curvatura última para as cargas de dimensionamento definidas a partir dos valores da carga última, segundo a NB1, foram obtidos de acordo com a recomendação do Texto para Revisão da NB-1 (1997), expressões (62) e (63), através dos quais, foi dimensionada a armadura, de acordo com os ábacos encontrados em VENTURINI \& RODRIGUES (1996).

$$
\begin{aligned}
& \frac{1}{r}=\frac{2 \cdot 10^{-3}}{h_{x} \cdot v} \leq \frac{5 \cdot 10^{-3}}{h_{x}} \\
& v=\frac{P_{\text {dim }}}{f_{c d} \cdot A_{c}}
\end{aligned}
$$


A partir dos valores da carga de dimensionamento e da armadura fixada, foi possível elaborar um arquivo de entrada de dados para o programa VERIFIC_PPADRAO e, a partir dos resultados, obter a comparação.

Os valores utilizados para análise da curvatura última encontram-se na TABELA 08, cuja relação é obtida apenas através da divisão direta do valor obtido através da norma, pelo valor obtido com o programa VERIFIC_PPADRAO, que apresenta o valor exato considerando a linha elástica senoidal. Os pilares da TABELA 08 são os mesmos da TABELA 04, diferindo apenas no valor da taxa de armadura.

TABELA 08 - FCN: Dados e resultados para pilares de seção retangular - Cálculo da curvatura última

\begin{tabular}{|c|c|c|c|c|c|c|c|c|c|}
\hline $\begin{array}{c}\text { Pilar } \\
n^{\circ}\end{array}$ & $\begin{array}{c}\lambda x \\
\operatorname{adm}\end{array}$ & $\begin{array}{l}\text { Seção } \\
\mathrm{cm} \times c \mathrm{~m}\end{array}$ & $\begin{array}{l}\mathbf{P}_{\text {dim }} \\
\mathrm{kN}\end{array}$ & $\begin{array}{c}f_{\text {cd }} \\
\mathrm{kN} / \mathrm{cm}^{2}\end{array}$ & $\begin{array}{c}f_{y d} \\
\mathrm{kN} / \mathrm{cm}^{2}\end{array}$ & $\begin{array}{l}\text { As } \\
\mathrm{cm}^{2}\end{array}$ & $\begin{array}{c}(1 / \mathrm{r})_{\mathrm{u}(\text { NORMA })} \\
\mathrm{cm}^{-1}\end{array}$ & $\begin{array}{c}(1 / \mathrm{r})_{\mathrm{u}(\text { PPADRAO })} \\
\mathrm{cm}^{-1}\end{array}$ & $\begin{array}{c}\text { Relação } \\
\text { adm. }\end{array}$ \\
\hline 01 & 60.6 & $20 \times 30$ & 543 & 2.78 & 43.48 & 4.99 & $2.5000 \mathrm{E}-04$ & $1.1649 \mathrm{E}-04$ & 2.15 \\
\hline 02 & 69.3 & $20 \times 30$ & 473 & 2.78 & 43.48 & 5.37 & $2.5000 \mathrm{E}-04$ & $9.9803 \mathrm{E}-05$ & 2.50 \\
\hline 03 & 77.9 & $20 \times 30$ & 408 & 2.78 & 43.48 & 4.99 & $2.5000 \mathrm{E}-04$ & 9.3787E-05 & 2.67 \\
\hline 04 & 86.6 & $20 \times 30$ & 355 & 2.78 & 43.48 & 5.37 & $2.5000 \mathrm{E}-04$ & 7.9176E-05 & 3.16 \\
\hline 05 & 95.3 & $20 \times 30$ & 308 & 2.78 & 43.48 & 5.75 & $2.5000 \mathrm{E}-04$ & $6.5396 \mathrm{E}-05$ & 3.82 \\
\hline 06 & 103.9 & $20 \times 30$ & 269 & 2.78 & 43.48 & 6.14 & $2.5000 \mathrm{E}-04$ & $5.5477 \mathrm{E}-05$ & 4.51 \\
\hline 07 & 112.6 & $20 \times 30$ & 236 & 2.78 & 43.48 & 6.52 & $2.5000 \mathrm{E}-04$ & $4.6548 \mathrm{E}-05$ & 5.37 \\
\hline 08 & 121.2 & $20 \times 30$ & 208 & 2.78 & 43.48 & 6.91 & $2.5000 \mathrm{E}-04$ & $3.9074 \mathrm{E}-05$ & 6.40 \\
\hline 09 & 57.7 & $12 \times 20$ & 261 & 2.91 & 43.48 & 2.89 & $4.1667 \mathrm{E}-04$ & $2.3804 \mathrm{E}-04$ & 1.75 \\
\hline 10 & 72.2 & $12 \times 20$ & 207 & 2.91 & 43.48 & 2.73 & $4.1667 \mathrm{E}-04$ & $2.2041 \mathrm{E}-04$ & 1.89 \\
\hline 11 & 86.6 & $12 \times 20$ & 165 & 2.91 & 43.48 & 2.73 & $4.1667 \mathrm{E}-04$ & $2.1246 \mathrm{E}-04$ & 1.96 \\
\hline 12 & 101.0 & $12 \times 20$ & 131 & 2.91 & 43.48 & 2.89 & $4.1667 \mathrm{E}-04$ & $1.3897 \mathrm{E}-04$ & 3.00 \\
\hline 13 & 115.5 & $12 \times 20$ & 105 & 2.91 & 43.48 & 2.89 & $4.1667 \mathrm{E}-04$ & $1.1361 \mathrm{E}-04$ & 3.67 \\
\hline 14 & 129.9 & $12 \times 20$ & 85 & 2.91 & 43.48 & 3.21 & $4.1667 \mathrm{E}-04$ & $8.0973 \mathrm{E}-05$ & 5.15 \\
\hline 15 & 144.4 & $12 \times 20$ & 71 & 2.91 & 43.48 & 3.05 & $4.1667 \mathrm{E}-04$ & 7.4398E-05 & 5.60 \\
\hline 16 & 158.8 & $12 \times 20$ & 59 & 2.91 & 43.48 & 3.21 & $4.1667 \mathrm{E}-04$ & $5.6438 \mathrm{E}-05$ & 7.38 \\
\hline 17 & 173.2 & $12 \times 20$ & 50 & 2.91 & 43.48 & 3.37 & $4.1667 \mathrm{E}-04$ & $4.3692 \mathrm{E}-05$ & 9.54 \\
\hline 18 & 187.6 & $12 \times 20$ & 44 & 2.91 & 43.48 & 3.53 & $4.1667 \mathrm{E}-04$ & $3.9556 \mathrm{E}-05$ & 10.53 \\
\hline 19 & 202.1 & $12 \times 20$ & 37 & 2.91 & 43.48 & 3.53 & $4.1667 \mathrm{E}-04$ & $3.0617 \mathrm{E}-05$ & 13.61 \\
\hline 20 & 60.6 & $20 \times 30$ & 954 & 6.49 & 43.48 & 5.37 & $2.5000 \mathrm{E}-04$ & $7.3337 \mathrm{E}-05$ & 3.41 \\
\hline 21 & 69.3 & $20 \times 30$ & 816 & 6.49 & 43.48 & 4.48 & $2.5000 \mathrm{E}-04$ & $6.5918 \mathrm{E}-05$ & 3.79 \\
\hline 22 & 77.9 & $20 \times 30$ & 693 & 6.49 & 43.48 & 6.27 & $2.5000 \mathrm{E}-04$ & $5.1686 \mathrm{E}-05$ & 4.84 \\
\hline 23 & 86.6 & $20 \times 30$ & 590 & 6.49 & 43.48 & 8.96 & $2.5000 \mathrm{E}-04$ & 4.0142E-05 & 6.23 \\
\hline 24 & 95.3 & $20 \times 30$ & 505 & 6.49 & 43.48 & 8.06 & $2.5000 \mathrm{E}-04$ & $3.4921 \mathrm{E}-05$ & 7.16 \\
\hline 25 & 103.9 & $20 \times 30$ & 435 & 6.49 & 43.48 & 8.96 & $2.5000 \mathrm{E}-04$ & $2.9247 \mathrm{E}-05$ & 8.55 \\
\hline 26 & 112.6 & $20 \times 30$ & 378 & 6.49 & 43.48 & 9.85 & $2.5000 \mathrm{E}-04$ & $2.4530 \mathrm{E}-05$ & 10.19 \\
\hline 27 & 121.2 & $20 \times 30$ & 332 & 6.49 & 43.48 & 8.06 & $2.5000 \mathrm{E}-04$ & $2.2612 \mathrm{E}-05$ & 11.06 \\
\hline
\end{tabular}




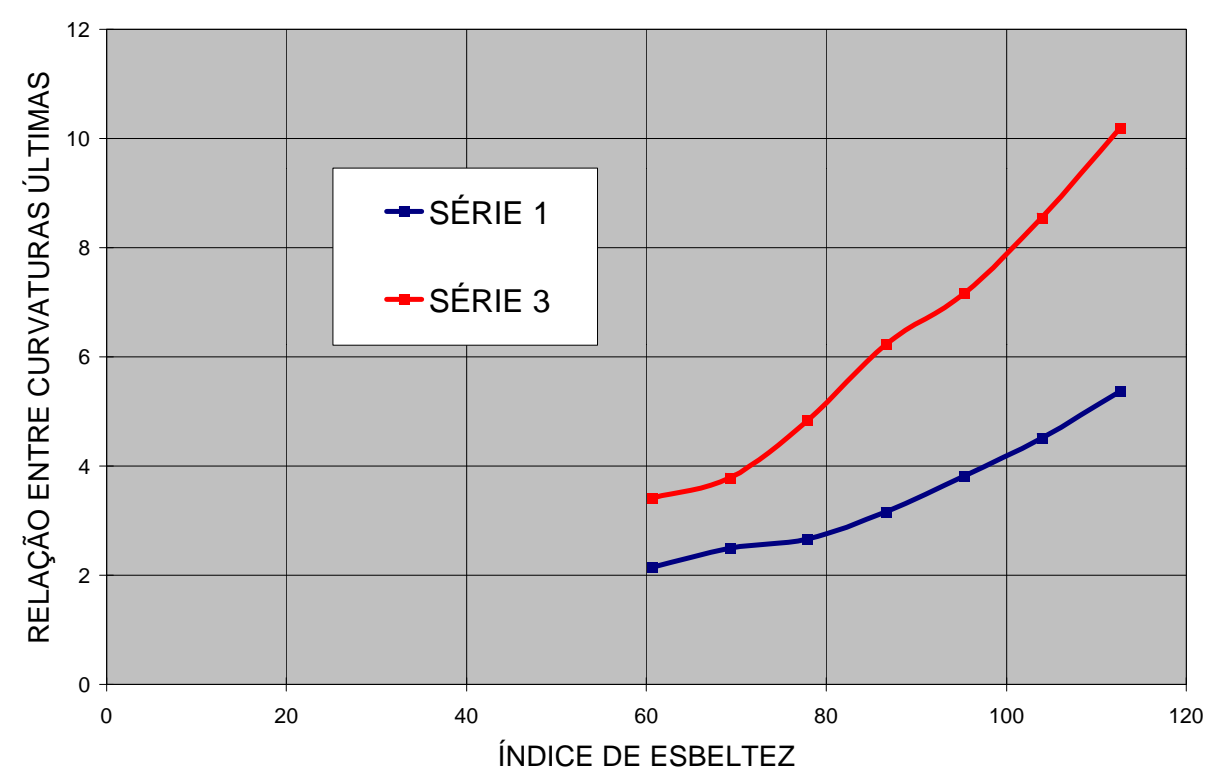

FIGURA 39 - Gráfico relativo a $1^{\underline{a}}$ e a $3^{\text {a }}$ séries de pilares da TABELA 08

Um dos fatores cuja influência mais ressalta aos olhos é o índice de esbeltez. Analisando os resultados apresentados pela TABELA 08 e observando 0 gráfico da FIGURA 39, percebe-se que os valores da curvatura obtidos através do processo recomendado pela norma, apresentam-se muito maiores do que os respectivos valores obtidos através do programa VERIFIC_PPADRAO, mesmo submetendo as curvaturas ao truncamento, como mostra a expressão (62). Em alguns casos, essa diferença se torna absurda, casos estes que compreendem índices de esbeltez elevados.

Através do gráfico da FIGURA 39 que apresenta o resultado de duas séries de pilares de mesmas características geométricas com resistências diferentes, também fica evidente a influência da resistência do concreto na divergência entre os resultados. Quanto maior é a resistência do concreto, maior será a diferença entre os valores encontrados.

Desse estudo, percebe-se que é justificável limitar o uso da expressão (62), devido ao fato de que a mesma depende apenas de dois fatores: carga e dimensão da seção transversal do pilar. Uma alternativa é realizar cálculos mais complexos, como os que são feitos pelo programa ou encontrar uma nova expressão que ajuste os resultados em função do maior número possível de fatores que influenciam no comportamento dos pilares. 


\subsubsection{Relação entre Valores de Carga Última}

Com o intuito de estudar mais a fundo a influência da esbeltez na diminuição da capacidade resistente de pilares à flexo-compressão normal, foi realizada uma série de ensaios de pilares de mesma seção transversal e de comprimentos variados, de forma que se pudesse obter uma relação entre a carga última de pilares de índice de esbeltez entre 60 e 140, e a carga última de pilares com índice de esbeltez 40, casos em que o efeito de $2^{\text {a }}$ ordem pode ser desprezado.

Esses ensaios foram realizados para seções de 20x20, 20x40 e 20x60 e, a partir deles, foi obtida uma relação entre carga última e índice de esbeltez, denominada coeficiente de minoração, para efeito de pré-dimensionamento. Os resultados dessa análise, encontram-se nas TABELAS 09 e 10, e a expressão correspondente ao ajuste para os coeficientes de minoração obtidos, encontra-se explicitada através da equação (64).

TABELA 09 - FCN: Dados e resultados da série de pilares - Cálculo da carga última

\begin{tabular}{|c|c|c|c|c|c|c|c|c|}
\hline $\begin{array}{c}\text { Pilar } \\
\mathrm{n}^{\circ}\end{array}$ & $\begin{array}{c}\lambda_{\mathbf{x}} \\
\mathrm{adm} .\end{array}$ & $\mathbf{e}$ & $\mathrm{e}$ & $\boldsymbol{f}_{\mathrm{cd}}$ & $\boldsymbol{f}_{\text {yd }}$ & As & \multicolumn{3}{|c|}{ CARGA ÚLTIMA em kN } \\
\cline { 8 - 10 } & $\mathrm{kN} / \mathrm{cm}^{2}$ & $\mathrm{kN} / \mathrm{cm}^{2}$ & $\mathrm{~cm}^{2}$ & $(20 \times 20)$ & $(20 \times 40)$ & $(20 \times 60)$ \\
\hline 01 & 40 & 2.0 & 2.14 & 43.48 & 16.08 & 1104 & 1692 & 2277 \\
\hline 02 & 60 & 2.0 & 2.14 & 43.48 & 16.08 & 985 & 1488 & 1986 \\
\hline 03 & 80 & 2.0 & 2.14 & 43.48 & 16.08 & 815 & 1196 & 1586 \\
\hline 04 & 100 & 2.0 & 2.14 & 43.48 & 16.08 & 622 & 915 & 1216 \\
\hline 05 & 120 & 2.0 & 2.14 & 43.48 & 16.08 & 473 & 699 & 929 \\
\hline 06 & 140 & 2.0 & 2.14 & 43.48 & 16.08 & 367 & 542 & 722 \\
\hline
\end{tabular}

TABELA 10 - FCN: Resultados da série de pilares em termos de coeficiente de minoração

\begin{tabular}{|c|c|c|c|c|}
\hline \multirow{2}{*}{$\begin{array}{c}\text { Pilar } \\
\mathrm{n}^{\circ}\end{array}$} & \multicolumn{4}{|c|}{ COEFICIENTE DE MINORAÇÃO DA CARGA $(\gamma)$} \\
\cline { 2 - 5 } & $(20 \times 20)$ & $(20 \times 60)$ & $(20 \times 40)$ & MÉDIA \\
\hline 01 & 1.00 & 1.00 & 1.00 & 1.00 \\
\hline 02 & 0.89 & 0.88 & 0.87 & 0.88 \\
\hline 03 & 0.74 & 0.71 & 0.70 & 0.71 \\
\hline 04 & 0.56 & 0.54 & 0.53 & 0.55 \\
\hline 05 & 0.43 & 0.41 & 0.41 & 0.42 \\
\hline 06 & 0.33 & 0.32 & 0.32 & 0.32 \\
\hline
\end{tabular}

$$
\gamma=1.07+2.73 \cdot 10^{-3} \cdot \lambda-1.32 \cdot 10^{-4} \cdot \lambda^{2}+5.33 \cdot 10^{-7} \cdot \lambda^{3}
$$




\subsection{ANÁLISE DA FLEXO-COMPRESSÃO OBLÍQUA (FCO)}

De acordo com as análises feitas sobre a flexo-compressão normal é possível detectar a influência de vários fatores sobre o comportamento dos pilares, e mais, que existe uma certa dificuldade em encontrar expressões que traduzam essa influência de forma a validar para um número maior de casos, a expressão para cálculo da curvatura segundo o processo aproximado do Pilar Padrão. Daí a importância de verificar a influência desses fatores também na flexo-compressão oblíqua.

\subsubsection{Comparação entre Valores de Carga Última}

A análise da flexo-compressão oblíqua foi iniciada com a comparação entre valores de carga última, obtidos através dos programas GERAL_EXATO e GERAL_PPADRAO do SISTEMA FLEXOR, com o intuito de estudar a validade do Processo do Pilar Padrão, no caso de momento aplicado às duas direções x e y. Os pilares e suas características, como também os resultados dessa análise, encontram-se na TABELA 11. Na FIGURA 40, encontram-se esquematizadas, as seções dos pilares contidos na TABELA 11.

TABELA 11 - FCO: Dados e resultados para pilares de seção retangular - Cálculo da carga última

\begin{tabular}{|c|c|c|c|c|c|c|c|c|c|c|c|}
\hline \multirow{2}{*}{$\begin{array}{c}\text { Pilar } \\
\mathrm{n}^{\circ}\end{array}$} & \multirow{2}{*}{$\begin{array}{c}\text { Ac } \\
\mathrm{cm} \times \mathrm{cm}\end{array}$} & \multirow{2}{*}{$\begin{array}{c}f_{\text {cd }} \\
\mathrm{kN} / \mathrm{cm}^{2}\end{array}$} & \multirow{2}{*}{$\begin{array}{c}f_{y d} \\
k N / \mathrm{cm}^{2}\end{array}$} & \multirow{2}{*}{$\begin{array}{l}\text { As } \\
\mathrm{cm}^{2}\end{array}$} & $\lambda x$ & $\lambda_{Y}$ & $e_{i x}$ & $e_{i y}$ & \multicolumn{2}{|c|}{ Pu (kN) } & \multirow{2}{*}{$\begin{array}{c}\text { Diferença } \\
\%\end{array}$} \\
\hline & & & & & \multicolumn{2}{|c|}{$\mathrm{adm}$} & \multicolumn{2}{|c|}{$\mathrm{Cm}$} & EXATO & PADRAO & \\
\hline 1 & $20 \times 60$ & 2.14 & 43.48 & 20.11 & 40 & 13 & 2 & 2 & 2326 & 2349 & 0.98 \\
\hline 2 & $20 \times 60$ & 2.14 & 43.48 & 20.11 & 60 & 20 & 2 & 2 & 1992 & 2032 & 1.97 \\
\hline 3 & $20 \times 60$ & 2.14 & 43.48 & 20.11 & 80 & 27 & 2 & 2 & 1580 & 1621 & 2.53 \\
\hline 4 & $20 \times 60$ & 2.14 & 43.48 & 20.11 & 100 & 33 & 2 & 2 & 1202 & 1240 & 3.06 \\
\hline 5 & $20 \times 60$ & 2.14 & 43.48 & 20.11 & 120 & 40 & 2 & 2 & 916 & 947 & 3.27 \\
\hline 6 & $20 \times 60$ & 2.14 & 43.48 & 20.11 & 140 & 47 & 2 & 2 & 710 & 736 & 3.53 \\
\hline 7 & $20 \times 20$ & 2.14 & 43.48 & 20.11 & 40 & 40 & 2 & 2 & 998 & 1017 & 1.87 \\
\hline 8 & $20 \times 20$ & 2.14 & 43.48 & 20.11 & 60 & 60 & 2 & 2 & 828 & 848 & 2.36 \\
\hline 9 & $20 \times 20$ & 2.14 & 43.48 & 20.11 & 80 & 80 & 2 & 2 & 645 & 664 & 2.86 \\
\hline 10 & $20 \times 20$ & 2.14 & 43.48 & 20.11 & 100 & 100 & 2 & 2 & 495 & 506 & 2.17 \\
\hline 11 & $20 \times 20$ & 2.14 & 43.48 & 20.11 & 120 & 120 & 2 & 2 & 378 & 385 & 1.82 \\
\hline 12 & $20 \times 20$ & 2.14 & 43.48 & 20.11 & 140 & 140 & 2 & 2 & 294 & 300 & 2.00 \\
\hline 13 & $20 \times 60$ & 2.14 & 43.48 & 20.11 & 40 & 13 & 5 & 2 & 1527 & 1551 & 1.55 \\
\hline 14 & $20 \times 60$ & 2.14 & 43.48 & 20.11 & 60 & 20 & 5 & 2 & 1240 & 1267 & 2.13 \\
\hline 15 & $20 \times 60$ & 2.14 & 43.48 & 20.11 & 80 & 27 & 5 & 2 & 943 & 961 & 1.87 \\
\hline 16 & $20 \times 60$ & 2.14 & 43.48 & 20.11 & 100 & 33 & 5 & 2 & 705 & 719 & 1.95 \\
\hline 17 & $20 \times 60$ & 2.14 & 43.48 & 20.11 & 120 & 40 & 5 & 2 & 534 & 545 & 2.02 \\
\hline 18 & $20 \times 60$ & 2.14 & 43.48 & 20.11 & 140 & 47 & 5 & 2 & 414 & 421 & 1.66 \\
\hline 19 & $20 \times 20$ & 2.14 & 43.48 & 20.11 & 40 & 40 & 5 & 2 & 734 & 748 & 1.87 \\
\hline 20 & $20 \times 20$ & 2.14 & 43.48 & 20.11 & 60 & 60 & 5 & 2 & 621 & 639 & 2.82 \\
\hline 21 & $20 \times 20$ & 2.14 & 43.48 & 20.11 & 80 & 80 & 5 & 2 & 503 & 518 & 2.90 \\
\hline 22 & $20 \times 20$ & 2.14 & 43.48 & 20.11 & 100 & 100 & 5 & 2 & 400 & 411 & 2.68 \\
\hline 23 & $20 \times 20$ & 2.14 & 43.48 & 20.11 & 120 & 120 & 5 & 2 & 318 & 327 & 2.75 \\
\hline 24 & $20 \times 20$ & 2.14 & 43.48 & 20.11 & 140 & 140 & 5 & 2 & 255 & 261 & 2.30 \\
\hline
\end{tabular}




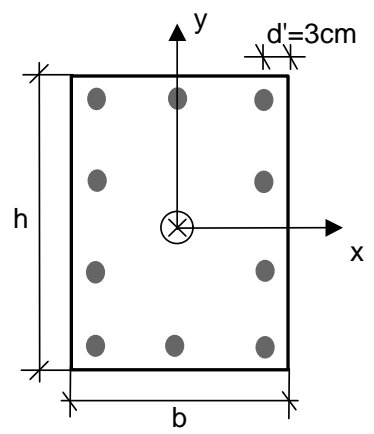

FIGURA 40 - FCO: Esquema das seções transversais dos pilares ensaiados

Observando os resultados apresentados na TABELA 11, vê-se que a qualidade se mantém, necessitando assim, novamente, de um estudo sobre as curvaturas últimas, de forma a se tentar otimizar o uso da expressão proposta pelo Texto para Revisão da NB-1 (1997).

\subsubsection{Comparação entre Valores de CurVatura Última}

Como dito anteriormente na análise da flexo-compressão normal, para a avaliação de um determinada parâmetro, é necessário fixar os demais, para que apenas o parâmetro em estudo possa variar. Portanto, um estudo adequado para análise da curvatura última deve partir de um valor de taxa mecânica da armadura, definido através da curvatura última dada pela equação (62), aplicada às duas direções ( $x$ e y), ou seja, decompondo-se a flexão oblíqua em duas flexões normais, obtendo-se $1 / r_{x}$ e1/ry e, a partir desses valores, os valores de $\mu_{x}$ e $\mu_{y}$ e, consequentemente de $\omega$. Do valor de $\omega$, é possível encontrar as curvaturas correspondentes a essa mesma situação, através do programa VERIFIC_PPADRAO.

Para tal, é necessário definir uma armadura qualquer para cálculo da carga última, ou seja, para os valores de $v$, com o intuito de perceber as diferenças que surgem nos valores de carga e curvatura, à medida que o comprimento dos pilares e, portanto sua esbeltez, é aumentada. Nessa análise, foram utilizados como carga última, os valores encontrados a partir do programa GERAL_EXATO para pilares

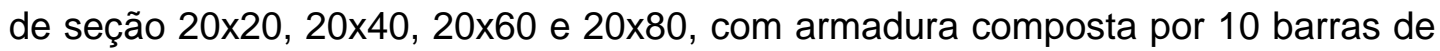
16mm (de acordo com o arranjo mostrado na FIGURA 40), sob excentricidade inicial igual a 2 centímetros na direção y e, na direção $x$, foram considerados os valores 2, 3, 4 e 5 centímetros. 
Tendo em mãos tais valores, foi utilizada como carga de dimensionamento, o valor correspondente a $77 \%$ da carga última, que corresponde ao valor último dividido pelo fator 1,3. Essa precaução foi tomada como medida de segurança para que, após dimensionada a seção, não houvesse risco da carga de dimensionamento corresponder a um valor maior do que o valor correspondente à sua capacidade máxima.

A partir da carga de dimensionamento, foi calculada a taxa de armadura através da expressão recomendada pelo Texto para Revisão da NB-1 (1997) e, com essa nova taxa, calculada a área da armadura, que fora localizada segundo o mesmo esquema da anterior. Com essa nova armadura e, sob o mesmo carregamento, foi obtido, de acordo com o programa VERIFIC_PPADRAO, os valores de curvatura, para então serem comparados com os valores últimos dados pela expressão recomendada pelo pelo Texto para Revisão da NB-1 (1997) sem submetê-los ao truncamento.

Os resultados dessa análise encontram-se nas TABELAS 12, 13, 14 e 15 mostradas a seguir.

Nas FIGURAS 41, 42, 43 e 44, estão mostradas graficamente as diferenças encontradas entre os valores de curvatura última, para os pilares das TABELAS 12 a 15 , respectivamente, com valores de excentricidade variando na direção mais crítica, direção x. 
TABELA 12 - FCO: Comparação entre os valores de curvatura última para os pilares de seção 20x20, com $e_{x}=2,3,4$ e $5 \mathrm{~cm}$

\begin{tabular}{|c|c|c|c|c|c|c|c|c|c|}
\hline $\begin{array}{l}\text { Pilar } \\
\mathrm{n}^{\circ}\end{array}$ & $\begin{array}{l}\text { seção } \\
\text { cmxcm }\end{array}$ & $\begin{array}{c}\lambda_{\mathbf{x}} \\
\mathrm{adm}\end{array}$ & $\begin{array}{r}\lambda_{\mathrm{y}} \\
\mathrm{adm}\end{array}$ & $\begin{array}{l}\mathbf{P}_{\text {dim }} \\
\mathrm{kN}\end{array}$ & v & $\begin{array}{c}\text { NB1 } \\
\text { CURV. } \alpha_{1}\end{array}$ & $\begin{array}{l}\text { As } \\
\mathrm{cm}^{2}\end{array}$ & $\begin{array}{c}\text { VERIFIC_PPADRA } \\
\text { O } \\
\text { CURV. } \alpha_{2}\end{array}$ & $\begin{array}{c}\text { Relação } \alpha \\
\text { adm }\end{array}$ \\
\hline 01 & $20 \times 20$ & 20 & 20 & 857 & 1.00 & 1.4127E-04 & 13.78 & 1.0855E-04 & 1.30 \\
\hline 02 & $20 \times 20$ & 40 & 40 & 768 & 0.90 & 1.5769E-04 & 13.39 & $1.0911 \mathrm{E}-04$ & 1.45 \\
\hline 03 & $20 \times 20$ & 60 & 60 & 637 & 0.74 & $1.9006 \mathrm{E}-04$ & 12.99 & $1.0520 \mathrm{E}-04$ & 1.81 \\
\hline 04 & $20 \times 20$ & 80 & 80 & 496 & 0.58 & $2.4399 \mathrm{E}-04$ & 15.75 & 7.2497E-05 & 3.37 \\
\hline 05 & $20 \times 20$ & 100 & 100 & 381 & 0.44 & 3.1793E-04 & 21.85 & 4.3416E-05 & 7.32 \\
\hline 06 & $20 \times 20$ & 120 & 120 & 291 & 0.34 & 4.1633E-04 & 29.53 & $2.6226 \mathrm{E}-05$ & 15.87 \\
\hline 07 & $20 \times 20$ & 140 & 140 & 226 & 0.26 & 5.3528E-04 & 40.16 & $1.5990 \mathrm{E}-05$ & 33.48 \\
\hline 08 & $20 \times 20$ & 20 & 20 & 772 & 0.90 & $1.5690 \mathrm{E}-04$ & 13.98 & 1.1998E-04 & 1.31 \\
\hline 09 & $20 \times 20$ & 40 & 40 & 690 & 0.81 & 1.7544E-04 & 13.98 & $1.1752 \mathrm{E}-04$ & 1.49 \\
\hline 10 & $20 \times 20$ & 60 & 60 & 576 & 0.67 & $2.1011 \mathrm{E}-04$ & 15.55 & 1.1449E-04 & 1.84 \\
\hline 11 & $20 \times 20$ & 80 & 80 & 455 & 0.53 & $2.6628 \mathrm{E}-04$ & 17.32 & 7.8104E-05 & 3.41 \\
\hline 12 & $20 \times 20$ & 100 & 100 & 352 & 0.41 & $3.4361 \mathrm{E}-04$ & 22.44 & $5.0174 \mathrm{E}-05$ & 6.85 \\
\hline 13 & $20 \times 20$ & 120 & 120 & 273 & 0.32 & $4.4331 \mathrm{E}-04$ & 32.29 & 2.8969E-05 & 15.30 \\
\hline 14 & $20 \times 20$ & 140 & 140 & 215 & 0.25 & 5.6406E-04 & 44.10 & 1.7722E-05 & 31.83 \\
\hline 15 & $20 \times 20$ & 20 & 20 & 695 & 0.81 & $1.7428 \mathrm{E}-04$ & 13.78 & 1.3640E-04 & 1.28 \\
\hline 16 & $20 \times 20$ & 40 & 40 & 622 & 0.73 & 1.9477E-04 & 13.39 & $1.3811 \mathrm{E}-04$ & 1.41 \\
\hline 17 & $20 \times 20$ & 60 & 60 & 522 & 0.61 & 2.3177E-04 & 13.58 & 1.3282E-04 & 1.74 \\
\hline 18 & $20 \times 20$ & 80 & 80 & 418 & 0.49 & $2.8929 E-04$ & 16.73 & 9.5084E-05 & 3.04 \\
\hline 19 & $20 \times 20$ & 100 & 100 & 328 & 0.38 & 3.6942E-04 & 22.84 & 5.8003E-05 & 6.37 \\
\hline 20 & $20 \times 20$ & 120 & 120 & 258 & 0.30 & 4.6977E-04 & 32.88 & 3.3686E-05 & 13.95 \\
\hline 21 & $20 \times 20$ & 140 & 140 & 205 & 0.24 & 5.9163E-04 & 45.08 & 2.0595E-05 & 28.73 \\
\hline 22 & $20 \times 20$ & 20 & 20 & 696 & 0.81 & 1.7389E-04 & 16.73 & 1.5620E-04 & 1.11 \\
\hline 23 & $20 \times 20$ & 40 & 40 & 565 & 0.66 & $2.1441 \mathrm{E}-04$ & 13.98 & $1.4840 \mathrm{E}-04$ & 1.44 \\
\hline 24 & $20 \times 20$ & 60 & 60 & 478 & 0.56 & $2.5342 E-04$ & 15.75 & 1.2746E-04 & 1.99 \\
\hline 25 & $20 \times 20$ & 80 & 80 & 387 & 0.45 & 3.1287E-04 & 17.52 & 1.0339E-04 & 3.03 \\
\hline 26 & $20 \times 20$ & 100 & 100 & 308 & 0.36 & 3.9343E-04 & 24.02 & 6.3998E-05 & 6.15 \\
\hline 27 & $20 \times 20$ & 120 & 120 & 245 & 0.29 & 4.9489E-04 & 31.89 & 4.0376E-05 & 12.26 \\
\hline 28 & $20 \times 20$ & 140 & 140 & 196 & 0.23 & 6.1715E-04 & 42.13 & 2.5531E-05 & 24.17 \\
\hline
\end{tabular}

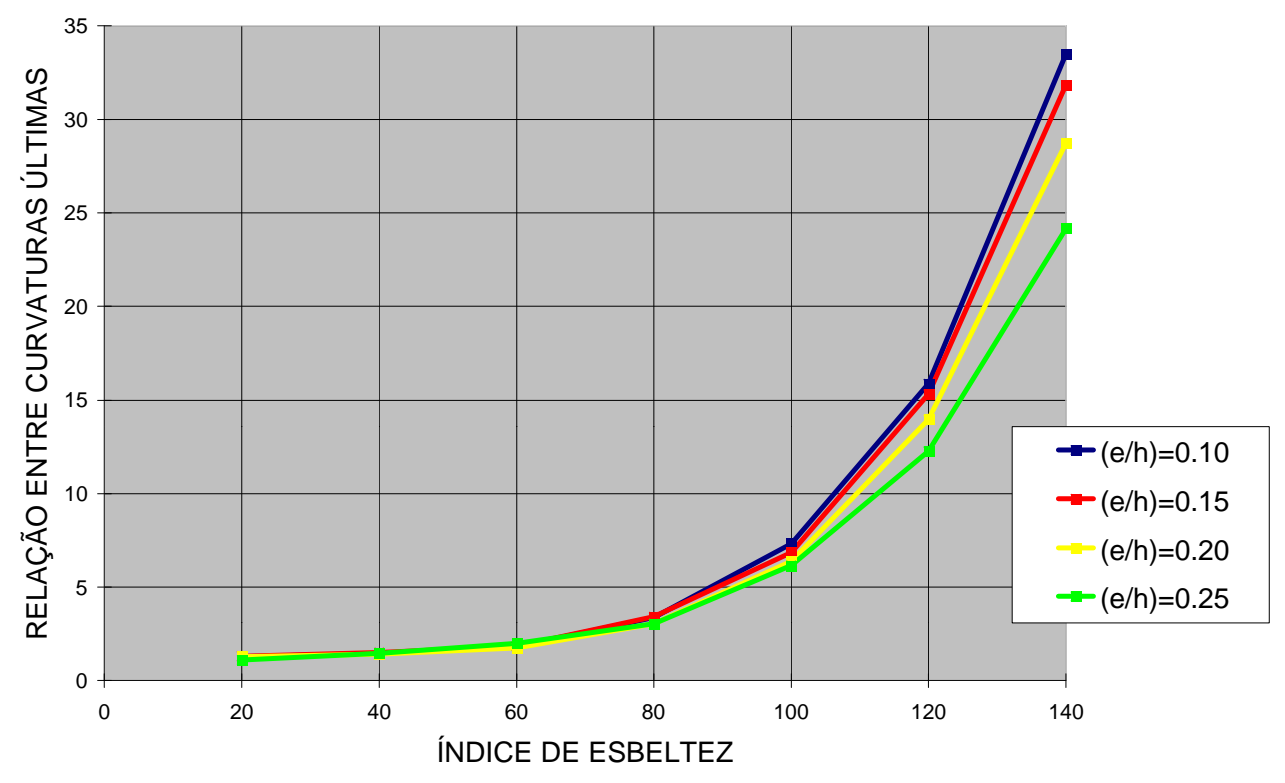

FIGURA 41 - Relação entre curvaturas últimas para seção 20x20, com ex =2, 3, 4 e 5cm 
TABELA 13 - FCO: Comparação entre os valores de curvatura última para os pilares de seção 20x40 com $e_{x}=2,3,4$ e $5 \mathrm{~cm}$

\begin{tabular}{|c|c|c|c|c|c|c|c|c|c|}
\hline $\begin{array}{l}\text { Pilar } \\
\mathrm{n}^{\circ}\end{array}$ & $\begin{array}{l}\text { seção } \\
\text { cmxcm }\end{array}$ & $\begin{array}{c}\lambda_{\mathbf{x}} \\
\mathrm{adm}\end{array}$ & $\begin{array}{c}\lambda_{y} \\
\operatorname{adm}\end{array}$ & $\begin{array}{c}P_{\text {dim }} \\
\mathrm{kN}\end{array}$ & $\begin{array}{c}v \\
\text { adm }\end{array}$ & $\begin{array}{c}\text { NB1 } \\
\text { CURV. } \alpha_{1}\end{array}$ & $\begin{array}{l}\text { As } \\
\mathrm{cm}^{2}\end{array}$ & $\begin{array}{c}\text { VERIFIC_PPADR } \\
\text { AO } \\
\text { CURV. } \alpha_{2}\end{array}$ & $\begin{array}{c}\text { Relação } \alpha \\
\text { adm }\end{array}$ \\
\hline 01 & $20 \times 40$ & 20 & 10 & 1446 & 0.84 & 1.3236E-04 & 11.81 & 8.3604E-05 & 1.58 \\
\hline 02 & $20 \times 40$ & 40 & 20 & 1327 & 0.78 & 1.4425E-04 & 11.42 & 8.2584E-05 & 1.75 \\
\hline 03 & $20 \times 40$ & 60 & 30 & 1138 & 0.66 & 1.6813E-04 & 12.21 & 7.2639E-05 & 2.31 \\
\hline 04 & $20 \times 40$ & 80 & 40 & 911 & 0.53 & $2.1016 \mathrm{E}-04$ & 13.78 & 5.6342E-05 & 3.73 \\
\hline 05 & $20 \times 40$ & 100 & 50 & 692 & 0.40 & $2.7678 \mathrm{E}-04$ & 19.29 & $3.5790 \mathrm{E}-5$ & 7.73 \\
\hline 06 & $20 \times 40$ & 120 & 60 & 526 & 0.31 & 3.6379E-04 & 28.74 & 2.1986E-05 & 16.55 \\
\hline 07 & $20 \times 40$ & 140 & 70 & 408 & 0.24 & 4.6949E-04 & 44.89 & 1.3133E-05 & 35.75 \\
\hline 08 & $20 \times 40$ & 20 & 10 & 1276 & 0.75 & 1.4999E-04 & 12.21 & 1.0124E-04 & 1.48 \\
\hline 09 & $20 \times 40$ & 40 & 20 & 1157 & 0.68 & 1.6545E-04 & 11.42 & 1.0092E-04 & 1.64 \\
\hline 10 & $20 \times 40$ & 60 & 30 & 975 & 0.57 & 1.9639E-04 & 10.63 & 9.6125E-05 & 2.04 \\
\hline 11 & $20 \times 40$ & 80 & 40 & 763 & 0.45 & $2.5084 \mathrm{E}-04$ & 14.17 & 6.5953E-05 & 3.80 \\
\hline 12 & $20 \times 40$ & 100 & 50 & 572 & 0.33 & 3.3445E-04 & 21.26 & 3.9428E-05 & 8.48 \\
\hline 13 & $20 \times 40$ & 120 & 60 & 433 & 0.25 & 4.4197E-04 & 30.71 & $2.4347 \mathrm{E}-05$ & 18.15 \\
\hline 14 & $20 \times 40$ & 140 & 70 & 334 & 0.20 & $5.7334 \mathrm{E}-04$ & 42.13 & $1.5615 \mathrm{E}-05$ & 36.72 \\
\hline 15 & $20 \times 40$ & 20 & 10 & 1128 & 0.66 & 1.6962E-04 & 12.60 & 1.1870E-04 & 1.43 \\
\hline 16 & $20 \times 40$ & 40 & 20 & 1014 & 0.59 & 1.8879E-04 & 11.42 & 1.2335E-04 & 1.53 \\
\hline 17 & $20 \times 40$ & 60 & 30 & 846 & 0.49 & $2.2621 \mathrm{E}-04$ & 12.60 & 1.0873E-04 & 2.08 \\
\hline 18 & $20 \times 40$ & 80 & 40 & 660 & 0.39 & $2.9001 \mathrm{E}-04$ & 14.96 & $8.1513 E-05$ & 3.56 \\
\hline 19 & $20 \times 40$ & 100 & 50 & 498 & 0.29 & 3.8459E-04 & 21.66 & 4.8352E-05 & 7.95 \\
\hline 20 & $20 \times 40$ & 120 & 60 & 378 & 0.22 & 5.0575E-04 & 30.71 & $2.9476 \mathrm{E}-05$ & 17.16 \\
\hline 21 & $20 \times 40$ & 140 & 70 & 294 & 0.17 & $6.5139 \mathrm{E}-04$ & 43.71 & $1.8251 \mathrm{E}-05$ & 35.69 \\
\hline 22 & $20 \times 40$ & 20 & 10 & 1002 & 0.59 & $1.9111 \mathrm{E}-04$ & 11.81 & 1.4831E-04 & 1.29 \\
\hline 23 & $20 \times 40$ & 40 & 20 & 897 & 0.52 & $2.1340 \mathrm{E}-04$ & 12.60 & $1.4140 \mathrm{E}-04$ & 1.51 \\
\hline 24 & $20 \times 40$ & 60 & 30 & 748 & 0.44 & $2.5600 \mathrm{E}-04$ & 13.39 & $1.3134 \mathrm{E}-04$ & 1.95 \\
\hline 25 & $20 \times 40$ & 80 & 40 & 588 & 0.34 & 3.2527E-04 & 16.14 & 9.9228E-05 & 3.28 \\
\hline 26 & $20 \times 40$ & 100 & 50 & 449 & 0.26 & $4.2608 \mathrm{E}-04$ & 22.84 & 5.8706E-05 & 7.26 \\
\hline 27 & $20 \times 40$ & 120 & 60 & 346 & 0.20 & 5.5295E-04 & 32.29 & 3.5274E-05 & 15.68 \\
\hline 28 & $20 \times 40$ & 140 & 70 & 272 & 0.16 & 7.0490E-04 & 43.71 & 2.2362E-05 & 31.52 \\
\hline
\end{tabular}

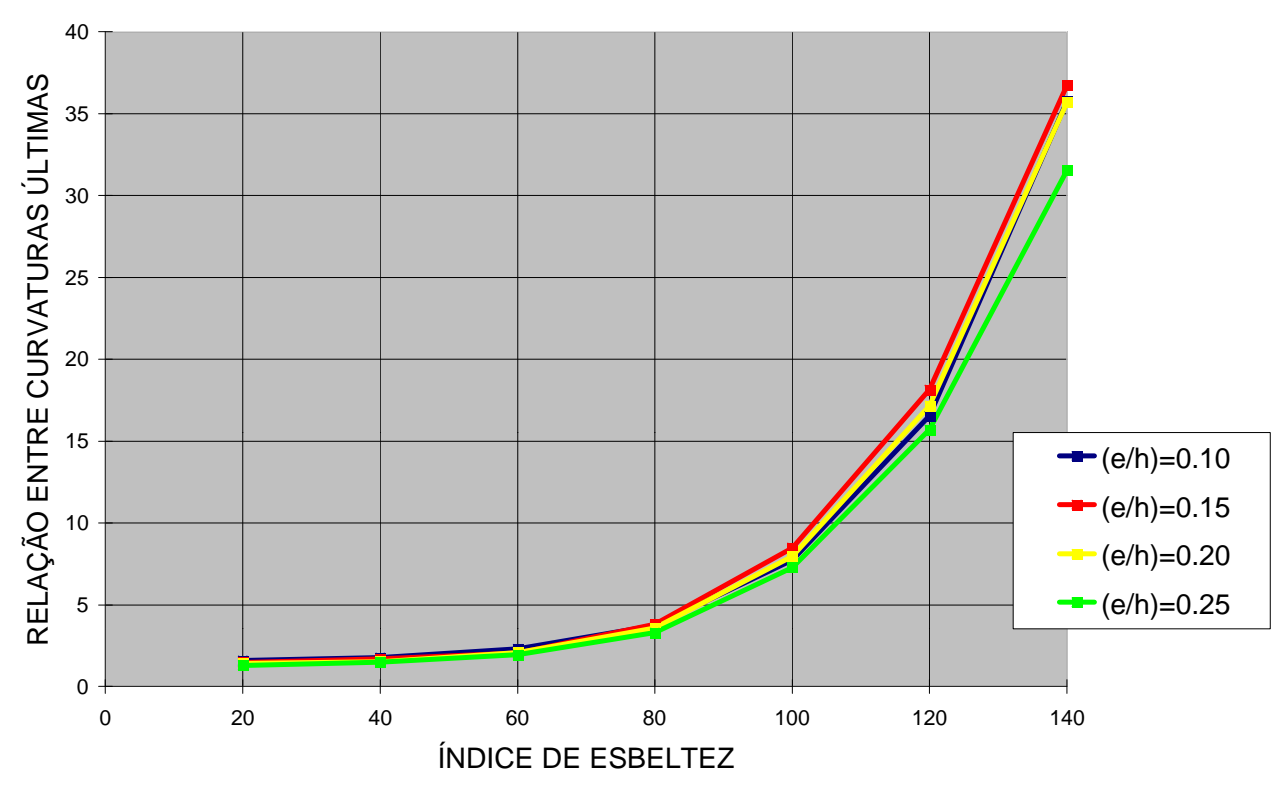

FIGURA 42 - Relação entre curvaturas últimas para seção 20x40, com e ex =2, 3, 4 e 5cm 
TABELA 14 - FCO: Comparação entre os valores de curvatura última para os pilares de seção 20x60 com $e_{x}=2,3,4$ e $5 \mathrm{~cm}$

\begin{tabular}{|c|c|c|c|c|c|c|c|c|c|}
\hline $\begin{array}{c}\text { Pilar } \\
n^{\circ}\end{array}$ & $\begin{array}{l}\text { seção } \\
\text { cmxcm }\end{array}$ & $\begin{array}{c}\lambda_{\mathbf{x}} \\
\mathrm{adm}\end{array}$ & $\begin{array}{c}\lambda_{y} \\
\text { adm }\end{array}$ & $\begin{array}{l}\mathbf{P}_{\text {dim }} \\
\mathrm{kN}\end{array}$ & $\begin{array}{c}\mathbf{v} \\
\mathrm{adm}\end{array}$ & $\begin{array}{c}\text { NB1 } \\
\text { CURV. } \alpha_{1}\end{array}$ & $\begin{array}{l}\text { As } \\
\mathrm{cm}^{2}\end{array}$ & $\begin{array}{c}\text { VERIFIC_PPADR } \\
\text { AO } \\
\text { CURV. } \alpha_{2}\end{array}$ & $\begin{array}{c}\text { Relação } \alpha \\
\text { Adm }\end{array}$ \\
\hline 01 & $20 \times 60$ & 20 & 6.7 & 1956 & 0.76 & 1.3838E-04 & 11.81 & 7.5163E-05 & 1.84 \\
\hline 02 & $20 \times 60$ & 40 & 13.3 & 1789 & 0.70 & 1.5129E-04 & 11.22 & 7.3093E-05 & 2.07 \\
\hline 03 & $20 \times 60$ & 60 & 20.0 & 1532 & 0.60 & 1.7666E-04 & 8.86 & 7.0342E-05 & 2.51 \\
\hline 04 & $20 \times 60$ & 80 & 26.7 & 1215 & 0.47 & $2.2272 \mathrm{E}-04$ & 14.77 & $4.8131 \mathrm{E}-05$ & 4.63 \\
\hline 05 & $20 \times 60$ & 100 & 33.3 & 925 & 0.36 & 2.9276E-04 & 23.62 & 3.0842E-05 & 9.49 \\
\hline 06 & $20 \times 60$ & 120 & 40.0 & 705 & 0.27 & 3.8417E-04 & 40.16 & 1.8644E-05 & 20.61 \\
\hline 07 & $20 \times 60$ & 140 & 46.7 & 546 & 0.21 & 4.9563E-04 & 57.29 & 1.2030E-05 & 41.20 \\
\hline 08 & $20 \times 60$ & 20 & 6.7 & 1720 & 0.67 & 1.5738E-04 & 11.22 & 9.3949E-05 & 1.68 \\
\hline 09 & $20 \times 60$ & 40 & 13.3 & 1550 & 0.60 & 1.7464E-04 & 10.63 & 8.9751E-05 & 1.95 \\
\hline 10 & $20 \times 60$ & 60 & 20.0 & 1291 & 0.50 & $2.0971 \mathrm{E}-04$ & 10.04 & 7.9925E-05 & 2.62 \\
\hline 11 & $20 \times 60$ & 80 & 26.7 & 991 & 0.39 & $2.7321 \mathrm{E}-04$ & 13.58 & 5.5769E-05 & 4.90 \\
\hline 12 & $20 \times 60$ & 100 & 33.3 & 738 & 0.29 & 3.6656E-04 & 27.17 & $3.1811 \mathrm{E}-05$ & 11.52 \\
\hline 13 & $20 \times 60$ & 120 & 40.0 & 555 & 0.22 & 4.8807E-04 & 38.98 & 2.0333E-05 & 24.00 \\
\hline 14 & $20 \times 60$ & 140 & 46.7 & 426 & 0.17 & 6.3520E-04 & 62.01 & 1.2402E-05 & 51.22 \\
\hline 15 & $20 \times 60$ & 20 & 6.7 & 1511 & 0.59 & 1.7917E-04 & 9.45 & 1.2058E-04 & 1.49 \\
\hline 16 & $20 \times 60$ & 40 & 13.3 & 1344 & 0.52 & $2.0143 E-04$ & 9.45 & 1.1550E-04 & 1.74 \\
\hline 17 & $20 \times 60$ & 60 & 20.0 & 1097 & 0.43 & 2.4677E-04 & 10.63 & 9.9356E-05 & 2.48 \\
\hline 18 & $20 \times 60$ & 80 & 26.7 & 830 & 0.32 & 3.2613E-04 & 17.72 & 6.0934E-05 & 5.35 \\
\hline 19 & $20 \times 60$ & 100 & 33.3 & 615 & 0.24 & 4.3987E-04 & 27.17 & 3.1239E-05 & 14.08 \\
\hline 20 & $20 \times 60$ & 120 & 40.0 & 462 & 0.18 & $5.8650 \mathrm{E}-04$ & 39.57 & $2.2871 \mathrm{E}-05$ & 25.64 \\
\hline 21 & $20 \times 60$ & 140 & 46.7 & 354 & 0.14 & 7.6500E-04 & 66.74 & 1.3182E-05 & 58.03 \\
\hline 22 & $20 \times 60$ & 20 & 6.7 & 1331 & 0.52 & $2.0341 \mathrm{E}-04$ & 13.58 & 1.2739E-04 & 1.60 \\
\hline 23 & $20 \times 60$ & 40 & 13.3 & 1175 & 0.46 & $2.3045 E-04$ & 11.81 & 1.3347E-04 & 1.73 \\
\hline 24 & $20 \times 60$ & 60 & 20.0 & 954 & 0.37 & $2.8379 \mathrm{E}-04$ & 12.40 & 1.2260E-04 & 2.31 \\
\hline 25 & $20 \times 60$ & 80 & 26.7 & 725 & 0.28 & 3.7317E-04 & 19.49 & 7.3496E-05 & 5.08 \\
\hline 26 & $20 \times 60$ & 100 & 33.3 & 542 & 0.21 & 4.9915E-04 & 30.12 & 4.2764E-05 & 11.67 \\
\hline 27 & $20 \times 60$ & 120 & 40.0 & 411 & 0.16 & 6.5899E-04 & 42.52 & 2.6499E-05 & 24.87 \\
\hline 28 & $20 \times 60$ & 140 & 46.7 & 318 & 0.12 & $8.5000 \mathrm{E}-04$ & 60.83 & 1.6485E-05 & 51.56 \\
\hline
\end{tabular}

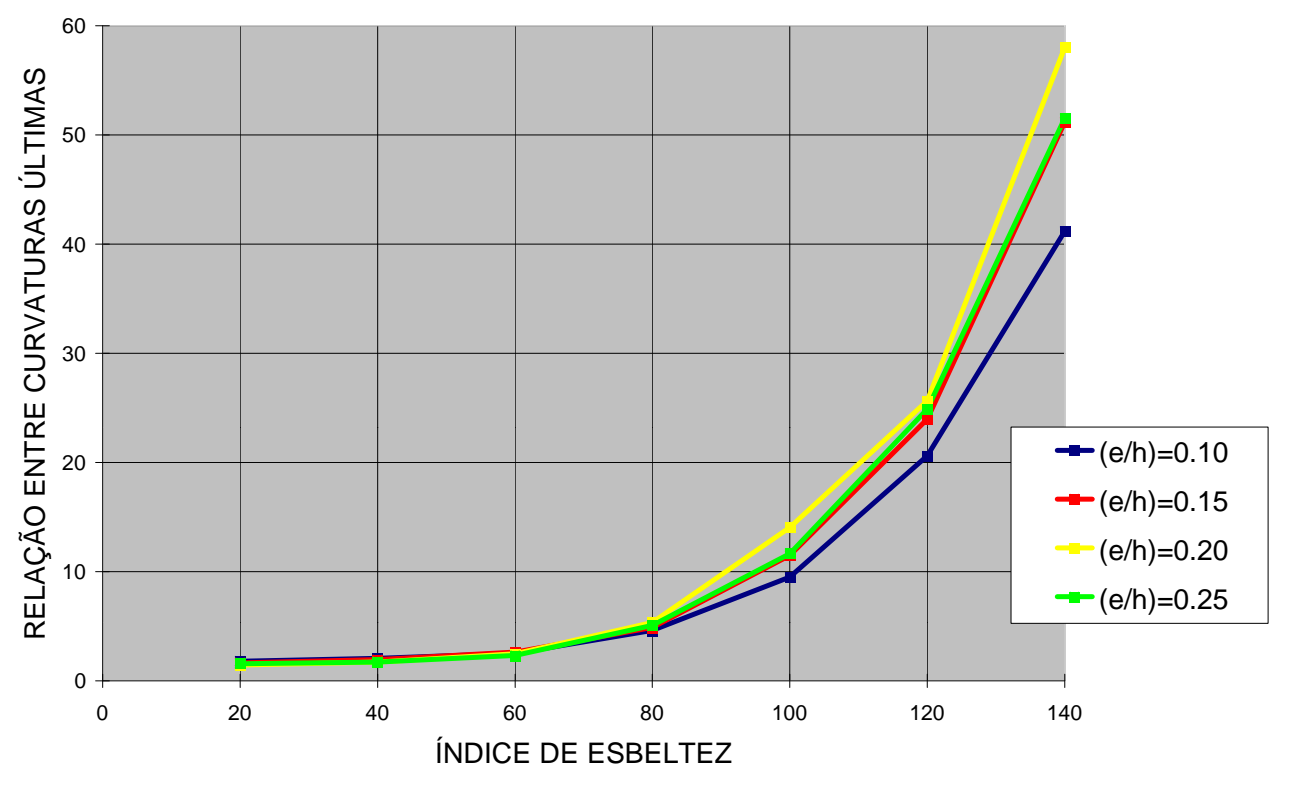

FIGURA 43 - Relação entre curvaturas últimas para seção 20x60, com $e_{x}=2,3$, 4 e 5cm 
TABELA 15 - FCO: Comparação entre os valores de curvatura última para os pilares de seção 20x80 com $e_{x}=2,3,4$ e $5 \mathrm{~cm}$

\begin{tabular}{|c|c|c|c|c|c|c|c|c|c|}
\hline $\begin{array}{c}\text { Pilar } \\
\mathrm{n}^{0}\end{array}$ & $\begin{array}{c}\text { seção } \\
\text { cmxc } \\
\text { m }\end{array}$ & $\begin{array}{c}\lambda_{\mathbf{x}} \\
\mathrm{adm}\end{array}$ & $\begin{array}{c}\lambda_{y} \\
\text { adm }\end{array}$ & $\begin{array}{l}\mathbf{P}_{\text {dim }} \\
\mathrm{kN}\end{array}$ & $\begin{array}{c}v \\
\operatorname{adm}\end{array}$ & $\begin{array}{c}\text { NB1 } \\
\text { CURV. } \alpha_{1}\end{array}$ & $\begin{array}{l}\text { As } \\
\mathrm{cm}^{2}\end{array}$ & $\begin{array}{c}\text { VERIFIC_PPADRAO } \\
\text { CURV. } \alpha_{2}\end{array}$ & $\begin{array}{c}\text { Relação } \alpha \\
\text { adm }\end{array}$ \\
\hline 01 & $20 \times 80$ & 20 & 5.0 & 2455 & 0.72 & 1.4704E-04 & 10.24 & 7.3433E-05 & 1.96 \\
\hline 02 & $20 \times 80$ & 40 & 10 & 2240 & 0.65 & $1.6113 \mathrm{E}-04$ & 8.66 & 7.1942E-05 & 2.19 \\
\hline 03 & $20 \times 80$ & 60 & 15 & 1918 & 0.56 & $1.8821 \mathrm{E}-04$ & 11.81 & 6.0089E-05 & 3.06 \\
\hline 04 & $20 \times 80$ & 80 & 20 & 1519 & 0.44 & 2.3757E-04 & 17.32 & 4.3650E-05 & 5.32 \\
\hline 05 & $20 \times 80$ & 100 & 25 & 1158 & 0.34 & 3.1155E-04 & 31.50 & 2.7547E-05 & 11.06 \\
\hline 06 & $20 \times 80$ & 120 & 30 & 883 & 0.26 & 4.0871E-04 & 48.82 & 1.7595E-05 & 22.72 \\
\hline 07 & $20 \times 80$ & 140 & 35 & 686 & 0.20 & 5.2601E-04 & 72.45 & 1.1330E-05 & 45.40 \\
\hline 08 & $20 \times 80$ & 20 & 5.0 & 2155 & 0.63 & $2.2474 \mathrm{E}-04$ & 9.45 & 9.1083E-05 & 1.80 \\
\hline 09 & $20 \times 80$ & 40 & 10 & 1932 & 0.56 & $2.5060 \mathrm{E}-04$ & 7.87 & 8.7438E-05 & 2.09 \\
\hline 10 & $20 \times 80$ & 60 & 15 & 1598 & 0.47 & 3.0293E-04 & 11.02 & 6.9733E-05 & 3.17 \\
\hline 11 & $20 \times 80$ & 80 & 20 & 1219 & 0.36 & 3.9716E-04 & 19.69 & 4.5827E-05 & 6.32 \\
\hline 12 & $20 \times 80$ & 100 & 25 & 905 & 0.26 & 5.3528E-04 & 33.07 & 2.8533E-05 & 13.67 \\
\hline 13 & $20 \times 80$ & 120 & 30 & 678 & 0.20 & $7.1371 \mathrm{E}-04$ & 51.19 & 1.7959E-05 & 28.97 \\
\hline 14 & $20 \times 80$ & 140 & 35 & 521 & 0.15 & 9.2983E-04 & 76.39 & 1.1459E-05 & 59.14 \\
\hline 15 & $20 \times 80$ & 20 & 5.0 & 1883 & 0.55 & 1.9167E-04 & 10.24 & 1.0787E-04 & 1.74 \\
\hline 16 & $20 \times 80$ & 40 & 10 & 1661 & 0.49 & 2.1732E-04 & 7.87 & 1.0820E-04 & 1.96 \\
\hline 17 & $20 \times 80$ & 60 & 15 & 1336 & 0.39 & $2.7012 \mathrm{E}-04$ & 12.6 & 8.1253E-05 & 3.25 \\
\hline 18 & $20 \times 80$ & 80 & 20 & 996 & 0.29 & 3.6231E-04 & 19.69 & 5.2804E-05 & 6.71 \\
\hline 19 & $20 \times 80$ & 100 & 25 & 729 & 0.21 & 4.9493E-04 & 36.22 & 3.0286E-05 & 15.98 \\
\hline 20 & $20 \times 80$ & 120 & 30 & 542 & 0.16 & 6.6647E-04 & 53.55 & 1.8807E-05 & 34.65 \\
\hline 21 & $20 \times 80$ & 140 & 35 & 413 & 0.12 & 8.7374E-04 & 77.96 & 1.1877E-05 & 71.94 \\
\hline 22 & $20 \times 80$ & 20 & 5.0 & 1648 & 0.48 & 2.9374E-04 & 11.02 & 1.3181E-04 & 1.62 \\
\hline 23 & $20 \times 80$ & 40 & 10 & 1439 & 0.42 & 3.3645E-04 & 8.66 & $1.4251 \mathrm{E}-04$ & 1.72 \\
\hline 24 & $20 \times 80$ & 60 & 15 & 1144 & 0.33 & 4.2333E-04 & 14.17 & $1.0076 \mathrm{E}-04$ & 3.06 \\
\hline 25 & $20 \times 80$ & 80 & 20 & 849 & 0.25 & 5.7019E-04 & 22.84 & 6.1013E-05 & 6.81 \\
\hline 26 & $20 \times 80$ & 100 & 25 & 625 & 0.18 & $7.7429 E-04$ & 35.44 & $3.6130 \mathrm{E}-05$ & 15.62 \\
\hline 27 & $20 \times 80$ & 120 & 30 & 468 & 0.14 & 1.0354E-03 & 54.34 & 2.1554E-05 & 35.01 \\
\hline 28 & $20 \times 80$ & 140 & 35 & 358 & 0.10 & 1.3508E-03 & 78.75 & 1.3437E-05 & 73.28 \\
\hline
\end{tabular}

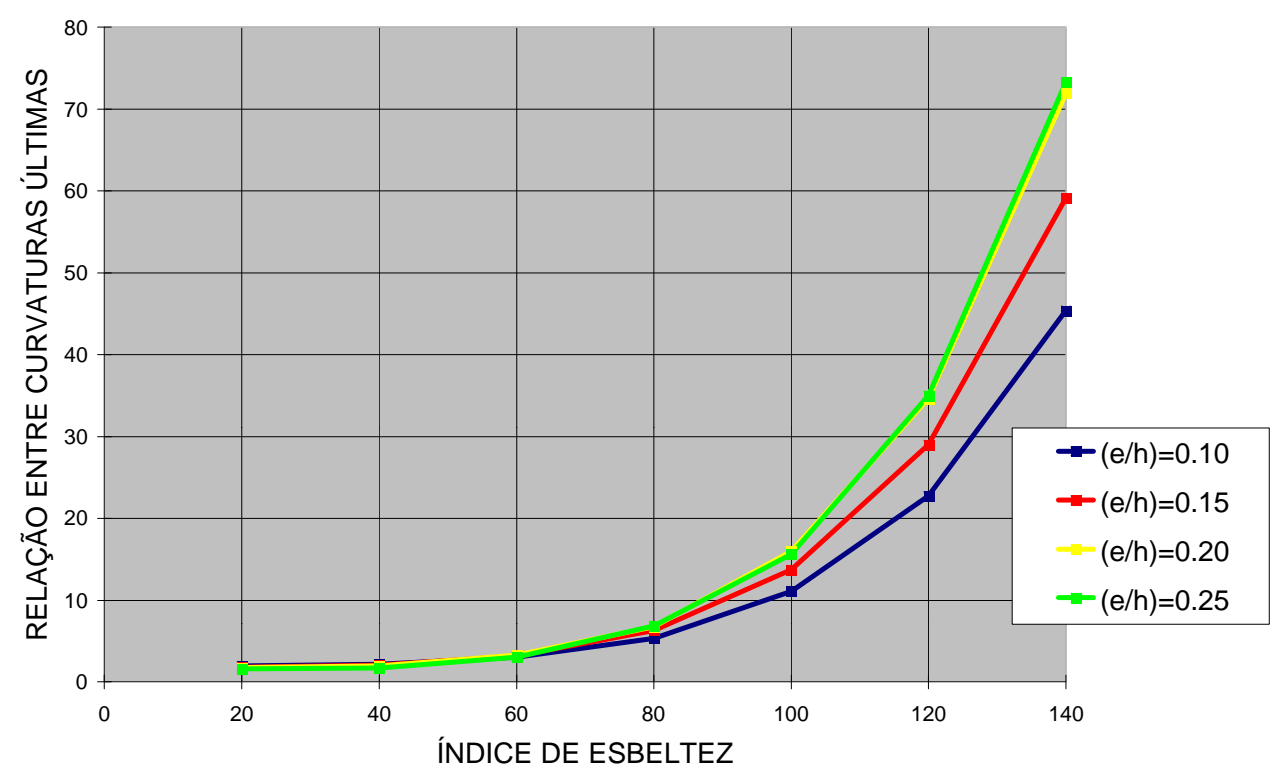

FIGURA 44 - Relação entre curvaturas últimas para seção 20x80, com $e_{x}=2,3,4$ e 5cm 
Para o estudo da curvatura, cada série apresenta 7 pilares ao invés de 6 como na TABELA 11, devido ao fato de que, para conseguir uma relação entre as cargas e curvaturas como será visto a seguir, fez-se necessário calcular um pilar com as mesmas características dos demais pilares de cada série, com $\lambda=20$.

É importante salientar que as curvaturas dadas pela expressão (62), oriundas do Texto para Revisão da NB-1 (1997), e pelo programa VERIFIC_PPADRAO, estão referenciadas a duas direções distintas, chamadas nesse trabalho de $\alpha_{1}$ e $\alpha_{2}$. Embora seja este um fator relevante, este fato por hora está sendo ignorado, já que a análise tem sua importância centralizada no maior valor que a curvatura pode assumir.

Observando então os resultados apresentados nas tabelas e figuras anteriores, percebe-se que, à medida que cresce o índice de esbeltez, cresce também a diferença entre os valores de curvatura dados pela expressão (62) e pelo programa. Isso acontece pelo fato de que, à medida que há um aumento na esbeltez, a curvatura dada pela expressão (62) não decresce com o decréscimo da carga, como acontece com os resultados apresentados pelo programa, já que a carga é um fator inversamente proporcional à esbeltez.

Esse acréscimo na relação entre os valores de curvatura, à medida que se dá o aumento do índice de esbeltez, é decorrente da consideração indireta da influência do índice de esbeltez, já que o valor da curvatura, segundo o processo do pilar padrão da NB1, é utilizado para cálculo das excentricidades de $2^{\underline{a}}$ ordem. Mas, o que se percebe também, é que esse aumento se dá de forma desordenada, chegando ao ponto em que a expressão (62) perde a validade, fazendo com que as excentricidades de $2^{\underline{a}}$ ordem assumam valores muito altos, tornando-se portanto inutilizável para alguns casos, casos estes que a norma classifica como pilares esbeltos $(\lambda>80)$.

Outra observação a ser feita, é relativa à influência das excentricidades de $1^{\text {a }}$ ordem, pois, à medida que é aumentado este valor, os resultados tendem a ser mais ou menos incoerentes, dependendo da outra dimensão da seção.

Tentando investigar, portanto, a lógica existente nesses resultados, com a finalidade de detectar o erro e propor soluções, foi calculada, para os pilares das TABELAS 12 a 15, a relação existente entre o pilar curto $(\lambda=20)$ e os demais pilares de cada série, segundo seus valores de carga e curvatura, como mostram as TABELAS 16 a 19. 
Nessa etapa, os pilares foram divididos não por seção, como feito anteriormente, mas sim por excentricidade de aplicação da carga. Essa nova organização se deu na tentativa de observar alguma tendência no comportamento dos pilares de mesma relação $e_{x} / h_{x}$.

TABELA 16 - FCO: Análise dos resultados dos pilares ensaiados com $e_{x}=2 \mathrm{~cm}$

\begin{tabular}{|c|c|c|c|c|c|c|c|c|}
\hline \multirow{2}{*}{$\begin{array}{c}\text { Pilar } \\
\mathrm{n}^{\circ}\end{array}$} & \multirow{2}{*}{$\begin{array}{c}\text { seção } \\
\text { cmxc } \\
\text { m }\end{array}$} & \multirow{2}{*}{$\begin{array}{c}\lambda \mathbf{x} \\
\mathrm{adm}\end{array}$} & \multirow{2}{*}{$\begin{array}{c}\lambda_{\mathrm{y}} \\
\mathrm{adm}\end{array}$} & \multirow{2}{*}{$\begin{array}{l}\mathbf{P}_{\text {dim }} \\
\mathrm{kN}\end{array}$} & \multirow{2}{*}{$\begin{array}{c}v \\
\text { Adm }\end{array}$} & \multirow{2}{*}{$\frac{\text { NB1 / Verific_ppadrao }}{\text { curvaturas }}$} & \multicolumn{2}{|c|}{ Curto / Esbeltos } \\
\hline & & & & & & & carga & curvatura \\
\hline 01 & $20 \times 20$ & 20 & 20 & 857 & 1.00 & 1.30 & 1.00 & 1.00 \\
\hline 02 & $20 \times 20$ & 40 & 40 & 768 & 0.90 & 1.45 & 1.12 & 0.99 \\
\hline 03 & $20 \times 20$ & 60 & 60 & 637 & 0.74 & 1.81 & 1.35 & 1.03 \\
\hline 04 & $20 \times 20$ & 80 & 80 & 496 & 0.58 & 3.37 & 1.73 & 1.50 \\
\hline 05 & $20 \times 20$ & 100 & 100 & 381 & 0.44 & 7.32 & 2.25 & 2.50 \\
\hline 06 & $20 \times 20$ & 120 & 120 & 291 & 0.34 & 15.87 & 2.95 & 4.14 \\
\hline 07 & $20 \times 20$ & 140 & 140 & 226 & 0.26 & 33.48 & 3.79 & 6.79 \\
\hline 08 & $20 \times 40$ & 20 & 10 & 1446 & 0.84 & 1.58 & 1.00 & 1.00 \\
\hline 19 & $20 \times 40$ & 40 & 20 & 1327 & 0.78 & 1.75 & 1.09 & 1.01 \\
\hline 10 & $20 \times 40$ & 60 & 30 & 1138 & 0.66 & 2.31 & 1.27 & 1.15 \\
\hline 11 & $20 \times 40$ & 80 & 40 & 911 & 0.53 & 3.73 & 1.59 & 1.48 \\
\hline 12 & $20 \times 40$ & 100 & 50 & 692 & 0.40 & 7.73 & 2.09 & 2.34 \\
\hline 13 & $20 \times 40$ & 120 & 60 & 526 & 0.31 & 16.55 & 2.75 & 3.80 \\
\hline 14 & $20 \times 40$ & 140 & 70 & 408 & 0.24 & 35.75 & 3.55 & 6.37 \\
\hline 15 & $20 \times 60$ & 20 & 6.7 & 1956 & 0.76 & 1.84 & 1.00 & 1.00 \\
\hline 16 & $20 \times 60$ & 40 & 13.3 & 1789 & 0.70 & 2.07 & 1.09 & 1.03 \\
\hline 17 & $20 \times 60$ & 60 & 20.0 & 1532 & 0.60 & 2.51 & 1.28 & 1.07 \\
\hline 18 & $20 \times 60$ & 80 & 26.7 & 1215 & 0.47 & 4.63 & 1.61 & 1.56 \\
\hline 19 & $20 \times 60$ & 100 & 33.3 & 925 & 0.36 & 9.49 & 2.12 & 2.44 \\
\hline 20 & $20 \times 60$ & 120 & 40.0 & 705 & 0.27 & 20.61 & 2.78 & 4.03 \\
\hline 21 & $20 \times 60$ & 140 & 46.7 & 546 & 0.21 & 41.20 & 3.58 & 6.25 \\
\hline 22 & $20 \times 80$ & 20 & 5.0 & 2455 & 0.72 & 1.96 & 1.00 & 1.00 \\
\hline 23 & $20 \times 80$ & 40 & 10.0 & 2240 & 0.65 & 2.19 & 1.10 & 1.02 \\
\hline 24 & $20 \times 80$ & 60 & 15.0 & 1918 & 0.56 & 3.06 & 1.28 & 1.22 \\
\hline 25 & $20 \times 80$ & 80 & 20.0 & 1519 & 0.44 & 5.32 & 1.62 & 1.68 \\
\hline 26 & $20 \times 80$ & 100 & 25.0 & 1158 & 0.34 & 11.06 & 2.12 & 2.67 \\
\hline 27 & $20 \times 80$ & 120 & 30.0 & 883 & 0.26 & 22.72 & 2.78 & 4.17 \\
\hline 28 & $20 \times 80$ & 140 & 35.0 & 686 & 0.20 & 45.40 & 3.58 & 6.48 \\
\hline
\end{tabular}


TABELA 17 - FCO: Análise dos resultados dos pilares ensaiados com $e_{x}=3 \mathrm{~cm}$

\begin{tabular}{|c|c|c|c|c|c|c|c|c|}
\hline \multirow{2}{*}{$\begin{array}{c}\text { Pilar } \\
n^{\circ}\end{array}$} & \multirow{2}{*}{$\begin{array}{c}\text { seção } \\
\text { cmxc } \\
\text { m }\end{array}$} & \multirow{2}{*}{$\begin{array}{c}\lambda x \\
\mathrm{adm}\end{array}$} & \multirow{2}{*}{$\begin{array}{c}\lambda_{y} \\
\operatorname{adm}\end{array}$} & \multirow{2}{*}{$\begin{array}{l}\mathbf{P}_{\text {dim }} \\
\mathrm{kN}\end{array}$} & \multirow{2}{*}{$\begin{array}{c}v \\
\mathrm{adm}\end{array}$} & \multirow{2}{*}{$\begin{array}{c}\text { NB1 / Verific_ppadrao } \\
\text { curvaturas }\end{array}$} & \multicolumn{2}{|c|}{ Curto / Esbeltos } \\
\hline & & & & & & & carga & curvatura \\
\hline 01 & $20 \times 20$ & 20 & 20 & 772 & 0.90 & 1.31 & 1.00 & 1.00 \\
\hline 02 & $20 \times 20$ & 40 & 40 & 690 & 0.81 & 1.49 & 1.12 & 1.02 \\
\hline 03 & $20 \times 20$ & 60 & 60 & 576 & 0.67 & 1.84 & 1.34 & 1.05 \\
\hline 04 & $20 \times 20$ & 80 & 80 & 455 & 0.53 & 3.41 & 1.70 & 1.54 \\
\hline 05 & $20 \times 20$ & 100 & 100 & 352 & 0.41 & 6.85 & 2.19 & 2.39 \\
\hline 06 & $20 \times 20$ & 120 & 120 & 273 & 0.32 & 15.30 & 2.83 & 4.14 \\
\hline 07 & $20 \times 20$ & 140 & 140 & 215 & 0.25 & 31.83 & 3.59 & 6.77 \\
\hline 08 & $20 \times 40$ & 20 & 10 & 1276 & 0.75 & 1.48 & 1.00 & 1.00 \\
\hline 19 & $20 \times 40$ & 40 & 20 & 1157 & 0.68 & 1.64 & 1.10 & 1.00 \\
\hline 10 & $20 \times 40$ & 60 & 30 & 975 & 0.57 & 2.04 & 1.31 & 1.05 \\
\hline 11 & $20 \times 40$ & 80 & 40 & 763 & 0.45 & 3.80 & 1.67 & 1.54 \\
\hline 12 & $20 \times 40$ & 100 & 50 & 572 & 0.33 & 8.48 & 2.23 & 2.57 \\
\hline 13 & $20 \times 40$ & 120 & 60 & 433 & 0.25 & 18.15 & 2.95 & 4.16 \\
\hline 14 & $20 \times 40$ & 140 & 70 & 334 & 0.20 & 36.72 & 3.82 & 6.48 \\
\hline 15 & $20 \times 60$ & 20 & 6.7 & 1720 & 0.67 & 1.68 & 1.00 & 1.00 \\
\hline 16 & $20 \times 60$ & 40 & 13.3 & 1550 & 0.60 & 1.95 & 1.11 & 1.05 \\
\hline 17 & $20 \times 60$ & 60 & 20.0 & 1291 & 0.50 & 2.62 & 1.33 & 1.18 \\
\hline 18 & $20 \times 60$ & 80 & 26.7 & 991 & 0.39 & 4.90 & 1.74 & 1.68 \\
\hline 19 & $20 \times 60$ & 100 & 33.3 & 738 & 0.29 & 11.52 & 2.33 & 2.95 \\
\hline 20 & $20 \times 60$ & 120 & 40.0 & 555 & 0.22 & 24.00 & 3.10 & 4.62 \\
\hline 21 & $20 \times 60$ & 140 & 46.7 & 426 & 0.17 & 51.22 & 4.04 & 7.58 \\
\hline 22 & $20 \times 80$ & 20 & 5.0 & 2155 & 0.63 & 1.80 & 1.00 & 1.00 \\
\hline 23 & $20 \times 80$ & 40 & 10.0 & 1932 & 0.56 & 2.09 & 1.12 & 1.04 \\
\hline 24 & $20 \times 80$ & 60 & 15.0 & 1598 & 0.47 & 3.17 & 1.35 & 1.31 \\
\hline 25 & $20 \times 80$ & 80 & 20.0 & 1219 & 0.36 & 6.32 & 1.77 & 1.99 \\
\hline 26 & $20 \times 80$ & 100 & 25.0 & 905 & 0.26 & 13.67 & 2.38 & 3.19 \\
\hline 27 & $20 \times 80$ & 120 & 30.0 & 678 & 0.20 & 28.97 & 3.18 & 5.07 \\
\hline 28 & $20 \times 80$ & 140 & 35.0 & 521 & 0.15 & 59.14 & 4.14 & 7.95 \\
\hline
\end{tabular}


TABELA 18 - FCO: Análise dos resultados dos pilares ensaiados com $e_{x}=4 \mathrm{~cm}$

\begin{tabular}{|c|c|c|c|c|c|c|c|c|}
\hline \multirow{2}{*}{$\begin{array}{l}\text { Pilar } \\
\mathrm{n}^{\circ}\end{array}$} & \multirow{2}{*}{$\begin{array}{c}\text { seção } \\
\text { cmxc } \\
\text { m }\end{array}$} & \multirow{2}{*}{$\begin{array}{c}\lambda_{\mathrm{x}} \\
\mathrm{adm}\end{array}$} & \multirow{2}{*}{$\begin{array}{c}\lambda_{\mathrm{y}} \\
\mathrm{adm}\end{array}$} & \multirow{2}{*}{$\begin{array}{l}\mathbf{P}_{\text {dim }} \\
\mathrm{kN}\end{array}$} & \multirow{2}{*}{$\begin{array}{c}v \\
\operatorname{adm}\end{array}$} & \multirow{2}{*}{$\begin{array}{c}\text { NB1 / Verific_ppadrao } \\
\text { curvaturas }\end{array}$} & \multicolumn{2}{|c|}{ Curto / Esbeltos } \\
\hline & & & & & & & carga & curvatura \\
\hline 01 & $20 \times 20$ & 20 & 20 & 695 & 0.81 & 1.28 & 1.00 & 1.00 \\
\hline 02 & $20 \times 20$ & 40 & 40 & 622 & 0.73 & 1.41 & 1.12 & 0.99 \\
\hline 03 & $20 \times 20$ & 60 & 60 & 522 & 0.61 & 1.74 & 1.33 & 1.03 \\
\hline 04 & $20 \times 20$ & 80 & 80 & 418 & 0.49 & 3.04 & 1.66 & 1.43 \\
\hline 05 & $20 \times 20$ & 100 & 100 & 328 & 0.38 & 6.37 & 2.12 & 2.35 \\
\hline 06 & $20 \times 20$ & 120 & 120 & 258 & 0.30 & 13.95 & 2.70 & 4.05 \\
\hline 07 & $20 \times 20$ & 140 & 140 & 205 & 0.24 & 28.73 & 3.39 & 6.62 \\
\hline 08 & $20 \times 40$ & 20 & 10 & 1128 & 0.66 & 1.43 & 1.00 & 1.00 \\
\hline 19 & $20 \times 40$ & 40 & 20 & 1014 & 0.59 & 1.53 & 1.11 & 0.96 \\
\hline 10 & $20 \times 40$ & 60 & 30 & 846 & 0.49 & 2.08 & 1.33 & 1.09 \\
\hline 11 & $20 \times 40$ & 80 & 40 & 660 & 0.39 & 3.56 & 1.71 & 1.46 \\
\hline 12 & $20 \times 40$ & 100 & 50 & 498 & 0.29 & 7.95 & 2.27 & 2.45 \\
\hline 13 & $20 \times 40$ & 120 & 60 & 378 & 0.22 & 17.16 & 2.98 & 4.03 \\
\hline 14 & $20 \times 40$ & 140 & 70 & 294 & 0.17 & 35.69 & 3.84 & 6.50 \\
\hline 15 & $20 \times 60$ & 20 & 6.7 & 1511 & 0.59 & 1.49 & 1.00 & 1.00 \\
\hline 16 & $20 \times 60$ & 40 & 13.3 & 1344 & 0.52 & 1.74 & 1.12 & 1.04 \\
\hline 17 & $20 \times 60$ & 60 & 20.0 & 1097 & 0.43 & 2.48 & 1.38 & 1.21 \\
\hline 18 & $20 \times 60$ & 80 & 26.7 & 830 & 0.32 & 5.35 & 1.82 & 1.98 \\
\hline 19 & $20 \times 60$ & 100 & 33.3 & 615 & 0.24 & 14.08 & 2.46 & 3.86 \\
\hline 20 & $20 \times 60$ & 120 & 40.0 & 462 & 0.18 & 25.64 & 3.27 & 5.27 \\
\hline 21 & $20 \times 60$ & 140 & 46.7 & 354 & 0.14 & 58.03 & 4.27 & 9.15 \\
\hline 22 & $20 \times 80$ & 20 & 5.0 & 1883 & 0.55 & 1.74 & 1.00 & 1.00 \\
\hline 23 & $20 \times 80$ & 40 & 10.0 & 1661 & 0.49 & 1.96 & 1.13 & 1.00 \\
\hline 24 & $20 \times 80$ & 60 & 15.0 & 1336 & 0.39 & 3.25 & 1.41 & 1.33 \\
\hline 25 & $20 \times 80$ & 80 & 20.0 & 996 & 0.29 & 6.71 & 1.89 & 2.04 \\
\hline 26 & $20 \times 80$ & 100 & 25.0 & 729 & 0.21 & 15.98 & 2.58 & 3.56 \\
\hline 27 & $20 \times 80$ & 120 & 30.0 & 542 & 0.16 & 34.65 & 3.48 & 5.74 \\
\hline 28 & $20 \times 80$ & 140 & 35.0 & 413 & 0.12 & 71.94 & 4.56 & 9.08 \\
\hline
\end{tabular}


TABELA 19 - FCO: Análise dos resultados dos pilares ensaiados com $e_{x}=5 \mathrm{~cm}$

\begin{tabular}{|c|c|c|c|c|c|c|c|c|}
\hline \multirow{2}{*}{$\begin{array}{c}\text { Pilar } \\
\mathrm{n}^{\circ}\end{array}$} & \multirow{2}{*}{$\begin{array}{c}\text { seção } \\
\text { Cmxc } \\
\text { m }\end{array}$} & \multirow{2}{*}{$\begin{array}{c}\lambda \mathbf{x} \\
\mathrm{adm}\end{array}$} & \multirow{2}{*}{$\begin{array}{c}\lambda_{\mathrm{y}} \\
\mathrm{adm}\end{array}$} & \multirow{2}{*}{$\begin{array}{l}\mathbf{P}_{\text {dim }} \\
\mathrm{kN}\end{array}$} & \multirow{2}{*}{$\begin{array}{c}v \\
\operatorname{adm}\end{array}$} & \multirow{2}{*}{$\begin{array}{c}\text { NB1 / Verific_ppadrao } \\
\text { curvaturas }\end{array}$} & \multicolumn{2}{|c|}{ Curto / Esbeltos } \\
\hline & & & & & & & carga & curvatura \\
\hline 01 & $20 \times 20$ & 20 & 20 & 696 & 0.81 & 1.11 & 1.00 & 1.00 \\
\hline 02 & $20 \times 20$ & 40 & 40 & 565 & 0.66 & 1.44 & 1.23 & 1.05 \\
\hline 03 & $20 \times 20$ & 60 & 60 & 478 & 0.56 & 1.99 & 1.46 & 1.23 \\
\hline 04 & $20 \times 20$ & 80 & 80 & 387 & 0.45 & 3.03 & 1.80 & 1.51 \\
\hline 05 & $20 \times 20$ & 100 & 100 & 308 & 0.36 & 6.15 & 2.26 & 2.44 \\
\hline 06 & $20 \times 20$ & 120 & 120 & 245 & 0.29 & 12.26 & 2.85 & 3.87 \\
\hline 07 & $20 \times 20$ & 140 & 140 & 196 & 0.23 & 24.17 & 3.55 & 6.12 \\
\hline 08 & $20 \times 40$ & 20 & 10 & 1002 & 0.59 & 1.29 & 1.00 & 1.00 \\
\hline 09 & $20 \times 40$ & 40 & 20 & 897 & 0.52 & 1.51 & 1.12 & 1.05 \\
\hline 10 & $20 \times 40$ & 60 & 30 & 748 & 0.44 & 1.95 & 1.34 & 1.13 \\
\hline 11 & $20 \times 40$ & 80 & 40 & 588 & 0.34 & 3.28 & 1.70 & 1.49 \\
\hline 12 & $20 \times 40$ & 100 & 50 & 449 & 0.26 & 7.26 & 2.23 & 2.53 \\
\hline 13 & $20 \times 40$ & 120 & 60 & 346 & 0.20 & 15.68 & 2.89 & 4.20 \\
\hline 14 & $20 \times 40$ & 140 & 70 & 272 & 0.16 & 31.52 & 3.69 & 6.63 \\
\hline 15 & $20 \times 60$ & 20 & 6.7 & 1331 & 0.52 & 1.60 & 1.00 & 1.00 \\
\hline 16 & $20 \times 60$ & 40 & 13.3 & 1175 & 0.46 & 1.73 & 1.13 & 0.95 \\
\hline 17 & $20 \times 60$ & 60 & 20.0 & 954 & 0.37 & 2.31 & 1.40 & 1.04 \\
\hline 18 & $20 \times 60$ & 80 & 26.7 & 725 & 0.28 & 5.08 & 1.83 & 1.73 \\
\hline 19 & $20 \times 60$ & 100 & 33.3 & 542 & 0.21 & 11.67 & 2.45 & 2.98 \\
\hline 20 & $20 \times 60$ & 120 & 40.0 & 411 & 0.16 & 24.87 & 3.24 & 4.81 \\
\hline 21 & $20 \times 60$ & 140 & 46.7 & 318 & 0.12 & 51.56 & 4.18 & 7.73 \\
\hline 22 & $20 \times 80$ & 20 & 5.0 & 1648 & 0.48 & 1.62 & 1.00 & 1.00 \\
\hline 23 & $20 \times 80$ & 40 & 10.0 & 1439 & 0.42 & 1.72 & 1.15 & 0.92 \\
\hline 24 & $20 \times 80$ & 60 & 15.0 & 1144 & 0.33 & 3.06 & 1.44 & 1.31 \\
\hline 25 & $20 \times 80$ & 80 & 20.0 & 849 & 0.25 & 6.81 & 1.94 & 2.16 \\
\hline 26 & $20 \times 80$ & 100 & 25.0 & 625 & 0.18 & 15.62 & 2.64 & 3.65 \\
\hline 27 & $20 \times 80$ & 120 & 30.0 & 468 & 0.14 & 35.01 & 3.52 & 6.12 \\
\hline 28 & $20 \times 80$ & 140 & 35.0 & 358 & 0.10 & 73.28 & 4.60 & 9.81 \\
\hline
\end{tabular}

Com esses resultados foi possível observar que as diferenças entre os valores de curvatura calculados através da expressão (62) e do programa, são decorrentes, diretamente, das diferenças apresentadas pelos valores de carga e curvatura de pilares esbeltos, com relação a um pilar curto de mesma seção e características idênticas, com comprimento menor. Isso é facilmente verificado, multiplicando os valores das duas últimas colunas das TABELAS 16 a 19 entre si, e por um coeficiente de segurança que é dado pela relação existente entre as curvaturas obtidas através do Texto para Revisão da NB-1 (1997) e do Programa VERIFIC_PPADRAO, para o pilar curto de cada série.

Outro fato observado é que não há uma tendência clara de comportamento para pilares de mesma relação $e_{x} / h_{x}$. Em alguns casos, os resultados se tornam mais convergentes quando a análise é feita utilizando como parâmetro a seção transversal, principalmente para os casos em que $\lambda \leq 80$.

Com base nisso, pensou-se em, através de uma expressão em função da esbeltez, chegar a um fator de ajuste de carga ou curvatura, que permita diminuir 
as diferenças existentes entre os valores de curvatura dados pela expressão (62) e pelo programa VERIFIC_PPADRAO e, com isso, diminuir o valor da excentricidade de $2^{\text {a }}$ ordem, fazendo com que a armadura resultante não seja antieconômica, e mais, que a expressão possa ser utilizada para pilares de esbeltez acima de 80 .

A primeira tentativa de ajuste consistiu em obter uma expressão para majoração da carga de dimensionamento. A expressão para obter o fator majorador de carga, foi obtida através de um ajuste entre os valores médios da relação entre as cargas últimas de um pilar curto e outro mais esbelto de mesma seção transversal, a princípio, apenas para os pilares de seção 20×20 e 20x60 com carga aplicada sob excentricidade inicial de 2 e $5 \mathrm{~cm}$.

O majorador de carga, que deve ser aplicado no cálculo aos valores de $v$ (carga adimensional), é chamado fator $\beta_{1}$, e é calculado através da seguinte expressão:

$$
\beta_{1}=0.997-\left(2.248 \cdot 10^{-3}\right) * \lambda+\left(1.291 \cdot 10^{-4}\right) * \lambda^{2}+\left(2.084 \cdot 10^{-7}\right) * \lambda^{3}
$$

onde $\lambda$ é o índice de esbeltez na direção mais crítica da seção.

A partir da equação (65), é possível recalcular os valores de $v$ e, com esses novos valores, calcular novos valores para as curvaturas. Os resultados após a correção proposta pela equação (65) encontram-se na TABELA 20, e a comparação entre as curvaturas encontra-se representada nas FIGURAS 45, 46, 47 e 48. 
TABELA 20 - FCO: Análise dos resultados dos pilares de seção 20×20 e 20x60, com excentricidades de 2 e $5 \mathrm{~cm}$, após a correção da carga

\begin{tabular}{|c|c|c|c|c|c|c|c|c|c|}
\hline $\begin{array}{l}\text { Pilar } \\
\mathrm{n}^{\circ}\end{array}$ & $\begin{array}{l}\text { seção } \\
\mathrm{cm} \times \mathrm{cm}\end{array}$ & $\begin{array}{c}\lambda_{\mathbf{x}} \\
\mathrm{adm}\end{array}$ & $\begin{array}{c}\lambda_{\mathrm{y}} \\
\mathrm{adm}\end{array}$ & $\begin{array}{l}\text { ex } \\
\mathrm{cm}\end{array}$ & $\begin{array}{l}\text { ey } \\
\mathrm{cm}\end{array}$ & $\begin{array}{l}\mathbf{P}_{\text {dim }} \\
\mathrm{kN}\end{array}$ & $\begin{array}{c}v \\
\text { adm }\end{array}$ & $\begin{array}{l}\mathrm{v}_{\text {cor }} \\
\mathrm{adm}\end{array}$ & $\begin{array}{c}\text { NB1 / Verific_ppadrao } \\
\text { curvaturas }\end{array}$ \\
\hline 01 & $20 \times 20$ & 20 & 20 & 2.0 & 2.0 & 857 & 1.00 & 1.00 & 1.29 \\
\hline 02 & $20 \times 20$ & 40 & 40 & 2.0 & 2.0 & 768 & 0.90 & 0.90 & 1.32 \\
\hline 03 & $20 \times 20$ & 60 & 60 & 2.0 & 2.0 & 637 & 0.74 & 0.87 & 1.52 \\
\hline 04 & $20 \times 20$ & 80 & 80 & 2.0 & 2.0 & 496 & 0.58 & 0.90 & 1.81 \\
\hline 05 & $20 \times 20$ & 100 & 100 & 2.0 & 2.0 & 381 & 0.44 & 0.86 & 2.21 \\
\hline 06 & $20 \times 20$ & 120 & 120 & 2.0 & 2.0 & 291 & 0.34 & 0.79 & 2.59 \\
\hline 07 & $20 \times 20$ & 140 & 140 & 2.0 & 2.0 & 226 & 0.26 & 0.72 & 3.31 \\
\hline 08 & $20 \times 60$ & 20 & 6.7 & 2.0 & 2.0 & 1956 & 0.76 & 0.76 & 1.80 \\
\hline 09 & $20 \times 60$ & 40 & 13.3 & 2.0 & 2.0 & 1789 & 0.70 & 0.70 & 2.02 \\
\hline 10 & $20 \times 60$ & 60 & 20.0 & 2.0 & 2.0 & 1532 & 0.60 & 0.70 & 2.27 \\
\hline 11 & $20 \times 60$ & 80 & 26.7 & 2.0 & 2.0 & 1215 & 0.47 & 0.74 & 2.88 \\
\hline 12 & $20 \times 60$ & 100 & 33.3 & 2.0 & 2.0 & 925 & 0.36 & 0.70 & 3.82 \\
\hline 13 & $20 \times 60$ & 120 & 40.0 & 2.0 & 2.0 & 705 & 0.27 & 0.64 & 5.09 \\
\hline 14 & $20 \times 60$ & 140 & 46.7 & 2.0 & 2.0 & 546 & 0.21 & 0.58 & 6.63 \\
\hline 15 & $20 \times 20$ & 20 & 20 & 5.0 & 2.0 & 696 & 0.81 & 0.81 & 0.93 \\
\hline 16 & $20 \times 20$ & 40 & 40 & 5.0 & 2.0 & 565 & 0.66 & 0.66 & 1.02 \\
\hline 17 & $20 \times 20$ & 60 & 60 & 5.0 & 2.0 & 478 & 0.56 & 0.65 & 0.94 \\
\hline 18 & $20 \times 20$ & 80 & 80 & 5.0 & 2.0 & 387 & 0.45 & 0.70 & 1.21 \\
\hline 19 & $20 \times 20$ & 100 & 100 & 5.0 & 2.0 & 308 & 0.36 & 0.70 & 1.06 \\
\hline 20 & $20 \times 20$ & 120 & 120 & 5.0 & 2.0 & 245 & 0.29 & 0.67 & 0.83 \\
\hline 21 & $20 \times 20$ & 140 & 140 & 5.0 & 2.0 & 196 & 0.23 & 0.62 & \#\#\#\# \\
\hline 22 & $20 \times 60$ & 20 & 6.7 & 5.0 & 2.0 & 1331 & 0.52 & 0.52 & 5.18 \\
\hline 23 & $20 \times 60$ & 40 & 13.3 & 5.0 & 2.0 & 1175 & 0.46 & 0.46 & 5.84 \\
\hline 24 & $20 \times 60$ & 60 & 20.0 & 5.0 & 2.0 & 954 & 0.37 & 0.43 & 7.21 \\
\hline 25 & $20 \times 60$ & 80 & 26.7 & 5.0 & 2.0 & 725 & 0.28 & 0.44 & 9.40 \\
\hline 26 & $20 \times 60$ & 100 & 33.3 & 5.0 & 2.0 & 542 & 0.21 & 0.41 & 13.01 \\
\hline 27 & $20 \times 60$ & 120 & 40.0 & 5.0 & 2.0 & 411 & 0.16 & 0.37 & 16.75 \\
\hline 28 & $20 \times 60$ & 140 & 46.7 & 5.0 & 2.0 & 318 & 0.12 & 0.34 & 21.95 \\
\hline
\end{tabular}

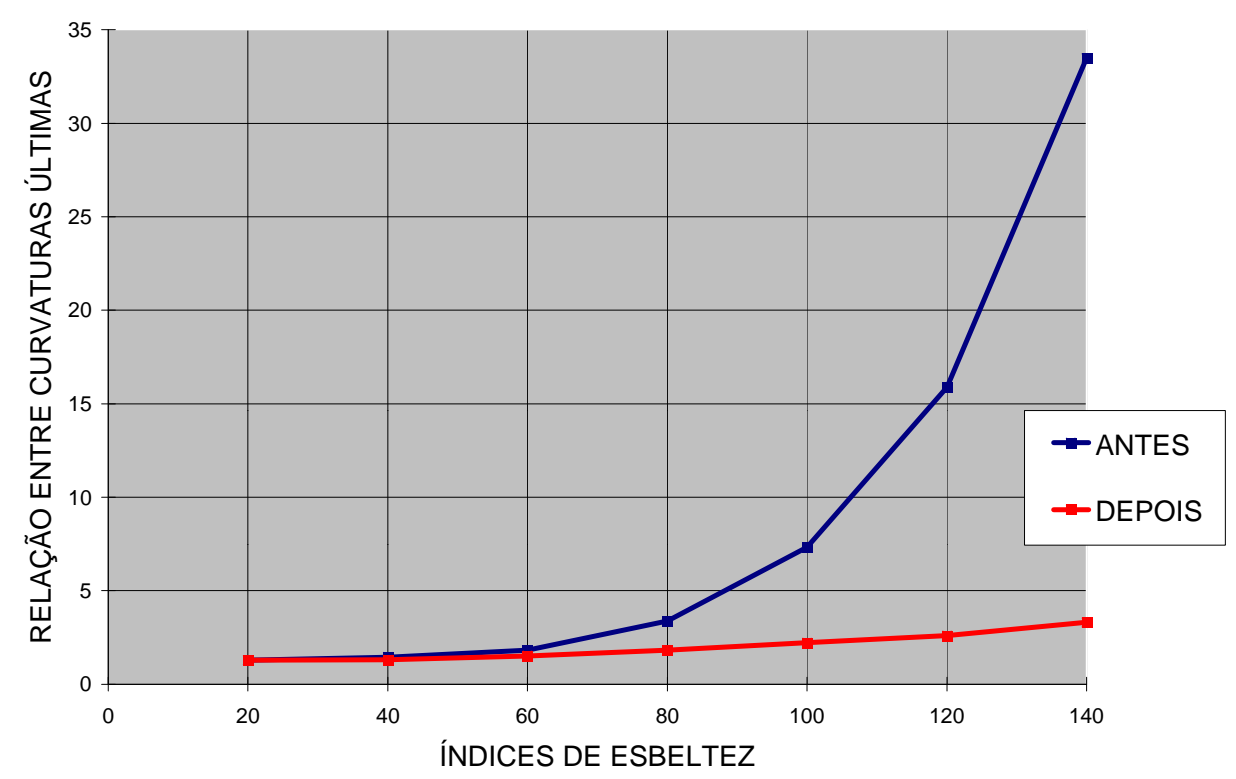

FIGURA 45 - Relação entre curvaturas últimas para seção 20x20 com e ex $=2 \mathrm{~cm}$, antes e depois da correção 


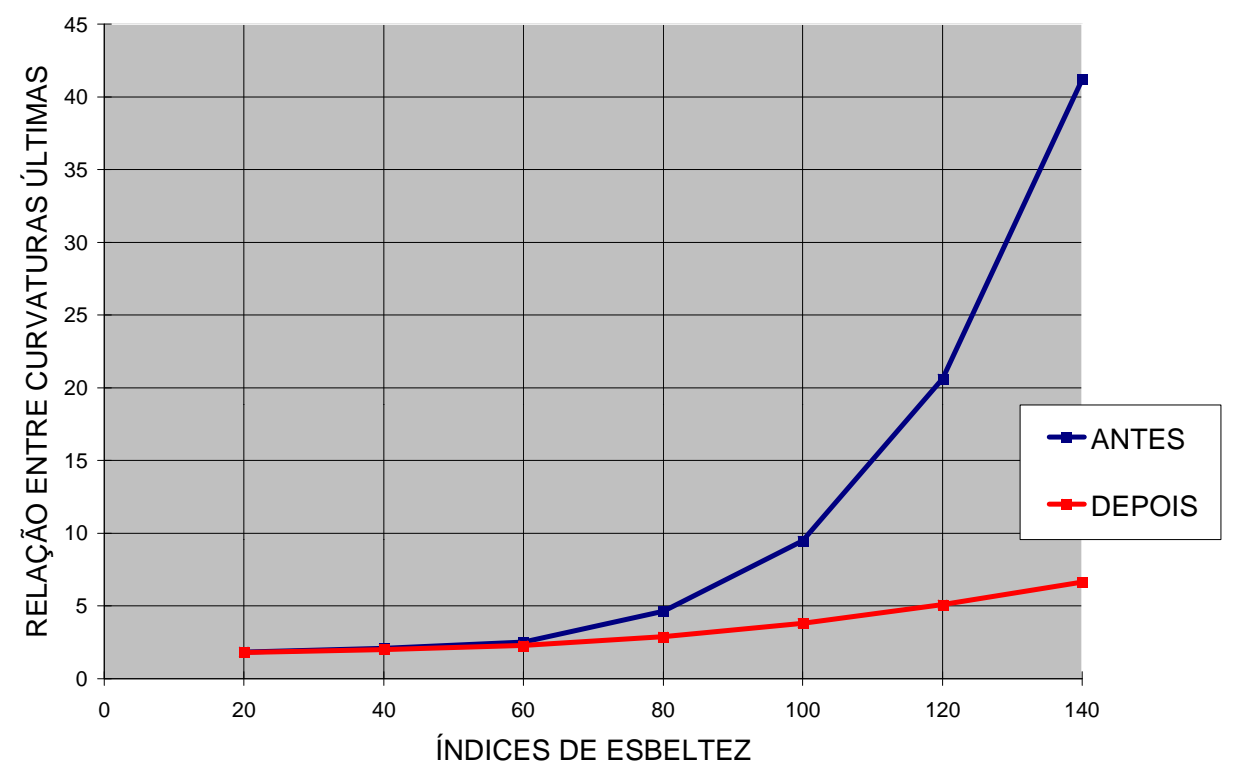

FIGURA 46 - Relação entre curvaturas últimas para seção 20x60 com $e_{x}=2 \mathrm{~cm}$, antes e depois da correção

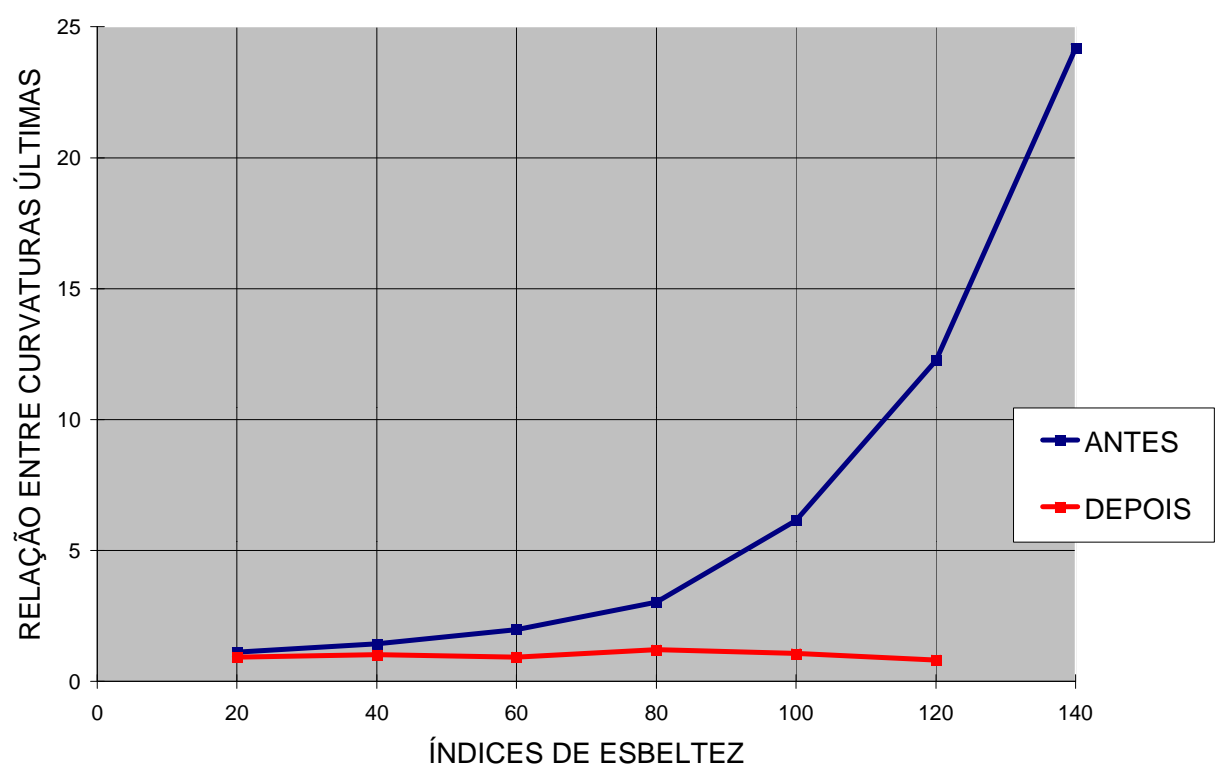

FIGURA 47 - Relação entre curvaturas últimas para seção 20x20 com $e_{x}=5 \mathrm{~cm}$, antes e depois da correção 


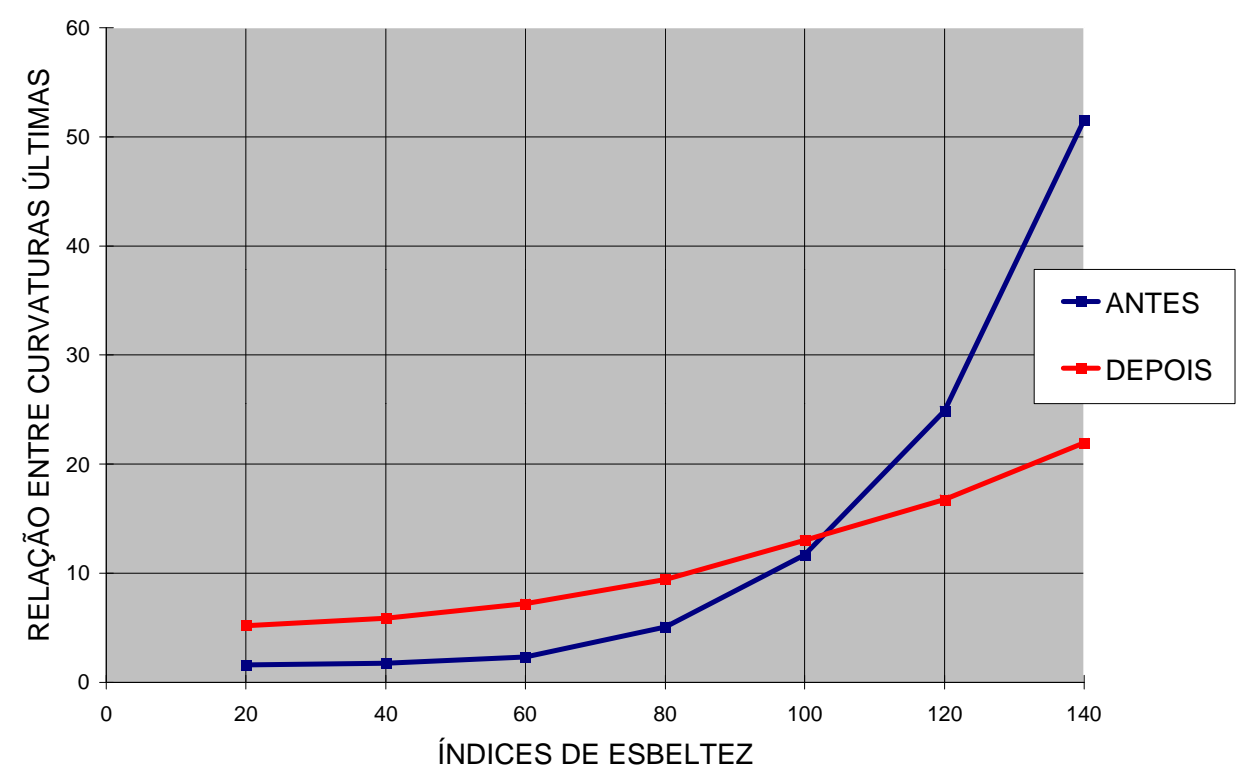

FIGURA 48 - Relação entre curvaturas últimas para seção 20x60 com $e_{x}=5 \mathrm{~cm}$, antes e depois da correção

A partir dessa análise, foi possível observar que, adotando o majorador $\beta_{1}$, os resultados melhoram consideravelmente, principalmente para seções cujas excentricidades de $1^{\underline{a}}$ ordem na direção crítica, apresentam valores baixos, ou seja, quando a parcela da força normal é predominante. Isso se torna perceptível pelo fato de que, para excentricidades de $5 \mathrm{~cm}$, na direção $\mathrm{x}$, o majorador piora a qualidade dos resultados, passa a não ter influência significativa ou, nos casos mais graves, passa a ser contra a segurança, levando o pilar a atingir um dos estados limites últimos, para a armadura recomendada por norma.

Uma outra tentativa de melhorar os resultados foi feita através da criação de um outro fator de correção, um minorador de curvaturas. Com esse novo índice, denominado de fator $\beta_{2}$, novo ajuste foi feito com os mesmos pilares ensaiados na TABELA 20, semelhante ao que foi feito para $\beta_{1}$, cujos resultados encontram-se na TABELA 21. A expressão para cálculo de $\beta_{2}$ está explicitada a seguir através da equação (66).

$$
\beta_{2}=1.034+\left(1.691 \cdot 10^{-3}\right) * \lambda-\left(2.179 \cdot 10^{-4}\right) * \lambda^{2}+\left(3.542 \cdot 10^{-6}\right) * \lambda^{3}
$$


TABELA 21 FCO: Análise dos resultados dos pilares de seção 20x20 e 20x60, com excentricidades de 2 e $5 \mathrm{~cm}$, após a correção da curvatura

\begin{tabular}{|c|c|c|c|c|c|c|c|}
\hline $\begin{array}{l}\text { Pilar } \\
\mathrm{n}^{\circ}\end{array}$ & $\begin{array}{c}\text { seção } \\
\text { cmxc } \\
\text { m }\end{array}$ & $\begin{array}{c}\lambda_{\mathbf{x}} \\
\operatorname{adm}\end{array}$ & $\begin{array}{c}\lambda_{\mathrm{y}} \\
\mathrm{adm}\end{array}$ & $\begin{array}{l}\mathbf{P}_{\text {dim }} \\
\mathrm{kN}\end{array}$ & $\begin{array}{l}\text { CURV } \alpha \\
\left(\mathrm{cm}^{-1}\right)\end{array}$ & $\begin{array}{l}\operatorname{CURV} \alpha_{\text {cor }} \\
\left(\mathrm{cm}^{-1}\right)\end{array}$ & $\begin{array}{c}\text { Relação NB1/V_ppadrao } \\
\text { curvaturas }\end{array}$ \\
\hline 01 & $20 \times 20$ & 20 & 20 & 857 & 1.4127E-04 & $1.4001 \mathrm{E}-04$ & 1.29 \\
\hline 02 & $20 \times 20$ & 40 & 40 & 768 & 1.5769E-04 & 1.6096E-04 & 1.48 \\
\hline 03 & $20 \times 20$ & 60 & 60 & 637 & 1.9006E-04 & 1.7029E-04 & 1.59 \\
\hline 04 & $20 \times 20$ & 80 & 80 & 496 & 2.4399E-04 & 1.5362E-04 & \#\#\# \\
\hline 05 & $20 \times 20$ & 100 & 100 & 381 & 3.1793E-04 & 1.2389E-04 & \#\#\# \\
\hline 06 & $20 \times 20$ & 120 & 120 & 291 & 4.1633E-04 & 9.8663E-05 & \#\#\# \\
\hline 07 & $20 \times 20$ & 140 & 140 & 226 & $5.3528 \mathrm{E}-04$ & 7.9666E-05 & \#\#\# \\
\hline 08 & $20 \times 60$ & 20 & 6.7 & 1956 & 1.3838E-04 & 1.3715E-04 & 1.76 \\
\hline 09 & $20 \times 60$ & 40 & 13.3 & 1789 & 1.5129E-04 & 1.5443E-04 & 2.15 \\
\hline 10 & $20 \times 60$ & 60 & 20.0 & 1532 & 1.7666E-04 & 1.5828E-04 & 2.06 \\
\hline 11 & $20 \times 60$ & 80 & 26.7 & 1215 & 2.2272E-04 & 1.4023E-04 & 2.13 \\
\hline 12 & $20 \times 60$ & 100 & 33.3 & 925 & $2.9276 \mathrm{E}-04$ & 1.1409E-04 & 2.18 \\
\hline 13 & $20 \times 60$ & 120 & 40.0 & 705 & 3.8417E-04 & $9.1041 \mathrm{E}-05$ & 2.42 \\
\hline 14 & $20 \times 60$ & 140 & 46.7 & 546 & 4.9563E-04 & 7.3764E-05 & 2.45 \\
\hline 15 & $20 \times 20$ & 20 & 20 & 696 & 1.7389E-04 & 1.7234E-04 & 10.49 \\
\hline 16 & $20 \times 20$ & 40 & 40 & 565 & $2.1441 \mathrm{E}-04$ & $2.1885 \mathrm{E}-04$ & 15.92 \\
\hline 17 & $20 \times 20$ & 60 & 60 & 478 & $2.5342 \mathrm{E}-04$ & $2.2706 \mathrm{E}-04$ & 1.21 \\
\hline 18 & $20 \times 20$ & 80 & 80 & 387 & $3.1287 \mathrm{E}-04$ & 1.9699E-04 & \#\#\# \\
\hline 19 & $20 \times 20$ & 100 & 100 & 308 & 3.9343E-04 & 1.5332E-04 & \#\#\# \\
\hline 20 & $20 \times 20$ & 120 & 120 & 245 & 4.9489E-04 & 1.1728E-04 & \#\#\# \\
\hline 21 & $20 \times 20$ & 140 & 140 & 196 & $6.1715 \mathrm{E}-04$ & $9.1850 \mathrm{E}-05$ & \#\#\# \\
\hline 22 & $20 \times 60$ & 20 & 6.7 & 1331 & $2.0341 \mathrm{E}-04$ & $2.0160 \mathrm{E}-04$ & 5.16 \\
\hline 23 & $20 \times 60$ & 40 & 13.3 & 1175 & $2.3045 \mathrm{E}-04$ & $2.3523 \mathrm{E}-04$ & 6.59 \\
\hline 24 & $20 \times 60$ & 60 & 20.0 & 954 & $2.8379 \mathrm{E}-04$ & 2.5427E-04 & 8.86 \\
\hline 25 & $20 \times 60$ & 80 & 26.7 & 725 & 3.7317E-04 & 2.3496E-04 & 10.73 \\
\hline 26 & $20 \times 60$ & 100 & 33.3 & 542 & 4.9915E-04 & 1.9452E-04 & 11.42 \\
\hline 27 & $20 \times 60$ & 120 & 40.0 & 411 & 6.5899E-04 & 1.5617E-04 & 11.80 \\
\hline 28 & $20 \times 60$ & 140 & 46.7 & 318 & 8.5000E-04 & 1.2650E-04 & 12.36 \\
\hline
\end{tabular}

Analisando os valores apresentados na última coluna da TABELA 21, percebe-se que a expressão (66) apresenta resultados contra a segurança, mesmo quando a excentricidade de $1^{\underline{a}}$ ordem apresenta valores baixos, por ser a curvatura mais sensível do que a carga, com relação as dimensões da seção transversal. Sendo assim, a tentativa de corrigir a curvatura, pela utilização do fator $\beta_{2}$ foi descartada, e o objetivo passou a ser estudar mais a fundo os resultados obtidos com relação à correção da carga, com o intuito de observar o comportamento dos pilares e, com isso definir critérios para encontrar uma expressão mais geral, que atenda a um número maior de casos e que apresente resultados seguros.

Voltando então a estudar os resultados apresentados nas TABELAS 16 a 19, observa-se que é impossível obter uma única expressão para ajuste da carga de pilares de índices de esbeltez variados, devido ao fato de que o comportamento dos mesmos é variável não só com relação aos diferentes valores de $e_{x} / h_{x}$, mas também, com relação às dimensões da seção transversal. 


\subsubsection{Relação entre os Valores de Carga Última}

Para realizar a análise do item anterior, foi necessário encontrar o valor da carga última dos pilares em estudo. Para tal foi utilizado o programa GERAL_EXATO do SISTEMA FLEXOR.

A importância dessa relação entre cargas últimas de pilares de índices de esbeltez diferentes é percebida quando se deseja saber qual a carga última suportada por um pilar esbelto, e não se tem à mão uma ferramenta como o SISTEMA FLEXOR. Desse estudo, o que se pretende é tornar conhecido esse valor a partir do valor da carga última de um pilar curto de mesmas características, para o qual a análise pode ser feita a nível de seção transversal.

No estudo da flexo-compressão normal, foi apresentada uma análise feita na tentativa de quantificar a diminuição da capacidade resistente utilizando uma expressão de ajuste de carga dependente do índice de esbeltez. O mesmo foi feito na flexo-compressão oblíqua aproveitando os ensaios de pilares de mesma seção transversal e de comprimentos variados apresentados anteriormente, a fim de obter uma relação entre a carga última de pilares de índice de esbeltez entre 40 e 140, e a carga última de pilares curtos com índice de esbeltez 20 , casos em que, como já foi dito, o efeito de $2^{\mathrm{a}}$ ordem pode ser desprezado.

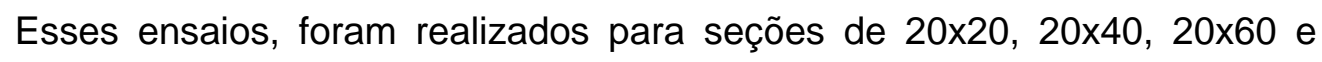
$20 \times 80$, com excentricidades de aplicação da carga de $2 \mathrm{~cm}$ em cada direção, por serem estes valores os que apresentam diferenças menores e, portanto podem ser aplicados para os demais casos. A partir desses ensaios, foi obtida uma relação entre carga última e índice de esbeltez, para efeito de pré-dimensionamento.

Os resultados dessa análise, encontram-se nas TABELAS 22 e 23, e a representação gráfica e a expressão correspondente ao ajuste entre esbeltez e carga última, encontram-se na FIGURA 49 e na equação (67), respectivamente. 
TABELA 22 - FCO: Dados e resultados da série de pilares - Cálculo da carga última

\begin{tabular}{|c|c|c|c|c|c|c|c|c|c|c|}
\hline \multirow{2}{*}{$\begin{array}{c}\text { Pilar } \\
\mathrm{n}^{\circ}\end{array}$} & \multirow{2}{*}{$\begin{array}{c}\lambda x \\
\text { adm }\end{array}$} & \multirow{2}{*}{$\begin{array}{l}e_{x} \\
\mathrm{~cm}\end{array}$} & \multirow{2}{*}{$\begin{array}{l}\mathbf{e}_{\mathbf{y}} \\
\mathrm{cm}\end{array}$} & \multirow{2}{*}{$\begin{array}{c}f_{\text {cd }} \\
\mathrm{kN} / \mathrm{cm}^{2}\end{array}$} & \multirow{2}{*}{$\begin{array}{c}\boldsymbol{f}_{\mathbf{y d}} \\
\mathrm{kN} / \mathrm{cm}^{2}\end{array}$} & \multirow{2}{*}{$\begin{array}{l}\text { As } \\
\mathrm{cm}^{2}\end{array}$} & \multicolumn{4}{|c|}{ CARGA ÚLTIMA em kN } \\
\hline & & & & & & & $(20 \times 20)$ & $(20 \times 40)$ & $(20 \times 60)$ & $(20 \times 80)$ \\
\hline 01 & 20 & 2.0 & 2.0 & 2.14 & 43.48 & 16.08 & 1114 & 1880 & 2543 & 3191 \\
\hline 02 & 40 & 2.0 & 2.0 & 2.14 & 43.48 & 16.08 & 998 & 1725 & 2326 & 2912 \\
\hline 03 & 60 & 2.0 & 2.0 & 2.14 & 43.48 & 16.08 & 828 & 1480 & 1992 & 2493 \\
\hline 04 & 80 & 2.0 & 2.0 & 2.14 & 43.48 & 16.08 & 645 & 1184 & 1580 & 1975 \\
\hline 05 & 100 & 2.0 & 2.0 & 2.14 & 43.48 & 16.08 & 495 & 899 & 1202 & 1506 \\
\hline 06 & 120 & 2.0 & 2.0 & 2.14 & 43.48 & 16.08 & 378 & 684 & 916 & 1148 \\
\hline 07 & 140 & 2.0 & 2.0 & 2.14 & 43.48 & 16.08 & 294 & 530 & 710 & 892 \\
\hline
\end{tabular}

TABELA 23 - FCO: Resultados da série de pilares em termos de coeficiente de minoração

\begin{tabular}{|c|c|c|c|c|c|}
\hline \multirow{2}{*}{$\begin{array}{c}\text { Pilar } \\
\mathrm{n}^{\circ}\end{array}$} & \multicolumn{5}{|c|}{ COEFICIENTE DE MINORAÇÃO DA CARGA $(\gamma)$} \\
\cline { 2 - 6 } & $(20 \times 20)$ & $(20 \times 40)$ & $(20 \times 60)$ & $(20 \times 80)$ & MÉDIA \\
\hline 01 & 1.00 & 1.00 & 1.00 & 1.00 & 1.00 \\
\hline 02 & 0.90 & 0.92 & 0.91 & 0.91 & 0.91 \\
\hline 03 & 0.74 & 0.79 & 0.78 & 0.78 & 0.77 \\
\hline 04 & 0.58 & 0.63 & 0.62 & 0.62 & 0.61 \\
\hline 05 & 0.44 & 0.48 & 0.47 & 0.47 & 0.47 \\
\hline 06 & 0.34 & 0.36 & 0.36 & 0.36 & 0.36 \\
\hline 07 & 0.26 & 0.28 & 0.28 & 0.28 & 0.28 \\
\hline
\end{tabular}

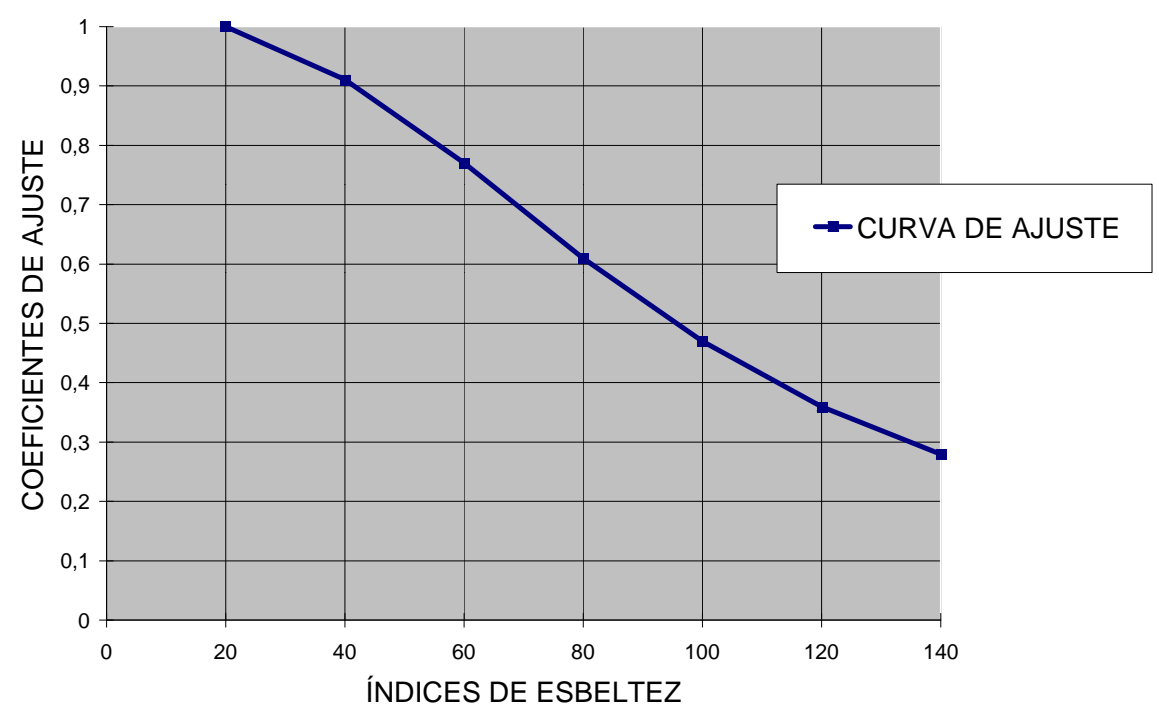

FIGURA 49 - Curva de ajuste da carga última em função da esbeltez

$$
\gamma=1.0415-9.8589 \cdot 10^{-5} \cdot \lambda-1.0117 \cdot 10^{-4} \cdot \lambda^{2}+4.5131 \cdot 10^{-7} \cdot \lambda^{3}
$$


A expressão do $\gamma$ da equação (67) além de mais completa, por apresentarse relacionada a pilares cuja esbeltez é 20 , também resulta em valores mais seguros por ser baseada no comportamento de pilares sob flexo-compressão oblíqua, que apresentam menores valores para os minoradores de carga. Nesse caso, estes resultados podem ser utilizados também no caso da flexo-compressão normal.

Sabendo-se que a expressão (67) deve ser utilizada apenas para fins de pré-dimensionamento, uma outra opção é utilizar uma expressão mais simples do tipo linear, cujos resultados sejam próximos aos oferecidos pela equação (67). Tem-se, então, a equação (68).

$$
\gamma=1.1371-6.3571 \cdot 10^{-3} \cdot \lambda
$$




\section{Capítulo $\ddot{0}$}

\section{CONCLUSÕES E COMENTÁRIOS}

\subsection{CONCLUSÕES}

Com o objetivo de estudar o comportamento de pilares esbeltos de concreto armado, foi realizado um trabalho fundamentado em conceitos teóricos e ensaios práticos.

Um dos principais objetivos da investigação foi o processo de cálculo para dimensionamento e verificação da estabilidade de pilares. O processo exato, como era de se esperar, apresenta resultados de excelente qualidade; o único problema encontrado para sua aplicação está no fato de que não se tem, com facilidade, uma ferramenta que permita realizar os cálculos necessários com rapidez e simplicidade de manuseio. Através do SISTEMA FLEXOR essa análise se tornou possível, unindo características importantes para um programa: segurança e qualidade, como pode ser comprovado através dos resultados apresentados no ítem 5.2 - AFERIÇÃO EXPERIMENTAL DO PROGRAMA.

Aferido o programa e, com os ensaios físicos e numéricos realizados por vários pesquisadores citados na bibliografia, e pelos ensaios realizados através do SISTEMA FLEXOR, a preocupação passou a ser investigar a validade do processo aproximado do pilar padrão, como também, a influência de fatores como: índice de esbeltez, resistência do concreto, taxa de armadura e valor da excentricidade de aplicação da força, no comportamento dos pilares.

O índice de esbeltez apresenta-se como um fator determinante na análise de pilares. Devido à sua tamanha influência, o índice de esbeltez é tomado como o parâmetro que define a análise a ser aplicada, de acordo com as recomendações da NB-1.

Quanto à resistência do concreto, constatou-se que, à medida que esse valor cresce, há um aumento significativo no valor da carga última em pilares curtos. Para pilares esbeltos também se verifica um aumento na capacidade de 
carga, só que, nesses casos, isso se dá de forma mais discreta. A possibilidade de ruína por instabilidade aumenta à medida que é aumentado o valor da resistência.

A partir da análise das curvaturas, foi possível observar que a resistência do concreto também tem influência perceptível quanto à qualidade dos resultados. Quanto maior é a resistência do concreto, maiores serão as diferenças encontradas entre os valores de curvatura apresentados pelo VERIFIC_PPADRAO do SISTEMA FLEXOR e pelo Texto para Revisão da NB-1 (1997).

Pilares com concretos de resistência muito alta apresentam grandes vantagens quando a excentricidade de aplicação da força é pequena em relação às dimensões da seção. Com o aumento da excentricidade, a capacidade de carga dos pilares de concreto de alta resistência decresce mais rapidamente do que para pilares nas mesmas condições, com concretos de resistência normal.

Também em relação às excentricidades de $1^{\text {a }}$ ordem, foi observado que para uma série de pilares de mesma base e mesmo valor de excentricidade, os resultados em termos de curvatura são piores para as seções cujas alturas são maiores. O mesmo não acontece no caso de pilares de mesma esbeltez e seção transversal, com valores diferentes de excentricidade de aplicação da força. Nesses casos só há evidente perda de qualidade nos resultados se as dimensões da seção, no caso de seção retangular, forem muito diferentes entre si.

Quanto ao processo do pilar padrão, foi verificado que é possível proceder com o dimensionamento e a verificação da estabilidade através do mesmo, devido à possibilidade de se obterem bons resultados, sendo respeitadas as suas limitações.

As falhas detectadas no processo do pilar padrão recomendado pela NB-1, que limitam o uso do roteiro de cálculo para pilares curtos ou medianamente esbeltos $(\lambda<80)$, são decorrentes da consideração da não-linearidade física de forma aproximada, e não devido à não-linearidade geométrica considerada a partir de uma elástica senoidal.

Essa falha nos resultados da norma torna-se evidente através da comparação entre os valores de curvatura apresentados pelo SISTEMA FLEXOR e pelo Texto para Revisão da NB-1 (1997). Essas diferenças apresentam valores elevados mesmo submetendo os valores da norma ao truncamento recomendado.

A discrepância entre os resultados torna-se maior à medida que cresce 0 valor da esbeltez, e é mais grave para os casos de flexo-compressão oblíqua. Nesses casos, a forma da seção transversal passa a ser um fator importante, isto 
é, quanto maior é a diferença entre dimensões da seção transversal, piores são os resultados; portanto, para seções retangulares, o melhor comportamento é verificado em seções em que a base é igual à altura, ou seja, em seções quadradas.

Do estudo das curvaturas últimas, para os vários pilares ensaiados, foi possível detectar que as diferenças existentes entre os resultados apresentados pela NB-1 e pelo SISTEMA FLEXOR aumentam à medida que cresce o valor do índice de esbeltez. Isso se dá pelo fato de que, pela expressão do Texto para Revisão da NB-1 (1997), quanto menor é o valor da carga de dimensionamento, maior será o valor da curvatura e, consequentemente, maior será também o valor da excentricidade de $2^{\underline{a}}$ ordem. Na realidade, o que acontece é o inverso, como pode ser verificado através dos valores obtidos a partir do programa.

É importante também ressaltar que essas diferenças são decorrentes, diretamente, das diferenças entre carga e curvatura de pilares esbeltos, com relação a um pilar de mesma seção e baixo índice de esbeltez. Com isso, pensouse em quantificar essa tendência, através de um ajuste, ou dos valores de carga, mediante um majorador de carga, ou dos valores de curvatura, mediante um minorador de curvaturas, para com isso forçar a expressão da NB-1 a assumir valores mais baixos para a armadura, tornando o dimensionamento de pilares esbeltos possível. A partir dessa verificação, vários ensaios foram feitos à procura de um ajuste a ser aplicado a expressão para cálculo da curvatura recomendada pelo Texto para Revisão da NB-1 (1997).

Um ajuste preliminar foi feito, mostrando que as curvaturas são mais sensíveis ao ajuste, ficando difícil transformar o ajuste proposto em regra geral. Quanto ao ajuste da carga, o mesmo funcionou para alguns casos, casos estes constituídos por pilares em que a relação e/h na direção mais crítica é pequena. Através dessa análise, pareceu possível detectar uma tendência nos resultados e, com isso, se chegar a uma expressão de fácil utilização, cujos resultados sejam mais próximos da realidade.

Um fato observado cuja importância deve ser ressaltada é o fato de que para realizar uma análise de boa qualidade é necessário que os protótipos sejam definidos de forma que somente o parâmetro em estudo varie. Um exemplo disso está na análise da curvatura na flexo-compressão oblíqua onde vários parâmetros mantiveram-se constantes, a exemplo da distância entre o centro da armadura e as faces da seção devido a grande influência gerada pela relação d'/h. 
Como última análise, foi feito um estudo sobre como obter o valor da carga última para pilares de vários índices de esbeltez,entre 40 e 140, a partir do valor da carga crítica de um pilar curto de mesma seção transversal. Desse estudo foram obtidas duas expressões: uma para flexo-compressão normal, mais restrita, e outra para o caso de flexo-compressão oblíqua, cuja análise é mais genérica, podendo portanto ser utilizada para os dois casos.

\subsection{COMENTÁRIOS}

Finalmente, concluído o trabalho, espera-se que o mesmo sirva como ponto de partida para outros estudos com o intuito de tornar mais amplo o uso dos pilares esbeltos, através da adoção de processos de cálculo mais genéricos.

O caminho para se chegar a propor um método expedito de dimensionamento e verificação da estabilidade de pilares esbeltos, tem que partir do conhecimento dos fatores que influem no comportamento dos mesmos, e foi com esse intuito que esse trabalho foi realizado, sendo fruto do esforço não apenas do autor e do seu orientador, mas também, de vários outros pesquisadores como CADAMURO Jr., que com seus trabalhos tornaram possível o desenvolvimento de ferramentas ágeis e seguras que possibilitam uma análise mais completa sobre pilares esbeltos, incluindo sua vulnerabilidade ao estado limite último de instabilidade.

Enfim, este trabalho é mais um exemplo de que o progresso está no esforço conjunto e na união de idéias, que colaborem para o desenvolvimento de trabalhos que, como este, tenham como objetivo contribuir para o progresso da construção civil, através da utilização de projetos mais arrojados, econômicos e seguros. 


\section{REFERÊNCIAS BIBLIOGRÁFICAS}

ASSOCIAÇÃO BRASILEIRA DE NORMAS TÉCNICAS (1982) - NB-1 - Projeto e execucão de obras de concreto armado. Rio de Janeiro.

ASSOCIAÇÃO BRASILEIRA DE NORMAS TÉCNICAS (1997) - NB-1 - Texto para revisão da NB-1 e comentários. Rio de Janeiro.

AUFIERO, L. (1977). - Estabilidade de colunas isostáticas de concreto armado. São Carlos. Dissertação (mestrado) - Escola de Engenharia de São Carlos, Universidade de são Paulo.

BAZANT, Z. P.; CEDOLIN, L.; TABBARA, M. R. (1991). - New method of analysis for slender columns. ACI Structural Journal, V.88, No.4, July-August.

BAZANT, Z. P.; XIANG, Y. Y. (1997). - Inelastic buckling of concrete in braced

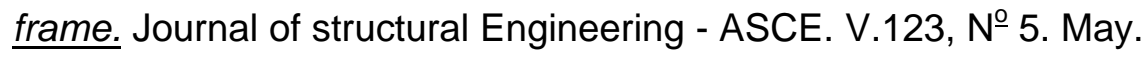

BORTOLIN, A. A. (1991). - Sobre a racionalização e a automação do cálculo de edifícios de concreto armado. São Carlos. Dissertação (mestrado) - Escola de Engenharia de São Carlos, Universidade de São Paulo.

BUCHAIM, R. (1979). - Efeitos de segunda ordem e estado limite último de instabilidade em pilares de concreto armado. São Carlos. Dissertação (mestrado) - Escola de Engenharia de São Carlos, Universidade de São Paulo. 
BURKE JÚNIOR, J. U. (1971). - Flexão normal composta. Peças de seção retangular em concreto armado com armadura lateral. São Paulo. Tese (doutorado) - Escola Politécnica, Universidade de São Paulo.

CADAMURO JÚNIOR, I. W. (1997). - Dimensionamento de pilares esbeltos de concreto armado com seção qualquer solicitados por flexão composta oblíqüa. São Carlos. Dissertação (mestrado) - Escola de Engenharia de São Carlos, Universidade de São Paulo.

CLAESON, C.; GYLLTOFT, K. (1998). - Slender high strength concrete columns subjected to eccentric loading. Journal of Structural Engineering - ASCE. V.124, № 3, March.

CHUANG, P. H. \& KONG, F. K. (1995). - Failure loads of slender reinforced concrete columns. Structures and Buildings, V.122, № 3, August.

CHUANG, P. H. \& KONG, F. K. (1997). - Large-scale tests on slender, reinforced concrete columns. The Structural Engineer, V.75, №s 23 \& 24, December.

EL-METWALLY, S. E. E. (1994). - Method of segment lenght for instability analysis of reinforced concrete beam-column. ACI Structural Journal, V.91, No.6, November-December.

ESPION, B.; HALLEUX, P. (1988). - Moment curvature relationship of reinforced concrete sections under combined bending and normal force. Materials and Structures, V.21, No.125, September.

FORNI, F. E. B. (1980). - Flexão oblíqua composta no concreto armado. São Paulo. Dissertação (mestrado) - Escola Politécnica, Universidade de São Paulo.

FRANÇA, R. L. S. (1984). - Relações momento-curvatura em peças de concreto armado submetidas à flexão oblíqua composta. São Paulo. Dissertação (mestrado) - Escola Politécnica, Universidade de São Paulo. 
FRANÇA, R. L. S. (1991). - Contribuição ao estudo dos efeitos de segunda ordem em pilares de concreto armado. São Paulo. Tese (doutorado) - Escola Politécnica, Universidade de São Paulo.

FUSCO, P. B. (1981). - Estruturas de concreto armado. Solicitações normais. Rio de Janeiro, Guanabara Dois.

GARCIA, G. (1981). - Elastic lateral instability of columns studied by the egree of fixity method ( $P$ - $\Delta$ Effect ). ACI Structural Journal, V.78, No.5, SeptemberOctober.

HOROWITZ, B. (1989). - Design of columns subjected to biaxial bending. ACI Structural Journal, V.92, No.6, November-December.

IBRAHIM, H. H. H.; MACGREGOR, J. G.(1996). - Tests of eccentrically loaded high-strenght concrete columns. ACI Structural Journal, V.93, № 5, September.

KIM, J. K.; YANG, J. G.(1995). - Buckling behavior of slender high strength concrete columns. Engineering Structures., V.17, №. 1, January.

LEONHARDT, F.; MONNIG, E. (1977). - Construções de concreto. Princípios básicos do dimensionamento de estruturas de concreto armado. Rio de Janeiro, Interciência.

LIN, C. H.; FURLONG, R. W. (1995) - Longitudinal steel limits for concrete columns. ACI Structural Journal, V. 92, №. 3, May-June.

LLOYD, N. A.; RANGAN, B. V. (1996) - Studies on high-strength concrete columns under eccentric compression. ACI Structural Journal, V. 93, № 6, NovemberDecember.

MACGREGOR, J. G.; BREEN, J. E.; PFRANG, E. O. (1970). - Design of slender reinforced concrete columns. Journal of the American Concrete Institute, V.67, $\mathrm{N}^{0} 1$, January. 
MARCOTTI, P. (1984). - Instabilidade na flexão composta oblíqua de pilares de concreto armado. São Paulo. Dissertação (mestrado) - Escola Politécnica, Universidade de São Paulo.

MENDES NETO, F. (1991). - Estudo de pilares de concreto armado submetidos a flexão oblíqua composta. São Paulo. Dissertação (mestrado) - Escola Politécnica, Universidade de São Paulo.

PAULA, J. A. (1988). - Algoritmos para o estudo de pilares esbeltos de concreto solicitados à flexão normal composta. São Carlos. Escola de Engenharia de São Carlos, Universidade de São Paulo.

PINHEIRO, L. M., BARALDI, L. T. \& POREM, M. E. (1994) - Concreto armado: Ábacos para flexão oblíqua. Publicação: 056/94. São Carlos. Escola de Engenharia de São Carlos, Universidade de São Paulo.

PRAKHYA, G. K. V.; MORLEY, C. T. (1990). - Tension-stiffening and momentcurvature relations of reinforced concrete elements. ACI Structutural Journal, V.87, No.5, September-October.

RANGAN, B. V. (1990). - Strength of reinforced concrete slender columns. ACI Structural Journal, V.87, No.1, January-February.

SAÉNZ, L. P.; MARTÍN, I. (1963).Test of reinforced concrete columns with high slenderness ratios. Journal of the American Concrete Institute. V.60, N5, May.

SANTOS, L. M. (1981). - Cálculo de concreto armado segundo a nova NB-1 e o CEB. Vol.2. São Paulo, Editora LMS.

SANTOS, L. M.(1994). - Sub-rotinas básicas do dimensionamento de concreto armado. São Paulo, Editora Thot.

SHEIKH, S. A.; YEH, C. C.; KHOURY, S. (1990). - Concrete strength in tied columns. ACI Structural Journal, V.87, No.4, July- August. 
SHEIKH, S. A.; YEH, C. C. (1990). - Tied columns under axial load and flexure. Journal of Structural Engeneering, V.16, No.10, October.

SÜSSEKIND, J.C. (1987). - Curso de Concreto: Concreto Armado. V.2. Rio de Janeiro, Editora Globo.

TSAO, W. H. (1992). - Behavior of square and L-shaped slender reinforced concrete columns under combined biaxial bending and axial compression. Dissertação. Faculty of the Graduate Studies of the New Jersey Institute of the Tecnology. December.

VENTURINI, W. S. \& RODRIGUES R. O.(1996). - Dimensionamento de pecas retangulares de concreto armado solicitados à flexão reta. São Carlos. Escola de Engenharia de São Carlos, Universidade de São Paulo.

VENTURINI, W. S.; BORTOLIN, A. A. (1992). - Dimensionamento de pecas retangulares de concreto solicitadas à flexão oblíqua. São Carlos. Escola de Engenharia de São Carlos, Universidade de São Paulo.

WANG, G. G.; HSU, C. T. T. (1992). - Complete biaxial load-deformation behavior of RC columns. Journal of structural Engeneering, V.118, No.9, September.

WEERAKOON, S. L.; AHMAD S. H. (1995). - Model for behavior of slender reinforced concrete columns under biaxial bending. ACI Structural Journal, V.92, No.2, March.

YAU, C. Y.; CHAN, S. L.; SO, A. K. W. (1993). - Biaxial bending design of arbitrarily shaped reinforced concrete column. ACI Structural Journal, V.90,No.3, MayJune.

ZAK, M. L. (1993). - Computer analysis of reinforced concrete cross sections under biaxial bending and longitudinal load. ACI Structural Journal, V.90, No.2, March-April. 
ZERIS, C. A.; MAHIN, S. A. (1991). - Behavior of reinforced structures subjected to biaxial excitation. Journal of Structural Engeneering, V.117, No.9, September. 